\title{
Activity-Based Costing and Inter-District Flows in the New Zealand Public Health Sector
}

Matthew Peter van Kesteren

A thesis submitted to Victoria University of Wellington in fulfilment of the requirements for the degree of Master of Commerce

Victoria University of Wellington 


\section{VICTORIA UNIVERSITY OF WELLINGTON \\ Te Whare Wānanga o te Ūpoko o te Ika a Mãui}

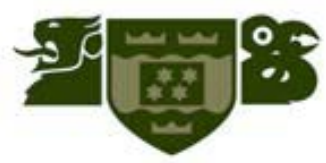

\section{STATEMENT OF ORIGINAL AUTHORSHIP}

This is to certify that the work contained in this project has never been previously submitted for a degree or diploma at any other tertiary education institution. To the best of my knowledge and belief, the project contains no material previously published or written by another person except where due reference is made in the project itself

Signed:

Date: 


\section{Abstract}

Changes in the New Zealand public health sector in recent years, such as heightened political, economic and social pressures to manage and reduce costs while improving the quality of care in conjunction with stringent health care guidelines, have forced district health boards (DHB) nationwide to reassess their approach to health care provision. This has chiefly involved evaluating current practices or institutions; revising health care systems, including locality of treatment; and assessing established accounting systems and mechanisms (or lack thereof) to understand the source of costs and resource consumption. Acknowledging that patient welfare has always held pre-eminence in the New Zealand public health sector, balancing the dual pressures to enhance the utilisation of limited resources and adhere to social pressures to provide sustained high quality health services has been a difficult exercise for DHBs. In recognition of the potential benefits of activity-based costing (ABC), and the fact that the New Zealand public health sector is severely underrepresented in current literature, this multi-site case study examines how sophisticated costing systems (such as ABC), are being used by DHBs. Using an institutional theory framework, this study posits that DHBs will use sophisticated costing systems to (1) improve cost understanding with the goal of managing and reducing their costs; and (2) contribute to more informed National Prices for Inter-District Flows (IDF), the aim of which is to plan and provide services to meet the directives and outcomes outlined by the Ministry of Health. Overall, the findings are compelling and reveal that costing systems are used on three levels to plan and provide health services, including unsophisticated costing systems that are not formally recognised; moderately sophisticated costing systems (such as CostPro) that are formally recognised; and sophisticated costing systems (such as PPM) that are formally recognised. Furthermore, the findings reveal that DHBs with sophisticated costing systems generate event-level information, which directly influences the calculation of National Prices for IDFs. The findings of this exploratory study also indicate a need to examine the nexus between $A B C$ and IDFs in a New Zealand public health sector context further.

\section{Key Words}

New Zealand Public Health Sector, District Health Board, Activity-Based Costing, Sophisticated Costing Systems, National Price, Inter-District Flow 


\section{Acknowledgments}

First and foremost, I would like to thank Dr. Carolyn Fowler. In particular, I would like to thank you for your dedication, guidance, patience and support over the duration of my research, without which, this thesis would not have been realised.

I would also like to take this opportunity to thank Victoria University of Wellington (specifically, the Victoria Business School) for giving me the chance to explore my chosen research area with freedom and flexibility.

To all the interviewees who took the time to participate in this research and offer their valuable knowledge and insights, I thank you too. Without your willingness to assist during the process of data collection and corroboration, this research would not have been realised.

And to my parents, Denise and Peter, and my sister, Samantha, I am forever grateful to you for all that you have done and continue to do for me. Without your unwavering love, understanding and support, I would not be the man I am today, nor would I have achieved all that I have in life.

In closing, working towards the degree of Master of Commerce has far and away been the most intellectual challenge I have ever undertaken. It has been an incredibly long and trying journey, with more sleepless nights than I care to remember. However, it has also been a journey of self-discovery and is one of my most satisfying accomplishments. The end result (being my final dissertation) is something I am very proud of, and symbolises that no matter how long the road may be, or how difficult it may seem, with hard work, devotion and a strong desire to succeed, you can reach the end and achieve what you set out to do. 


\section{Table of Contents}

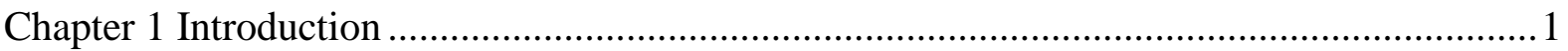

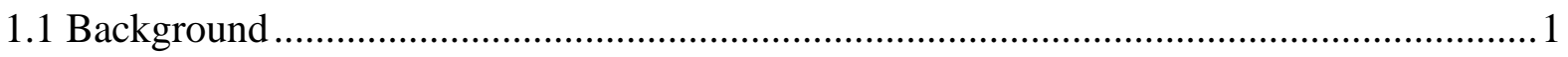

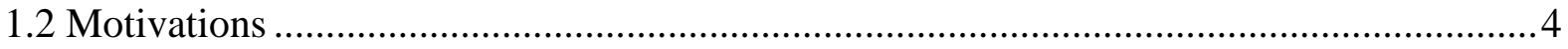

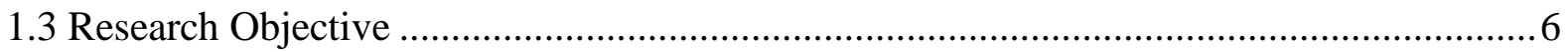

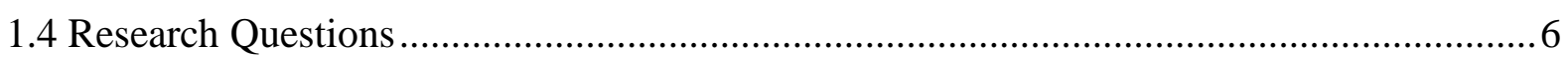

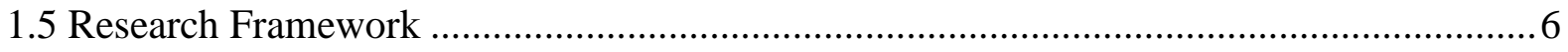

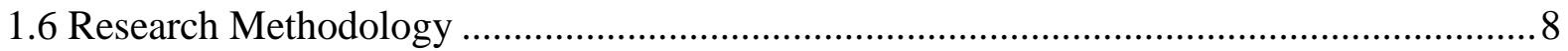

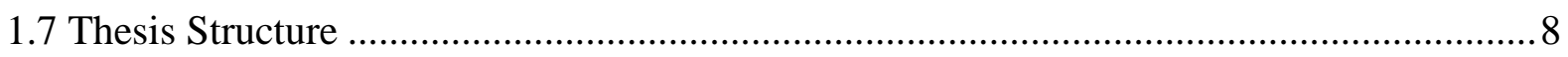

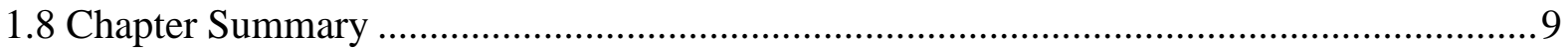

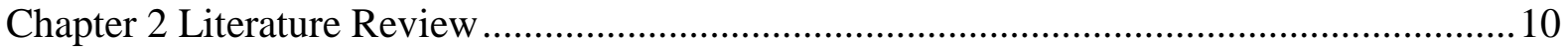

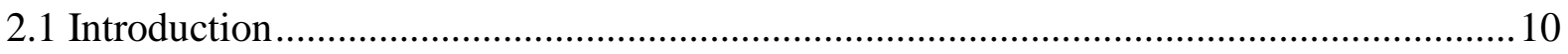

2.2 Costing Systems Sophistication: Traditional Costing versus Activity-Based Costing......10

2.3 Activity-Based Costing and the Health Sector in the 1990s............................................17

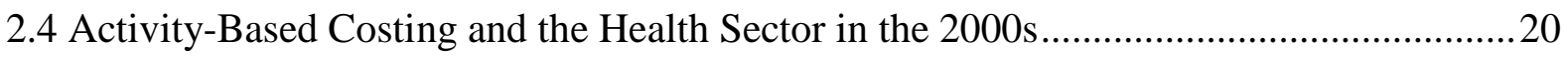

2.5 Activity-Based Costing and the New Zealand Public Health Sector................................ 23

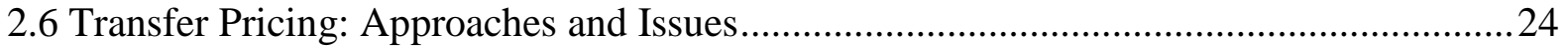

2.7 Transfer Pricing and the Health Sector in the 1990s and 2000s .....................................28

2.8 Transfer Pricing and the New Zealand Public Health Sector ........................................... 32

2.9 Applicability of Transfer Pricing to the New Zealand Public Health Sector ....................32

2.10 Activity-Based Costing and Transfer Pricing ................................................................. 33

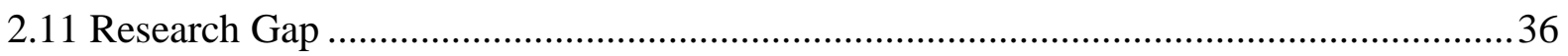

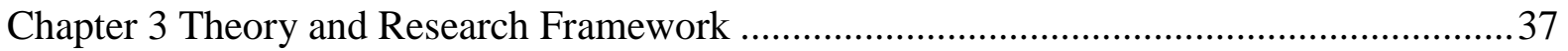

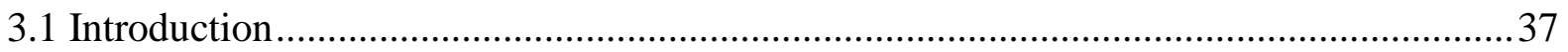

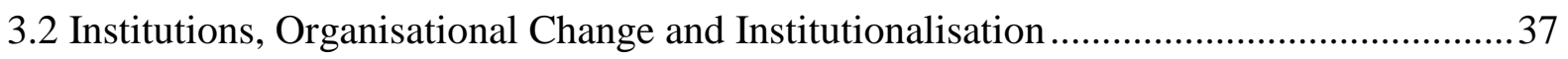

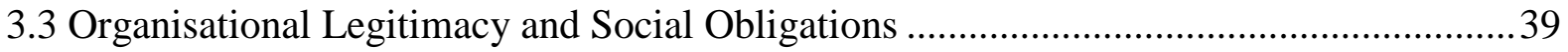

3.4 Organisational Legitimacy and the Three Pillars of Institutions ..................................... 40

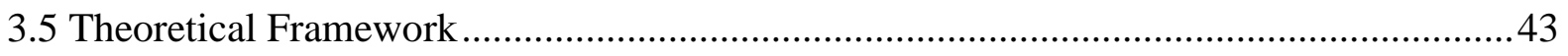

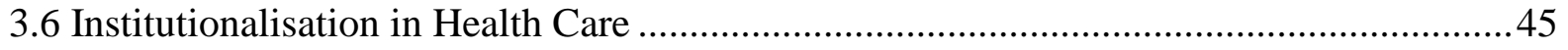

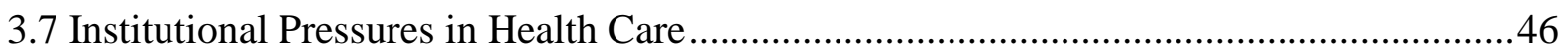

3.8 Organisational Legitimacy and the Notion of Social Contract in Health Care.................. 47

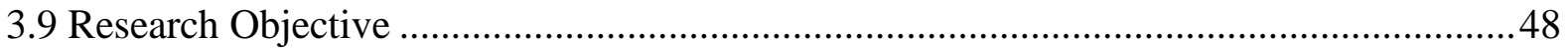




\section{Table of Contents Continued}

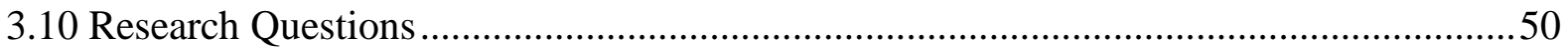

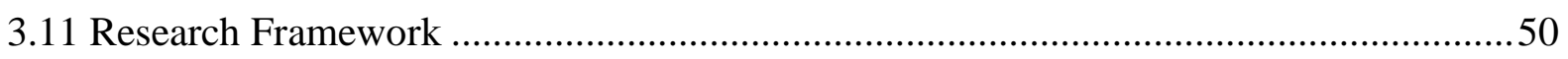

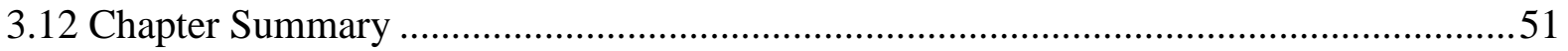

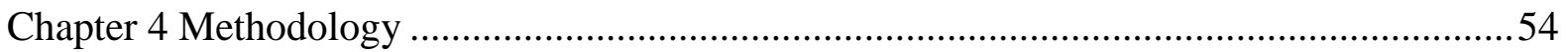

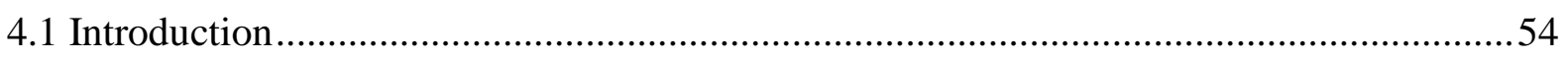

4.2 A Multi-Site Case Study Approach ….......................................................................... 54

4.3 Benefits of the Multi-Site Case Study Approach.............................................................55

4.4 Mitigating Potential Limitations of Qualitative Research ..............................................56

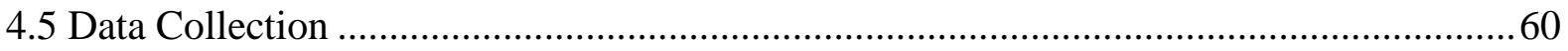

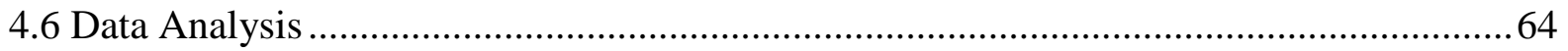

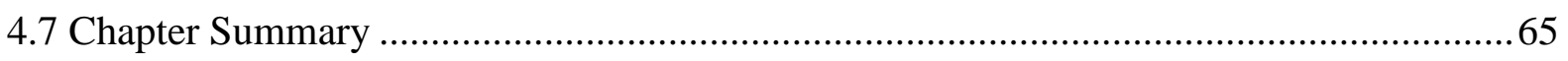

Chapter 5 DHB Funding, Purchasing and Costing: An Organisational Overview ..................66

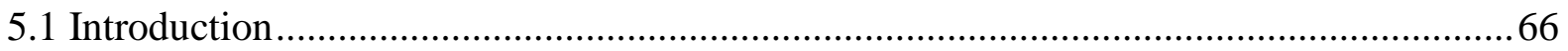

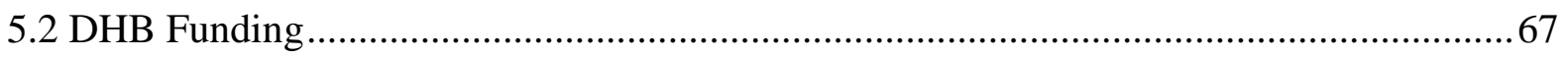

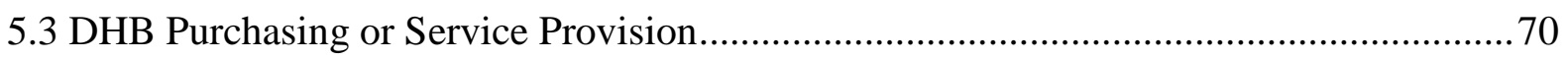

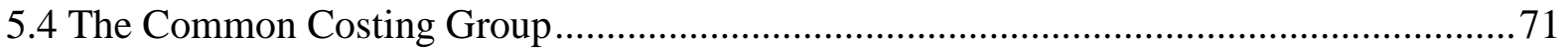

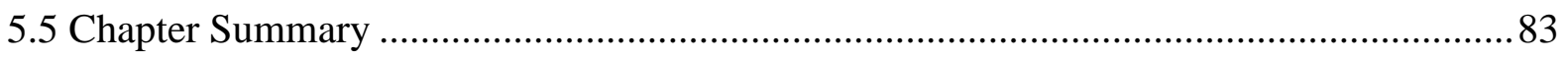

Chapter 6 The Common Costing Standards and Costing Systems Adoption..........................85

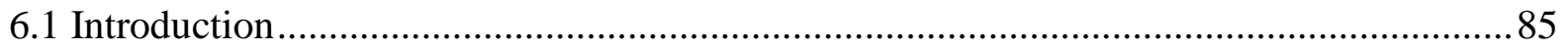

6.2 Unsophisticated Costing Systems Not Formally Recognised.......................................... 85

6.3 Formally Recognised Moderately Sophisticated Costing Systems ................................87

6.4 Formally Recognised Sophisticated Costing Systems ..................................................93

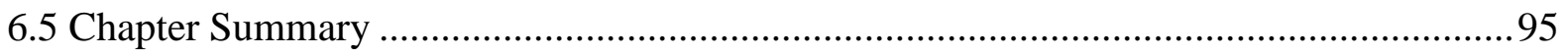

Chapter 7 National Cost Collection and Pricing Programme Data Submission.....................96

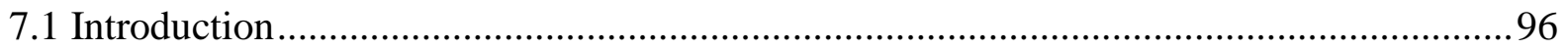

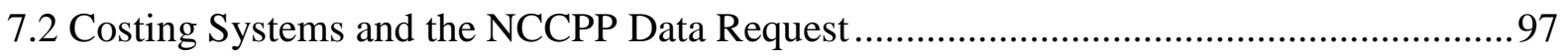

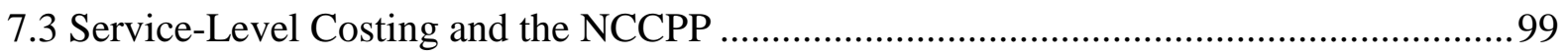

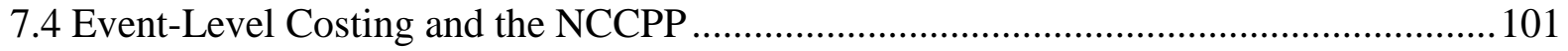

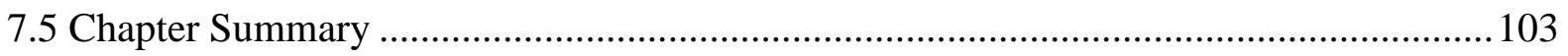

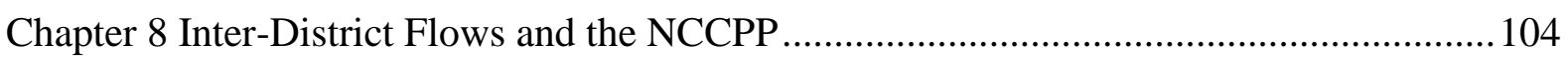

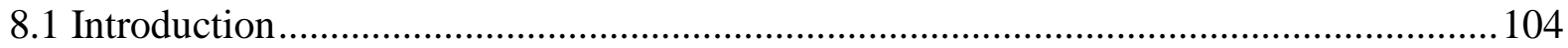




\section{Table of Contents Continued}

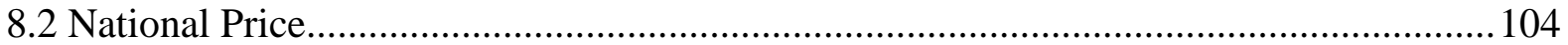

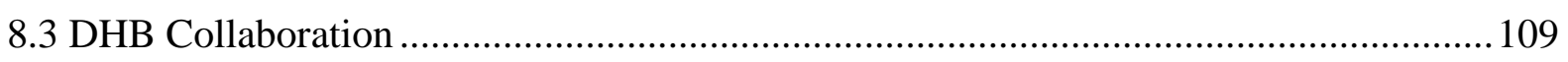

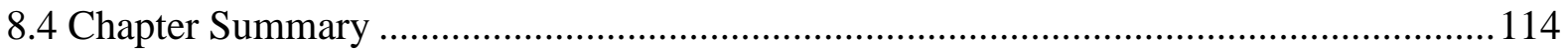

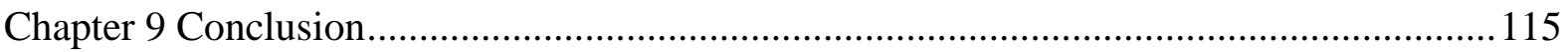

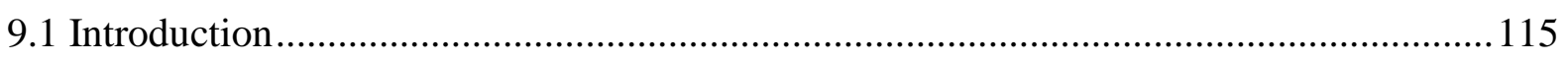

9.2 Costing Systems Adoption and Use in New Zealand DHBs .........................................115

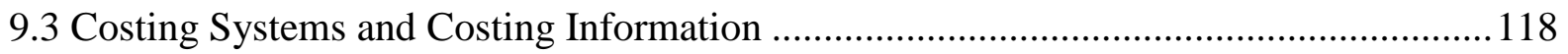

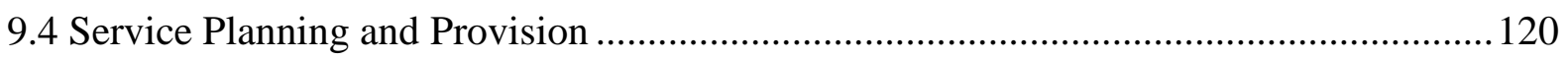

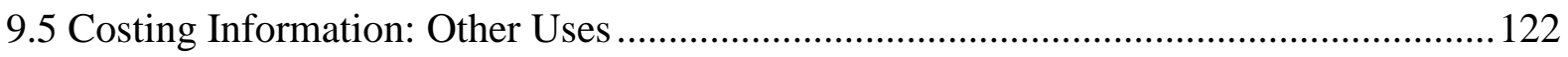

9.6 Approaches to Transfer Pricing for Inter-DHB Trading................................................123

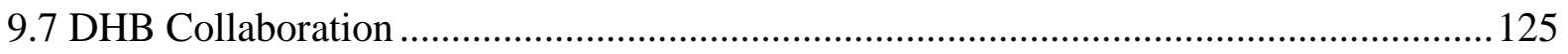

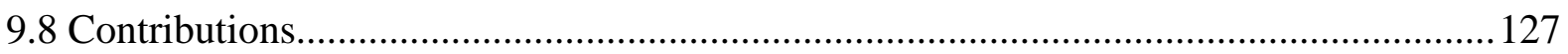

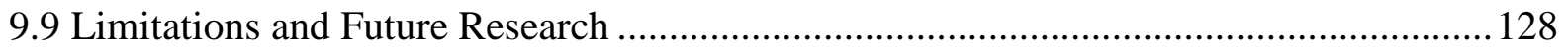

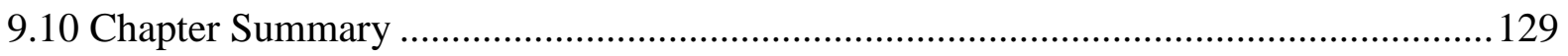

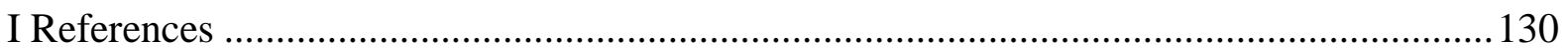

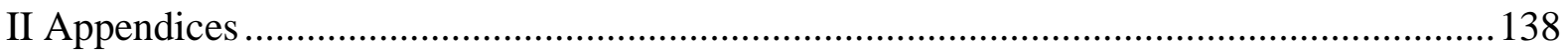




\section{List of Figures}

Figure 1: Ministry of Health Organisation Chart .................................................................

Figure 2: Comparison of Traditional Costing View to Activity-Based Costing View.............12

Figure 3: Steps in the Activity-Based Costing Methodology ................................................ 14

Figure 4: Dimensions determining the varying levels of Cost System Sophistication............17

Figure 5: Inter-Organisational Transfer Prices in the New Zealand Public Health Sector .......33

Figure 6: Organisational Legitimacy and the Three Pillars of Institutional Theory ................44

Figure 7: Public Health Sector Organisational-Field Research Framework...........................53

Figure 8: Cost Centre Allocation Order .............................................................................. 75

Figure 9: Sophisticated versus Unsophisticated Costing ........................................................ 79

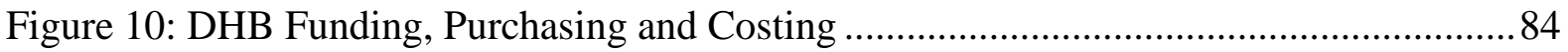

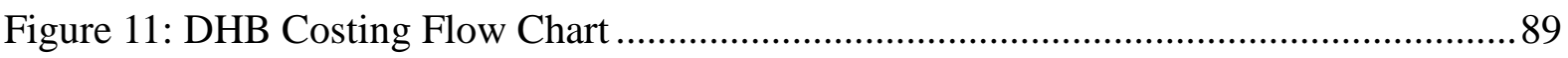

\section{List of Tables}

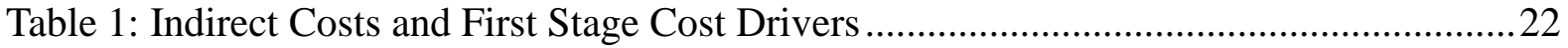

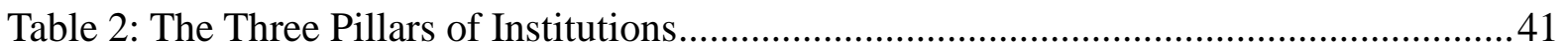

Table 3: Cost Centre Allocation and Recommended Cost Drivers......................................... 77

Table 4: Costing Calculation Example for Doctors Costs Associated with IT Systems..........92

Table 5: Summary of File Submission Requirements for Service and Event-Level DHBs ....97 


\section{Abbreviations}

\begin{tabular}{|c|c|}
\hline $\mathrm{ABC}$ & Activity-Based Costing \\
\hline CCoA & Common Chart of Accounts \\
\hline CCG & Common Costing Group \\
\hline CCGL & Common Costing Guidelines \\
\hline CCS & Common Costing Standards \\
\hline CCWG & Casemix Cost Weights Group \\
\hline CEO & Chief Executive Officer \\
\hline CFA & Crown Funding Agreement \\
\hline $\mathrm{CFO}$ & Chief Financial Officer \\
\hline CLG & Clinical Leadership Group \\
\hline DHB & District Health Board \\
\hline DRG & Diagnosis Related Group \\
\hline ED & Emergency Department \\
\hline FTE & Full-Time Equivalent \\
\hline GDP & Gross Domestic Product \\
\hline GL & General Ledger \\
\hline IDF & Inter-District Flow \\
\hline MCS & Multi-Site Case Study \\
\hline $\mathrm{MOH}$ & Ministry of Health \\
\hline MSG & Major Service Group \\
\hline NSF & National Service Framework \\
\hline NSFL & National Service Framework Library \\
\hline NCCPP & National Cost Collection and Pricing Programme \\
\hline NHB & National Health Board \\
\hline NHI & National Health Index \\
\hline NMDS & National Minimum Data Set \\
\hline OAG & Office of the Auditor-General \\
\hline OPF & Operational Policy Framework \\
\hline PFA & Planning and Funding Analyst \\
\hline PFU & Planning and Funding Unit \\
\hline PMSUID & Patient Management System Unique Identifier \\
\hline PPM & PowerPerformance Manager \\
\hline PU & Purchase Unit \\
\hline RVU & Relative Value Unit \\
\hline SCT & Surgically Controlled Time \\
\hline SIDU & Service Integration and Development Unit \\
\hline WIES & Weighted Inlier Equivalent Separation \\
\hline
\end{tabular}




\section{Chapter 1 Introduction}

\subsection{Background}

In 2001, the newly elected Labour-led coalition Government passed the 2000 New Zealand Public Health and Disability Act (Ashton et al., 2008; Tenbensel et al., 2011; Ettelt et al., 2012). Under the auspices of this Act, the Government reformed the New Zealand health and disability support sector by disestablishing existing hospital and health service providers and the Health Funding Authority, and replaced them with twenty-one partially elected district health boards (DHB). ${ }^{1}$ The DHBs were established as local agencies accountable to the Ministry of Health (MOH or "the Ministry") for organising health care, and latterly, disability support services for the populations of their district (Tenbensel et al., 2011). In accordance with the 2001 reform, DHBs were set up specifically to "undertake periodic assessments of the needs of their populations, plan services for their districts, provide services through their provider arms (public hospitals and related services) and contract for services delivered by non-DHB providers” (Tenbensel et al., 2011, p. 243).

One of the foremost issues with the reform of the New Zealand health and disability system (referred to as the New Zealand public health sector hereafter) concerned health service planning. Specifically, "planning at district level was considered to be insufficiently aligned with national objectives, and inter-district co-ordination too weak, leading to inefficiencies, duplication of services and concerns about future sustainability” (Ettelt et al., 2012, p. 55). Following a change in Government in 2008 and a ministerial review in early 2009, the 2010 New Zealand Public Health and Disability Act was revised in an attempt to mitigate the aforementioned concerns. As a result of the review, the Government was specifically advised to centralise some functions related to purchasing and planning of health services. "Other changes included the introduction of regional planning and co-ordination of services; changes to the distribution of operational and strategic plans, which made regions responsible for strategic and regional operational planning and districts responsible for operational planning” (Ettelt et al., 2012, p. 55).

In late 2009 (and as a direct result of the ministerial review), the National Health Board (NHB) was established within the $\mathrm{MOH}$ with the explicit aim to improve the planning of services across district boundaries (for an overview of the NHB and its associated functions see Figure 1). "A key role of the NHB is to oversee and assist district and regional level

\footnotetext{
${ }^{1}$ On 1 May 2010, Otago DHB and Southland DHB merged to form Southern DHB, resulting in one less DHB operating under the MOH. There are currently twenty DHBs in the New Zealand public health sector.
} 
planning and to devise national strategies for services that are organised and/or planned at national level” (Ettelt et al., 2012, p. 55). Specifically, the NHB is responsible for developing a long-term view for service planning and reconfiguration, and planning and purchasing numerous national services - typically those services that are highly specialised or vulnerable to workforce shortages (Ettelt et al., 2012). The NHB is also expected to monitor development and implementation of DHB annual plans, which should align with the outcomes outlined by the MOH (Ashton et al., 2008). There are several outcomes for the $\mathrm{MOH}$ and health system that the Ministry considers to be main strategic emphases. The outcomes include New Zealanders living longer, healthier and more independent lives; a health system that is cost-effective and supports a productive economy; health services that are delivered better, sooner and more conveniently; and finally, assurance of the future sustainability of the health system. ${ }^{2}$ If a DHB is found to be failing against these outcomes, the NHB will advise the $\mathrm{MOH}$ when or if it needs to intervene (as the $\mathrm{MOH}$ holds all statutory powers) (Ettelt et al., 2012).

Though there is strong evidence that the current New Zealand Government acknowledges it must do more to ensure the sustainability of its health sector (i.e. establishing the NHB and attempting to strengthen the MOH's control over DHBs activities through emphasising central planning and oversight) there is inconclusive evidence of the effectiveness of these mechanisms (Ettelt et al., 2012). “Good planning requires good information, based on data that is complete, reliable, consistent and comparable” (OAG, 2013, p. 4). However, in a 2013 review of regional services planning in the New Zealand public health sector, the Office of the Auditor-General (OAG) found a wide range of problems when they looked at how data is used in planning services. Specifically, the data the OAG reviewed was not always consistent, comparable, or complete - despite these conditions being important for planning and reporting purposes. "A lack of baseline information means that the contribution of regional services planning to reducing service vulnerability, reducing costs, and improving the quality of care is unproven” (OAG, 2013, p. 4). The OAG concluded that well-known and systematic problems need to be resolved to ensure that data can form a sound basis for planning and decision-making (OAG, 2013). As a result, there is a need to better understand how DHBs plan to provide services and how costing information influences this process. Consequently, this study has numerous motivations, which are discussed next.

\footnotetext{
${ }^{2}$ To achieve the outcomes outlined above, the MOH has separated the public health sector into several distinct business units, each with its own specific objectives (see Figure 1 for an overview of each Business Unit and its associated functions).
} 
Figure 1: Ministry of Health Organisation Chart

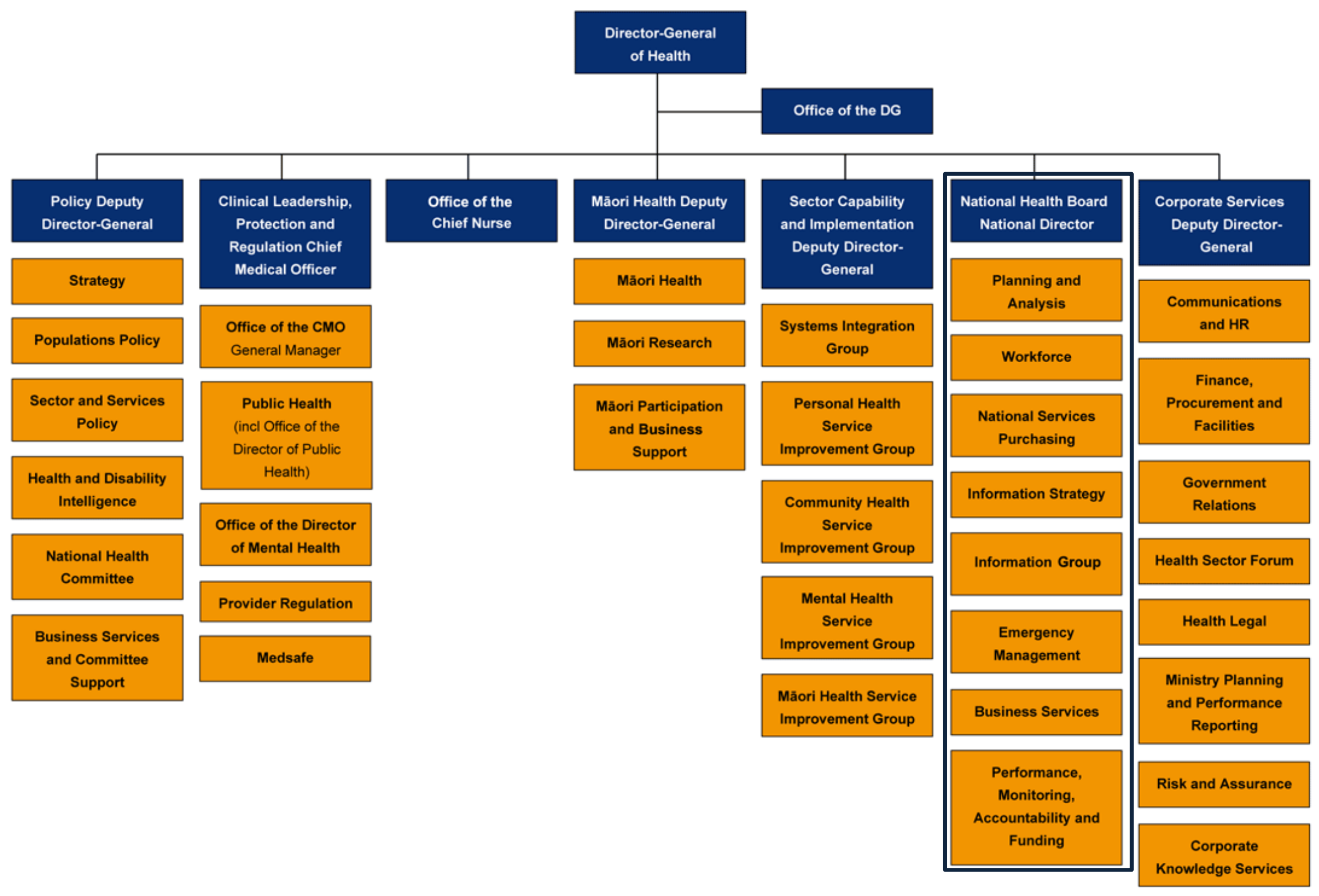

(Source: www.health.govt.nz, 14/10/2013) 


\subsection{Motivation}

From 1950 until now, the amount of money the country has spent on health care has risen approximately three times the rate of increase of gross domestic product (GDP). Acknowledging the fact that the New Zealand public health sector has been predominantly funded through general taxation for the past 60 years, and continues to be funded through general taxation supplemented by statutory insurance for accidents and injuries, there are concerns that the current ongoing growth of spending on health care is not sustainable in the future (Tenbensel et al., 2011; Ettelt et al., 2012). These concerns are exacerbated by increasing demands on New Zealand's health services, driven by causes such as a generally increasing population, an ageing population (with a lower proportion of people active in the workforce) and the rising prevalence of long-lasting health conditions (OAG, 2013). While the NHB has been established purposively to (1) improve service planning at the district and national level (including stronger alignment of service, capital and capacity planning); (2) improve inter-district co-ordination (with the aim of gaining efficiencies, reducing duplication of services, improving the quality of care and eradicating concerns about the sustainability of health care); and (3) achieve the overall outcomes outlined by the $\mathrm{MOH}$, there is a need to assess the influence of the NHB and the twenty DHBs it monitors to fulfil their reformed roles (Ettelt et al., 2012; OAG, 2013). This is corroborated by the fact that eight DHBs did not meet their budgets in the 2012 financial year, and DHBs have historically faced difficulties meeting their annual budgets (OAG, 2013).

As noted above, changes in the New Zealand public health sector in recent years, such as heightened political and economic pressures to manage and reduce costs while improving the quality of care in conjunction with stringent health care guidelines, have forced DHB's nationwide to reassess their approach to health care provision. With the intention of preserving legitimacy, this has chiefly involved evaluating current practices or institutions; revising health care systems, including locality of treatment; and assessing established accounting systems and mechanisms (or lack thereof) to understand the source of costs and resource consumption (OAG, 2013). Acknowledging that patient welfare has always held pre-eminence in the New Zealand public health sector, balancing the dual pressures to enhance the utilisation of limited resources and adhere to social expectations to provide sustained high quality health services has been a difficult exercise for DHBs (OAG, 2013). 
As a result, this study will assess the influence of the NHB and the twenty DHBs it monitors, using a twofold consideration. The first consideration is adoption and use of costing systems by DHBs operating in the New Zealand public health sector. As current cost accounting literature indicates (Cooper \& Kaplan, 1992; Drury \& Tayles, 1995; Hussain \& Gunasekaran, 2001; Abdallah \& Li, 2008), more sophisticated costing systems provide higher quality cost information compared to traditional costing systems, which leads to more informed and effective decision-making. Thus, bearing in mind the MOH's directives and desired outcomes, and the recent issues observed by the OAG, it is expected that DHBs operating in the New Zealand public health sector will adopt and use more sophisticated costing systems, such as activity-based costing (ABC), to plan and provide health services. Based on this expectation, there is a need to ascertain whether or not DHBs adopt and use costing systems (including their level of sophistication), how well DHBs understand their costs and cost structures for effective service planning and provision, and how DHB's contribute to effective regional and national service planning and provision using information provided by their respective costing systems.

The second consideration is how service planning and provision is effectuated by interdistrict co-ordination and inter-district flows (IDF), and the impact costing systems adoption and use have on these processes. As Ashton et al. (2008) notes, most DHBs do not provide a full set of services within their districts; therefore around one in six admissions are for patients from other districts. Thus, there is a process of inter-district co-ordination that takes place to plan and provide services via IDFs. Ashton et al. (2008) expressed concerns about deficiencies in payments for IDFs. Specifically, there are concerns regarding poor quality data on the numbers and types of flows, inaccurate pricing and late payments. There is also a belief that mechanisms used to inform prices unfairly affect smaller secondary DHBs compared to larger tertiary DHBs due to the excessive influence tertiary DHB's supposedly have over the price setting process, which is done at national level. As there is no published literature on IDFs in the New Zealand public health sector, this study will set out to determine how National Prices for IDFs are calculated, how costing systems information is used to inform these prices, how effective these prices are for inter-district trading, and to what extent DHBs are in collaboration with each other to plan and provide health services. 


\subsection{Research Objective}

In recognition of the potential benefits of sophisticated costing systems, and the fact that the New Zealand public health sector is severely underrepresented in current cost accounting and transfer pricing literature, the objective of this study is as follows:

To examine the costing systems used by DHBs to plan and provide health services, and to evaluate how the use of such costing systems influence service planning and provision (at the district, regional and national level) in accordance with the outcomes outlined by the MOH.

In particular, the study will explore how more sophisticated costing techniques, such as $A B C$, are being used by DHBs to (1) enhance the utilisation of limited resources; and (2) adhere to social expectations to provide sustained high quality health services. The study also sets out to contribute to transfer pricing literature from a New Zealand public health sector context by exploring the processes that underpin IDFs, including (1) how National Prices for IDFs are calculated; and (2) to what extent the cost information produced by DHBs costing systems influences this calculation.

\subsection{Research Questions}

To achieve the overall research objective outlined above a series of research questions are posed. The specific research questions, which are based on the research objective, literature reviewed and theory considered are set out below:

RQ 1: What determines and guides the costing systems used in New Zealand DHBs?

RQ 2: How are costs calculated in DHB costing systems?

RQ 3: How is cost information produced by cost systems used to plan and provide services?

RQ 4: How and for what other purposes is cost information used in the public health sector?

RQ 5: How are the transfer prices to be charged for inter-DHB trading determined?

RQ 6: How and for what purposes do DHBs collaborate with each other?

\subsection{Research Framework}

The research framework, developed to achieve the research objective outlined at section 1.3 and answer the research questions posed at section 1.4, is an organisational-field focused research framework based in the New Zealand public health sector (see Figure 7). According to DiMaggio \& Powell (1983, p. 148) an organisational-field is defined as a set of 
"organizations that, in the aggregate, constitute a recognized area of institutional life; key suppliers, resource and product consumers, regulatory agencies, and other organizations that produce similar services or products”. The research framework for this study posits that institutionalisation is deeply embedded in the New Zealand public health sector, and will endeavour to contribute to literature and theory by identifying, with particular emphasis on costing and IDFs, (1) how institutional pressures impact on the organisational environment in which DHBs operate; and (2) the institutions New Zealand DHBs adopt.

Based on the literature reviewed at Chapter 3, which relates to institutional theory in health care, hospitals face a unique challenge in balancing institutional pressures imposed on them by various constituents. With the intention of preserving organisational legitimacy, health care organisations potentially will use institutions as ceremonial processes to create and affirm conformity with regulatory, political and social agencies. Moreover, health care organisations will tend to conform to those pressures that are most influential. Acknowledging the fact that there are three agencies which institutional pressures can emanate from, the research framework for this study posits that the pressures placed on a health care organisation (i.e. a DHB) include (1) institutional pressures from authorities such as the $\mathrm{MOH}$, the NHB and associated costing and pricing groups; (2) institutional pressures from other DHBs operating in the New Zealand public health sector; and (3) institutional pressures from the external organisational environment about how the organisation should behave (i.e. public expectations on DHBs to provide sustained high quality health services).

While the research framework does not suggest the extent to which a DHB will implement any one institution, it does posit that these institutions (which are based on the twofold consideration documented at section 1.2) will include costing practices, costing systems, costing rules and procedures, the provision of cost and volume information for decisionmaking, pricing mechanisms, and product/service mix. Moreover, the research framework suggests that a DHB which conforms to institutional pressures is likely to possess greater organisational legitimacy and be subjected to lower regulatory and behavioural scrutiny by internal and external constituents. This suggestion is justified by the fact that conformity to institutional pressures will lead to less public outcry that DHBs are reneging on their duty (i.e. their social contract) to the general public to provide sustained high quality health services. 


\subsection{Research Methodology}

To achieve the research objective and answer the six research questions, this study employs a multi-site case study (MCS) approach. The case sites selected for this study are tertiary and secondary DHBs and the $\mathrm{MOH}$. The resulting sample of six case sites comprises one main case site (DHB A), one supplementary case site (MOH) and several confirmatory sites (DHB B, DHB C, DHB D and DHB E). The two primary sources of data collected are interviews (with site visits and assisted access to organisational costing and information systems) and primary and archival documents (acquired during the interview process and from electronic sources recommended by interviewees). To add rigor to the study, demonstrate impartiality of the research process and gather findings that maximise validity, reliability and richness verification strategies were also used. The verification strategies, which include replication, reflection and triangulation, are used throughout the processes of sample selection, data collection and data analysis.

To interpret and analyse the data collected this study makes use of qualitative procedures and techniques. Firstly, the data from each interview is transcribed and subsequently analysed to identify key terms and findings. The key terms and findings are then interpreted to discern the meanings and rationale that underlie the opinions, statements and explanations given by interviewees, and through which practical and theoretical explanations can be achieved (Silverman, 2006). To corroborate interview findings, the documentation acquired during data collection is also analysed to identify key terms and findings. Subsequent to data interpretation and analysis, the findings are presented as direct quotations, references to points made by interview participants or references to points made in relevant documentation.

\subsection{Thesis Structure}

The rest of the thesis is organised as follows. In Chapter 2, prior literature is reviewed to gain an understanding of previous studies' findings regarding adoption and use of sophisticated costing systems, with a focus on ABC systems, and transfer pricing in health care settings. Chapter 3 justifies the institutional theory framework based on findings from prior literature and insights from the theory, namely organisational legitimacy and the three pillars of institutions. The use of a MCS approach and methods for data collection and analysis will be discussed in Chapter 4. Chapter 5 provides an overview of the New Zealand public health sector and in particular, how DHBs fund, purchase and cost health services to meet local, regional and national needs. Chapter 6 presents evidence of costing systems adoption and use 
in New Zealand DHBs. Chapter 7 discusses the costing and pricing group data submission requirements for DHBs operating in the New Zealand public health sector. Chapter 8 discusses the calculation of National Price and presents evidence of how National Price influences IDFs. Chapter 9 discusses key findings, evaluates them in relation to the research objective, research questions and research framework, highlights this study's contributions to the literature and provides a conclusion to the thesis.

\subsection{Chapter Summary}

This chapter has provided a brief background on the New Zealand public health sector and outlined the main motivations for conducting the current study. This chapter has also provided the research objective, research questions and research framework that will be used to guide the study as well as the research methodology that will be employed to conduct the study. This chapter then provides a breakdown of the structure of the rest of this thesis. The next chapter will review the literature to gain an understanding of costing systems sophistication, transfer pricing, and previous studies' findings on the nexus between adoption and use of sophisticated costing systems (as represented by ABC techniques) and organisational-field transfer pricing in a health care context. 


\section{Chapter 2 Literature Review}

\subsection{Introduction}

In this chapter prior literature is reviewed to gain an understanding of costing systems sophistication, transfer pricing, and previous studies' findings on the nexus between adoption and use of sophisticated costing systems (as represented by ABC techniques) and organisational-field transfer pricing in a health care context. The gaps in literature identified during this review will (in conjunction with the theoretical framework) inform the research objective, research questions and research framework that will guide the study. The rest of the chapter is organised as follows. Section 2.2 reviews the cost accounting literature on the various costing systems available, their respective approaches to overhead allocation and contextual factors that influence adoption and use of sophisticated costing systems (as represented by ABC). Section 2.3 reviews the cost accounting literature on adoption and use of ABC systems in the health sector during the 1990s, while section 2.4 reviews the cost accounting literature on adoption and use of $\mathrm{ABC}$ systems in the health sector during the 2000s. Section 2.5 discusses several contributing factors which may help to explain why there are no published studies on adoption and use of sophisticated costing systems, such as ABC, in the New Zealand public health sector. Section 2.6 reviews the literature on the various approaches to transfer pricing (and their inherent limitations), while section 2.7 reviews literature on transfer pricing in the health sector. Section 2.8 reviews literature on IDFs in the New Zealand public health sector, while section 2.9 evaluates the potential usefulness of transfer pricing to DHBs operating in the New Zealand public health sector. Section 2.10 reviews literature on the nexus between ABC and transfer pricing. Finally, section 2.11 discusses gaps in the literature identified through the review and proposes research areas that this study may explore to contribute to current cost accounting and transfer pricing literature.

\subsection{Costing Systems Sophistication: Traditional Costing versus Activity-Based Costing}

Garrison et al. (2012) define costing systems as information systems which collect financial information (such as department costs) and non-financial information (such as direct labour hours and units produced) that can then be used as the input data to determine product and/or service costs and other useful information on operations, performance and capacity. According to Geri \& Ronen (2005), the information costing systems generate plays a major role in the decision-making process and has a crucial influence on organisational performance. Specifically, the information can be used to determine product and/or service 
mix, calculate prices, assess whether or not to outsource and evaluate investment alternatives. Moreover, the type of costing system institutionalised by an organisation will largely dictate the quality of cost and volume information that can be generated for decision-making. There are several types of cost system (with varying levels of sophistication) that can be institutionalised by an organisation, which include (but are not limited to) variable costing systems, absorption costing systems and ABC systems.

The variable costing system focuses on direct costs (such as direct materials and direct labour), which can be attributed to a product and/or service through cost tracing. However, the variable costing system is flawed in its approach to allocating indirect costs to products and/or services (Geri \& Ronen, 2005). Specifically, the variable costing system often only utilises a single overhead pool with a single arbitrary basis to allocate variable overhead and omits fixed costs from costing altogether, instead calculating "contribution per unit” to fixed costs.

The absorption costing system attributes direct costs to a product and/or service through cost tracing (consistent with the variable costing system); however it is inherently flawed in that it allocates overhead using an arbitrary volume-related allocation basis. The added issue with the absorption costing system is that it allocates a proportional rate of fixed costs to the units produced but not necessarily sold. This approach to costing can distort cost information for decision-making because it does not consider fixed costs as periodic, meaning fixed costs from a previous period can be caught in the cost of inventory. The result of which can be an inaccurate understanding of actual costs incurred to manufacture a product and/or provide a service (Geri \& Ronen, 2005).

In recent years there has been considerable criticism of unsophisticated direct and absorption costing systems, which focus on physical volume-based cost allocations and short-term cost information usage in organisations (Geri \& Ronen, 2005). This premise is intrinsically flawed, as many resources are also used for activities that are not directly related to physical volume (Hussain \& Gunasekaran, 2001). Consequently, traditional volume-based cost allocation practices may report distorted product and service costs and add little value to short-term operational control (Cooper \& Kaplan, 1992). Recognising the problematic nature of traditional costing, more recent cost accounting literature has proposed a shift to an alternative basis, which provides more sophisticated cost information (Cooper \& Kaplan, 
1992; Drury \& Tayles, 1995; Hussain \& Gunasekaran, 2001; Abdallah \& Li, 2008). This alternative is commonly referred to as ABC (see Figure 2).

Figure 2: Comparison of Traditional Costing View to Activity-Based Costing View

Traditional Costing View

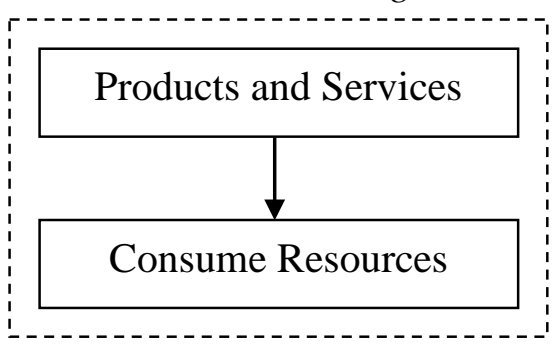

Activity-Based Costing View

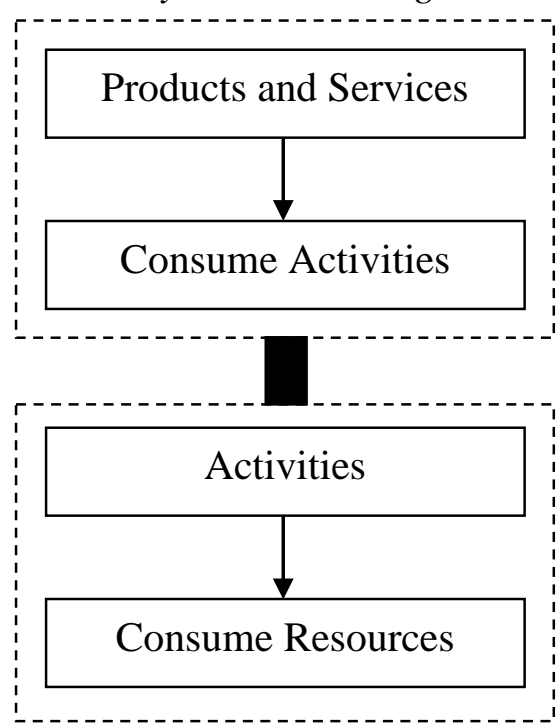

In contrast to traditional volume-based costing, which suggests that physical output of products and services drive costs, $\mathrm{ABC}$ rationale posits that organisational activities involved in the supply of products and provision of services drive costs (Cooper \& Kaplan, 1992). This view is supported by Figure 2, which illustrates that products and services create demand for organisational activities; however it is actually those activities which induce resource consumption (and consequently drive costs). Though there is often a causal relationship between volume and incurrence of direct costs (such as direct materials and direct labour), as these costs tend to change as volume changes, the relationship between volume and indirect costs is not as explicit (Baker, 1994). Indirect costs are known as overheads and require an allocation basis to be apportioned to products and services. ${ }^{3}$ The next section will expand on the limitations of a traditional volume-based costing system (such as a variable costing system and an absorption costing system) and the benefits of a more sophisticated ABC system for the purposes of overhead allocation.

\footnotetext{
${ }^{3}$ Al-Omiri \& Drury (2007) note that both simplistic and sophisticated costing systems can accurately assign direct costs to products and services. Cost assignment merely involves the implementation of data processing systems to identify and record the resources consumed by products and services. Therefore, the choice of costing system design generally only applies to the assignment of indirect costs.
} 


\subsubsection{Overhead Allocation}

Traditional costing systems have been criticised for their overly simplistic and arbitrary approach to overhead allocation. Traditional costing systems often only utilise a single overhead pool with a single allocation base related to direct labour or direct materials (Bromwich \& Bhimani, 1994). This traditional approach was developed in an era when direct labour and direct materials were undoubtedly the most significant product costs, and overheads were as low as $15 \%$ of total product cost. However, as some organisations become increasingly complex and overheads continue to grow as a percentage of total costs, this approach to allocating overheads becomes less relevant (Brown et al., 2003). Relevance is lost because overhead costs are not typically caused by changes in volume. Therefore, assigning overhead costs using a single volume-based allocation approach can provide management with a distorted view of how costs are incurred (Hussain \& Gunasekaran, 2001). Additionally, through a traditional costing system little attention is given to rapid increases in overhead costs, or where such increases originate. These deficiencies are a significant cause for concern, as poor cost understandings and inaccurate cost information can seriously inhibit managerial decision-making, particularly regarding product and/or service mix and price formulation (Hussain \& Gunasekaran, 2001).

Unlike the potentially arbitrary nature of overhead allocation through traditional costing systems, a well-designed $\mathrm{ABC}$ system reflects a careful understanding of the type of activities or processes that generate overhead costs (Colbert \& Spicer, 1998). Through ABC "the costs that cannot be allocated directly to products or services are captured in overhead pools and allocated to products [and services] based on activities that have cause-effect relationships with cost incurrence” (Brown et al., 2003, p. 7). This allocation process requires an organisation to develop thorough understandings of how overhead costs are incurred, which can often lead to in-depth analysis to successfully identify activities or processes and the cost drivers associated with each activity or process (Baker, 1994). Ultimately, more thorough understandings of the cost drivers associated with overhead costs will enable more accurate overhead cost allocations (see Figure 3). This leads to more accurate product and service costs, which flows into more informed product and/or service mix and pricing decisions (Brown et al., 2003). Well-informed decisions, based on accurate cost information, can be vital to the success of an organisation, particularly in a competitive environment, as product and/or service mix must be profitable and prices need to be competitive with the market. 
Figure 3: Steps in the Activity-Based Costing Methodology
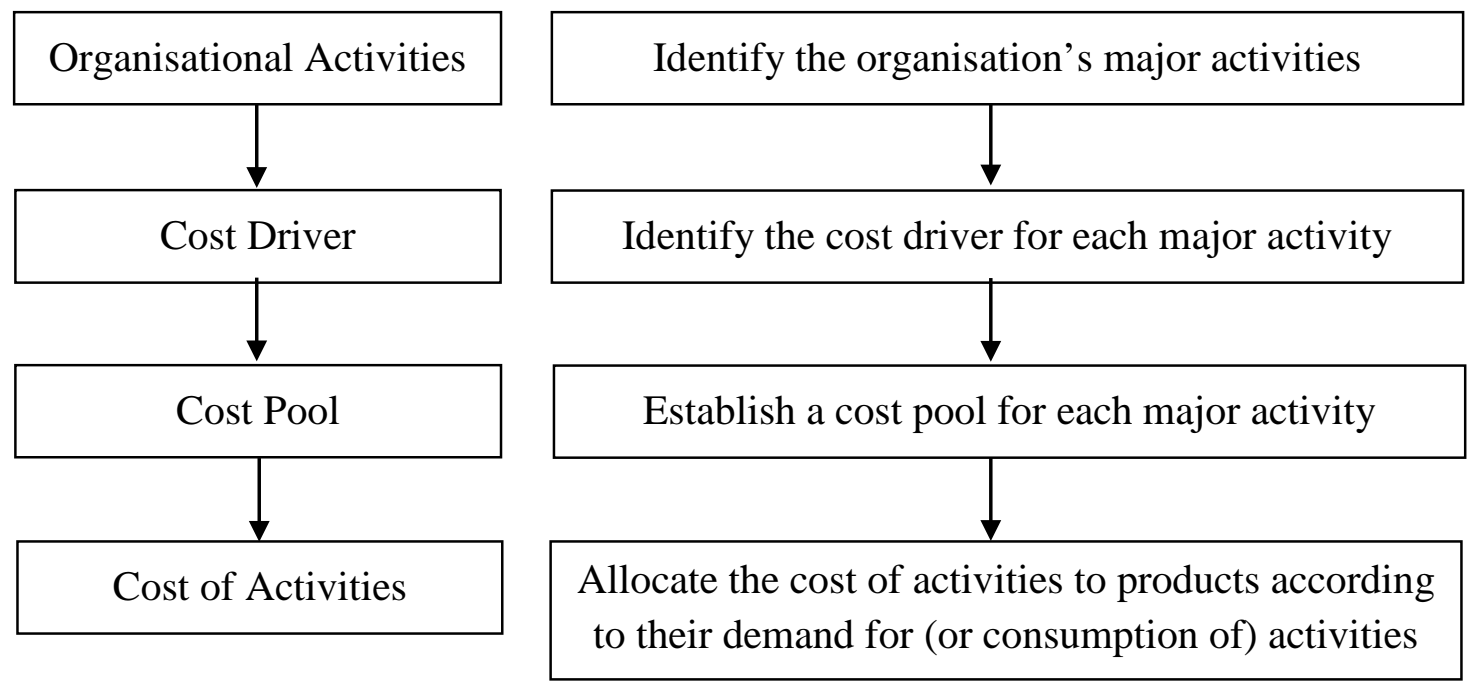

It is argued that continually using more traditional costing approaches may reflect management inertia and reluctance to abandon techniques that have become embedded in an organisation (Drury \& Tayles, 1995). Management inertia and reluctance to abandon techniques can create a culture of resistance to change, which may severely impede the successfulness of strategy and constrain opportunities to improve efficiency within an organisation. In particular, maximising resource utilisation and improving cost control can be significantly limited if an organisation refuses to move away from more traditional costing approaches (Cobb et al., 1993). To assist organisations in determining whether or not they should move away from traditional costing approaches (i.e. unsophisticated costing systems) to more advanced costing approaches (i.e. sophisticated costing systems such as $A B C$ ), Cooper (1988) provides four factors to evaluate the suitability of ABC in different organisational settings. The factors are listed and discussed next.

\subsubsection{Organisational Factors and ABC Systems}

Cooper (1988) provides four contextual factors to assist organisations in evaluating whether or not their structure and the environment in which they operate warrants adoption and use of more sophisticated costing systems, such as ABC. The factors are:

1) An organisation operates in a competitive environment

2) An organisation provides numerous products/services

3) Organisational operations are multi-faceted and complex

4) The cost of measurement is lower than the likely benefits that will eventuate 
A review paper by Drury \& Tayles (1995) reaffirms the importance of the factors identified by Cooper (1988) when an organisation is evaluating the merits of sophisticated costing systems. Firstly (and more generally), Drury \& Tayles (1995) suggest that organisations should theoretically implement more sophisticated costing systems, such as ABC, when they foster the factors identified by Cooper (1988) in any capacity. This suggestion is substantiated with numerous justifications, including (1) that organisations operating in a more competitive environment have a greater need for sophisticated costing systems that report more accurate product and service costs. This need arises because competitors are likely to take advantage of any errors arising from managerial decisions guided by distorted cost information; (2) organisations that provide numerous products and services should adopt ABC. This is largely because traditional costing systems only report costs that can be directly assigned to products and services, such as direct labour and direct materials; and (3) "Increased diversity arising from products [and services] consuming resources in different proportions also favours more sophisticated systems because, as diversity increases, so does the level of distortion reported by traditional systems that rely on simplistic costing systems” (Drury \& Tayles, 1995, p. 272).

Though there is cost accounting literature on adoption and use of more sophisticated costing systems, such as ABC, including Bjørnenak (1997); Gosselin (1997); Krumwiede (1998); Malmi (1999); Clarke et al. (1999); Hoque (2000); and Cagwin \& Bouwman (2002), these previous research efforts have been criticised by Al-Omiri \& Drury (2007, p. 400) for being "inconclusive and unable to establish strong links between the adoption of $\mathrm{ABC}$ and those contextual factors that have been identified in the literature that are conducive to the adoption of ABC systems”. Specifically, Al-Omiri \& Drury (2007) have criticised this prior surveybased research, for (1) use of weak measures for dependent and independent variables; (2) the terms 'adoption of ABC' and 'non-adoption of ABC' have been subject to different interpretations; (3) researchers have allowed respondents to self-specify whether their organisation operates an ABC system; and (4) previous research efforts have yielded inconsistent findings on the factors which influence adoption and use of ABC systems.

Lee (2002) emphasises that pioneers of ABC theory development have worked tirelessly with client organisations on a worldwide basis to test and enhance ABC. Lee (2002, p. 75) also argues, "global homogenization in management accounting practices explains why there have been very little differences in the ABC theory development”. With reference to Cooper 
(1988), who believes that the optimum cost system is different for different organisations and that this is dependent on various contextual factors, the argument put forward by Lee (2002) appears to be a blatant oversimplification. Over the past two decades there has been very little conclusive research on the factors that influence the adoption of ABC systems, and whether or not these factors have evolved over time. There is an unequivocal need for further research to determine the factors that influence adoption and use of sophisticated costing systems; if the factors change based on different organisational environments; and if the factors outlined by Cooper (1988) still apply (and if so, whether or not they have become more or less important). Moreover, there is a significant lack of literature on the contextual factors that influence adoption and use of more sophisticated costing systems, such as ABC, from a health care perspective.

To rectify the issues with previous survey-based research, and contribute to cost accounting literature on adoption and use of costing systems from a health care perspective, this study will apply the sophistication continuum developed by Al-Omiri \& Drury (2007) to explore costing systems adoption and use in the New Zealand public health sector (see Figure 4). Specifically, this study will use the sophistication continuum to (1) determine the factors that influence adoption and use of costing systems (and their varying levels of sophistication) in the New Zealand public health sector; and (2) understand the dimensions of costing systems used in the New Zealand public health sector that makes them unsophisticated or sophisticated. According to Al-Omiri \& Drury (2007), there are four dimensions that determine the sophistication of an organisation's costing system. The dimensions include (1) the number of cost pools; (2) the extent to which costs are directly assigned to each cost pool during the first-stage allocation process, or the extent to which cause-and-effect first-stage drivers are used (first-stage allocation is the process by which overhead costs are assigned to activity cost pools (Garrison et al., 2012)); (3) the number of different types of second-stage cost drivers (second-stage allocation is the process by which overhead costs relate to cost objects (i.e. products, services and customer orders). In this stage activity rates are used to apply costs to products and services (Garrison et al., 2012)); and (4) the extent to which transaction drivers (which are less sophisticated) or duration drivers (which are more sophisticated) are used in the second-stage of the allocation process. 
Figure 4: Dimensions determining the varying levels of Cost System Sophistication

\section{Lowest level of sophistication}

Highest level of sophistication

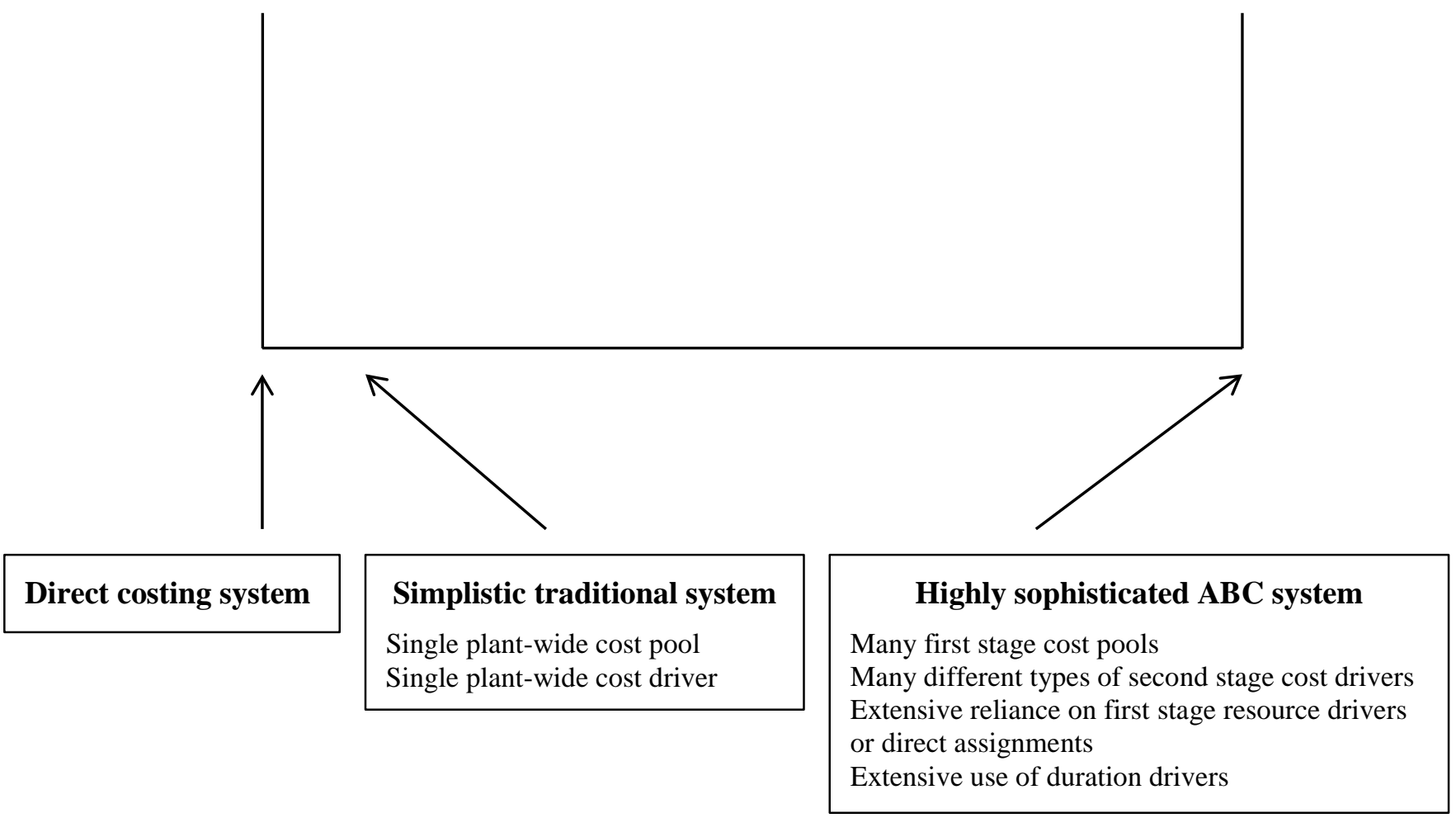

(Source: Al-Omiri \& Drury, 2007, p. 401)

The purpose of the next three sections is to review the cost accounting literature that has been written on adoption and use of sophisticated costing systems (with a focus on ABC systems) in the health sector over the past two decades.

\subsection{Activity-Based Costing and the Health Sector in the 1990s}

Despite overt acceptance that ABC was not developed for service organisations, several advocates considered its usefulness in the health sector during the 1990s (Chan, 1993; King et al., 1994; Lawson, 1994; Ramsey, 1994; Canby, 1995; Aird, 1996; Udpa, 1996; Baker, 1998). One such advocate, Chan (1993, p. 73), contends "patients are unique products themselves [and] regardless of whether we are manufacturing one million units of a product, or treating one patient, the principle of cost application with ABC remains unchanged”. In addition, Aird (1996) and Baker (1998) recognise that hospitals typically have a high volume of broad and complex operations, with multiple services being offered to patients. These attributes are consistent with two of the four contextual factors outlined by Cooper (1988), which support adoption and use of sophisticated costing systems (discussed at section 2.1.2). 
Specifically, factor 2) An organisation that provides numerous products/services, and factor 3) Organisational operations are multi-faceted and complex (Cooper, 1988).

Canby (1995) conducted a case study that investigated the applicability of ABC to four separate types of x-ray services (i.e. knee, hand, cervical and shoulder) provided at the x-ray department of a mid-sized outpatient clinic. After observing practices, interviewing clinicians, and reviewing archival records, Canby (1995) determined that each X-ray procedure functioned uniquely. Moreover, Canby (1995) deduced from his investigation that each x-ray procedure used activities in different quantities, creating procedure-specific costs (i.e. each x-ray series required a particular quantity of staff time, technology with varying levels of sophistication, and certain films with different costs and in different quantities).

While it is indisputable that Canby's (1995) findings are not exhaustive, they do provide evidence to support adoption and use of ABC (a more sophisticated costing system) in the health sector to improve cost information and cost understandings. Firstly, the findings highlight that $\mathrm{ABC}$ can assist the determination of costs associated with hospital processes (in this instance x-ray department processes). Secondly, the findings highlight that ABC can provide a more accurate measurement of financial performance compared to traditional costing approaches. Thirdly, as health care organisations often have limited resources to deliver services, $\mathrm{ABC}$ presents an accurate and meaningful cost-information system to develop operational control and potentially eliminate waste (Canby, 1995). According to Ramsey (1994), the ability of a hospital to develop stringent control over its operations and reduce waste is extremely important to its long-term viability. This is because hospitals must be able to provide low-cost, high-quality care for a large number of patients continuously.

To corroborate suggestions that $\mathrm{ABC}$ systems can be used to gain operational control and eliminate waste, an article by Chan (1993) was reviewed, which considers adoption and use of ABC at a hospital laboratory (albeit hypothetically). According to Chan (1993, p. 77), for "health care organizations facing spiralling expenses, ABC can be a valuable tool... in controlling costs and making strategic decisions”. More specifically, Chan (1993) posits that ABC systems can promote operational control and reduce waste. This position is substantiated by Ramsey (1994), who conducted a case study to evaluate the applicability of an ABC system to a hospital radiology department. Findings from Ramsey (1994) indicate that an ABC system can be used to identify 1) key activities involved in radiological procedures; 2) where process improvements can be made; and 3) where non-value added 
activities can be eliminated, while ensuring proper functionality of each radiology procedure. Overall, the ability of $\mathrm{ABC}$ to promote operational control and reduce waste is due to its emphasis on activity analysis, which results in superior cost measurement and cost management compared to traditional costing systems (Cooper \& Kaplan, 1990; Schneider, 1992; Chan, 1993; Ramsey, 1994). ${ }^{4}$ For example, activity analysis can allow departmental management to evaluate whether or not employee skills are being utilised appropriately; if it is feasible to cross-train staff to perform additional activities; and if the diagnostic yield of radiologists is being reduced due to administrative matters and/or other departmental inconveniences (Ramsey, 1994).

King et al. (1994) conducted a MCS into adoption and use of ABC systems at four acute general United Kingdom National Health Service sites and while they acknowledged the applicability of $\mathrm{ABC}$ to the health sector in principle; they also accepted that there are major implications associated with the implementation of ABC systems in health care organisations. The major implications include "the high level of educational, communicative, data gathering, processing and interpretive work necessary to introduce $\mathrm{ABC}$ and the consequent need for resources and funding which its development will create” (King et al., 1994, p. 147). Regardless of its technical merits, these implications can act as a major deterrent to the adoption and use of ABC systems. As King et al. (1994, p. 159) revealed, operational and resourcing difficulties identified at the hospital sites investigated made it likely that $A B C$ would only "be adopted in a piecemeal, fragmentary fashion in the National Health Service".

While there is evidence that the pragmatic potential of $A B C$ to the health sector was considered during the 1990s, a very limited number of studies were identified in the cost accounting literature, and they tended to be introductory, partial and speculative in nature (Chan, 1993; King et al., 1994; Ramsey, 1994; Canby, 1995; Aird, 1996). As Udpa (1996, p. 83) highlights, these "studies of ABC in health care settings focus on a narrow application of ABC to a department within the health care organization”. For instance, Chan (1993) merely examines the application of ABC systems to the costing of laboratory tests in a hypothetical hospital setting; King et al. (1994) to orthopaedics and radiography; Ramsey (1994) to a radiology department; and Canby (1995) to an x-ray department. Furthermore, these research

\footnotetext{
${ }^{4}$ As a caveat, though $\mathrm{ABC}$ can provide more accurate costing information to assist managers in identifying activities that are costly or non-value added, making changes in the mix of health services offered and instigating operating efficiency improvements, it is not a panacea to all problems within a hospital. ABC is only a decision support tool and ultimately it is at the discretion of management whether remedial action is taken and what that action should be (Chan, 1993).
} 
efforts only spanned over the mid-1990s and none of them relate to adoption and use of ABC systems in a New Zealand public health sector context. To determine if this changes in the 2000s, the next section reviews the relevant cost accounting literature on adoption and use of $\mathrm{ABC}$ in the health sector written during the $21^{\text {st }}$ century.

\subsection{Activity-Based Costing and the Health Sector in the 2000s}

Consistent with the 1990's, there has been very few published studies on adoption and use of ABC systems in the health sector over the past decade or so. While scholars (such as Ross, 2004; Arnaboldi \& Lapsley, 2005; Lawson, 2005; Yereli, 2009 and Shander et al., 2010) maintain that health care organisations need to manage their rapidly increasing costs more effectively and efficiently, and that $\mathrm{ABC}$ is viable tool to achieving this, there is a complete deficiency of evidence-based literature to support its use in the health sector. As Lawson (2005) states, prospective adopters have greater familiarity with ABC systems (including the benefits thereof) than they did when ABC was first developed, and it is well established as a sophisticated cost accounting approach compared with the more traditional cost accounting approaches. "However, contrary to expectations, use of these [ABC] systems has declined slightly over [the past decade], as has the percentage of health care organizations contemplating implementing such systems” (Lawson, 2005). ${ }^{5}$

Despite the perceived benefits of $\mathrm{ABC}$ systems (i.e. superior cost information and cost understandings, improved organisational control, more accurate decisions on budgeting and strategy planning, and more efficient and effective use of resources), it is evident there are barriers to its use in the health sector. Findings made by Lawson (2005) indicate that health care organisations have several reservations about adopting and using $\mathrm{ABC}$. These reservations include (but are not limited to) the cost of designing and implementing an $\mathrm{ABC}$ system; the need to create new systems for data capture and processing; failure to gain acceptance from managers; and lack of commitment by senior management. Lack of commitment by senior management is also noted by Ross (2004) and Arnaboldi \& Lapsley (2005) as an overarching factor that can impede the success of ABC systems adoptions to health care. Specifically, Ross (2004) states, there is a clear division between medical and accounting personnel, which negatively affects each, as well as patients, the health delivery system, and society. Health care organisations need to comprehensively shift management

\footnotetext{
${ }^{5}$ Lawson (2005, p. 81) concludes, "this result is surprising given that in 1994 activity-based costing was a relatively new technique, only beginning to be utilized in service industries such as health care. Given the typical adoption pattern of management techniques, it would have been expected that the use of ABC would have increased over the last decade".
} 
thinking from a functional departmental view to a more cross-functional view of hospital activities and processes, and to re-educate personnel organisation-wide on the benefits $A B C$ systems can provide to all aspects of health care (namely low-cost high-quality service provision). "Health care can ill-afford managers who limit their duties to providing the best possible care or the most efficient use of resources” (Ross, 2004, p. 20). As a result, the initiative and impetus for change should come from them, as they have the power to influence how and for what purpose(s) health care organisations function.

Though the previous paragraph has discussed the hurdles/reservations associated with adoption and use of $\mathrm{ABC}$ systems there are some success stories to demonstrate how $\mathrm{ABC}$ can be used effectively in health care settings. The first of these is a case study conducted by Yereli (2009) that explores the benefits of ABC systems over traditional accounting systems to cost gall bladder surgeries in the general surgery department of one university hospital in Turkey. The findings of Yereli's (2009) study indicate that ABC is an effective cost management model that determines costs and evaluates financial performance across departments in a hospital. However, the main contribution of Yereli (2009) is his discussion of how ABC systems can be applied to health care (specifically, to cost gall bladder surgeries that are performed openly and laparoscopically), which is summarised below.

Consistent with traditional costing, direct costs of the hospital are directly distributed to appropriate cost departments with an ABC system (Yereli, 2009). However, unlike traditional costing, which allocates indirect costs to services using the arbitrary criteria 'number of patient days', the ABC system allocates indirect costs to activities using a two-stage approach. "In the first stage, indirect costs are allotted to activity pools where certain activity groups are collected. Therefore, similar activities performed in accordance with the main services the hospital renders are collected in the same activity pools” (Yereli, 2009, p. 582). The activity pools are 1) procedure for admitting patients to the hospital; 2) laboratory procedures; 3) preoperational procedures; 4) surgeries; and 5) patient care. Once the activity pools are determined, indirect costs are allocated to them with first stage cost drivers, which forms the basis of cost pools (see Table 1). 
Table 1: Indirect Costs and First Stage Cost Drivers

\begin{tabular}{|l|l|}
\hline \multicolumn{1}{|c|}{ Indirect Costs } & \multicolumn{1}{c|}{ Cost Drivers } \\
\hline Indirect labour & Number of employees \\
\hline Dining hall & Number of meals \\
\hline Medical consumables & Quantity of materials used \\
\hline Transportation and communication & Number of patients \\
\hline Electricity and water & Area $\left(\mathrm{m}^{2}\right)$ \\
\hline Equipment depreciation & Quantity of medical devices \\
\hline Maintenance and repair & Quantity of medical devices \\
\hline Heating and fuel & Area (m $\left.{ }^{2}\right)$ \\
\hline Cleaning work & Area (m $\left.{ }^{2}\right)$ \\
\hline Laundry & Amount of laundry washed $(\mathrm{kg})$ \\
\hline Office stationery and materials & Number of patients \\
\hline Accounting & Number of patients \\
\hline Computer expenses & Number of computers \\
\hline
\end{tabular}

(Source: Yereli, 2009, p. 584)

In the second stage, indirect costs are allocated to open or laparoscopic treatments from the cost pools. To carry out this distribution process, second stage cost drivers and data used for the designated activity pools is applied. For activity pool 1) procedure for admitting patients to the hospital, the cost driver is number of patients admitted; 2) laboratory procedures, the second stage cost driver is number of tests; 3) preoperational procedures, the second stage cost driver is number of patient days and preparation period of the patient (open surgery - 75 minutes and laparoscopic surgery - 12 minutes); 4) surgeries, the second stage cost driver is number of patient days and surgery hours (open surgery - 90 minutes and laparoscopic surgery - 60 minutes); and 5) patient care, the second stage cost driver is number of patient days. Once both direct costs and indirect costs are allocated to open or laparoscopic treatments, the unit cost per surgical procedure can be calculated. As Yereli (2009) concludes, the ABC system (which has been described above) provides management with more accurate unit costs, which translates into more accurate decisions on budgeting and strategy planning.

The second success story that demonstrates how ABC systems can be used effectively in health care settings is a case study conducted by Shander et al. (2010) that considers the applicability of ABC to the delivery of red blood cell transfusions at two hospitals in the 
United States and two hospitals in Europe. The study was motivated by the fact that health sector organisations have limited resources, and blood transfusions have long been suspected to consume more resources than previously reported. Furthermore, the nature of blood transfusions warrants use of more sophisticated costing systems, such as ABC, because "each process step involves diverse personnel, capital, and consumable resources that are then multiplied by their usage frequencies" (Shander et al. (2010, p. 754). The main findings of Shander et al. (2010) reveal that the cost estimates previously reported for all major process steps, staff, and consumables required to provide red blood cell transfusions have been underestimated (both in the United States and in Europe). Overall, Shander et al. (2010) conclude that $\mathrm{ABC}$ systems represents the most detailed and rigorous method available to account for the cost of blood transfusions (which require vast and complex activities), while facilitating cost-containment through improved cost information.

The literature reviewed in this section provides evidence that authors have considered the usefulness of $\mathrm{ABC}$ systems to the health sector during the $21^{\text {st }}$ century; however this evidence is very limited. Specifically, only two evidence-based studies were identified in the cost accounting literature and they focused on adoption and use of $\mathrm{ABC}$ systems to a single department within the health care organisation. Moreover, these studies only explored adoption and use of ABC systems in the United States and Europe. As a result, this section of the literature review indicates a greater need for research to explore adoption and use of $A B C$ (and other forms of sophisticated costing systems) from a holistic organisational perspective (including how and for what purposes), and in a New Zealand public health sector context.

In recognition of the fact that none of the studies identified and reviewed as part of the literature reviews performed at section 2.3 and section 2.4 relate to costing systems sophistication or the adoption and use of ABC (as a form of sophisticated costing system) in a New Zealand public health sector context, the next section will offer a brief potential explanation for this complete lack of cost accounting literature.

\subsection{Activity-Based Costing and the New Zealand Public Health Sector}

There are several contributing factors which may help to explain why there are no published studies on adoption and use of sophisticated costing systems, such as ABC, in the New Zealand public health sector. Firstly, public sector organisations tend not to operate within a general market like private sector organisations and they face far less competition. Furthermore, any competition faced tends to be less fierce (i.e. public health sector 
organisations are the primary providers of government funded health care services in New Zealand and are expected to provide a set range of services to the general public. If a public health sector organisation is not able to provide such services they will outsource to other providers such as private providers). Secondly, public sector organisations must consider more than just economic and technical matters. As providers of goods and services to the general public they are required to meet more rigorous political, ethical and social objectives. Thirdly, public sector organisations are not motivated by profit-maximisation, but a main objective of public satisfaction. Objectives such as cost reduction and resource efficiency are a secondary consideration (Guthrie and Parker, 1996).

Irrespective of the factors outlined above, which may contribute to explaining why there are no published studies on adoption and use of sophisticated costing systems, such as ABC, in the New Zealand public health sector, it is evident (based on the review of prior literature) that this presents a significant gap in the cost accounting literature that needs to be filled. Consequently, the current study, which focuses on the nexus between adoption and use of sophisticated costing systems (as represented by ABC techniques) and IDFs in the New Zealand public health sector, will strive to contribute to cost accounting literature on adoption and use of sophisticated costing systems, such as ABC, from a New Zealand public health sector perspective.

While this study is exploring IDFs in the New Zealand public health sector at an interorganisational-field level (i.e. between DHBs), the literature vastly focuses on transfer pricing at an intra-organisational-field level (i.e. between divisions of an organisation). As a result, the next section will review the literature on the various approaches to transfer pricing (and their inherent limitations), which has been written from a divisionalised perspective, but with the intention of applying it to the organisational environment within which IDFs take place.

\subsection{Transfer Pricing: Approaches and Issues}

A transfer pricing system facilitates cost determination and control together with performance accountability. According to Hoque (2003) and Baldenius \& Reichelstein (2006), there are a number of strategic and practical issues associated with transfer pricing, which create what is commonly known as the "transfer pricing problem”. Such issues include (1) resolving pricing disputes between divisions via negotiation, arbitration or directives; (2) giving divisions the freedom to decide whether to buy and sell amongst themselves; (3) allowing divisions to source externally when resources are available internally; (4) deciding what type of transfer 
pricing method to use; and (5) determining the final price transfers will be made at. Wider organisational issues also have an influence on transfer pricing. Specifically, contextual factors such as size, managerial autonomy, market factors, product diversity and overall strategy (Desheh et al., 1997; Colbert \& Spicer, 1998; Baldenius et al., 1999; Ghosh, 2000; Pfeiffer et al., 2011).

The three most common transfer pricing methods applied by organisations are market-based, cost-based and negotiated transfer prices. In practice, each of these methods is used in conjunction with the opportunity cost approach when a transfer price is being set. "The opportunity cost approach identifies the minimum price that a selling division would be willing to accept and the maximum price that the buying division would be willing to pay” (Hoque, 2003, p. 151). If a fair compromise cannot be reached internally, buying and selling divisions will opt out of transfer pricing and choose to interact in the external market instead (if it exists). The purpose of the next three subsections is to define the main approaches to transfer pricing (from a divisionalised organisation perspective) and to outline their inherent flaws. Following this, section 2.7 will review literature on transfer pricing in health care settings from an inter-organisational perspective that has been written over the past two decades. Acknowledging the fact that the literature vastly focuses on transfer pricing at an intra-organisational-field level (i.e. between divisions of an organisation), section 2.8 will review literature on IDFs (an inter-organisational form of transfer pricing specific to the New Zealand public health sector) before section 2.9 evaluates the potential usefulness of transfer pricing (based on literature reviewed at section 2.6 and section 2.7) to DHBs operating in the New Zealand public health sector.

\subsubsection{Market-based Transfer Pricing}

If a perfectly competitive market for a product or service exists, the prevailing market price is recommended for transfer pricing. For a perfectly competitive market to exist, a homogenous product or service with equivalent buying and selling prices is typically required. Moreover, no individual buyer or seller should be able to affect those prices by their own actions (Hoque, 2003). Provided these conditions are present, market-based approach is deemed the most suitable approach to transfer pricing, as it will lead to efficient decentralisation of decision-making (Hirshleifer, 1956; Cook, 1955). However, as Baldenius \& Reichelstein (2006) emphasise, the competitive market scenario can be debated as nothing more than a conceptual benchmark. "In many industries the very rationale for vertical integration appears 
to be that intermediate products and services are specialized or even proprietary” (Baldenius \& Reichelstein, 2006, p. 2). See also Eccles \& White (1988); Milgrom \& Roberts (1992); Brickley et al. (1995); Kaplan \& Atkinson (1998); Joskow (2004).

\subsubsection{Cost-based Transfer Pricing}

If a market price cannot be identified, does not exist, or is unsatisfactory to the parties involved, cost-based transfer prices should be used in its place (Colbert \& Spicer, 1998). Though cost-based transfer pricing is a credible substitute to market-based pricing, there is an inherent expectation that organisations applying this approach can calculate accurate product or service costs (Atkinson et al., 2007). There are a range of different cost-based transfer pricing methods, including (1) the variable cost approach; (2) the full cost approach; and (3) the dual approach (Tebogo, 2011).

(1) Variable cost-based transfer pricing is based on the total variable costs incurred by the selling unit, which include direct labour, direct materials and variable overhead (Hunt \& Fowler, 2009). When the variable cost-based transfer pricing approach is applied, the selling division will always make a loss equal to its fixed costs of production (Tebogo, 2011). The major benefit of this approach is that it encourages prospective buying divisions to purchase goods and services internally, as the transfer price is lower than external market prices.

(2) Full cost-based transfer pricing is based on the total cost of the provider's product and is equivalent to the variable costs plus fixed costs per transfer unit (Colbert \& Spicer, 1998). A full cost-based transfer price includes costs from other relevant business functions within the division (commonly referred to as overhead), such as research and development, design, marketing, distribution and customer service (Tebogo, 2011). The major benefits of this approach are simplicity of use (as the data is already available and easily understood) and it puts the selling division in a position to cover all production costs incurred (Colbert \& Spicer, 1998; Tebogo, 2011).

Considering the definitions of variable and fixed cost transfer pricing provided above, it is evident that divisionalised organisations face a significant transfer pricing dilemma. While the use of variable cost transfer pricing may motivate buying divisions to purchase goods and services internally, transfer pricing without regard to fixed assets, overhead, and profit for the selling division leads to an unfair measure of its contribution to the company (Eccles, 1985). This may lead to short-term profit maximisation, as value is held in the firm, but from a long- 
term perspective such a focus may remove any advantage that comes from treating divisions as independent profit centres (Sahay, 2003). However, if a transfer price is set at full cost this demotivates buying divisions to purchase internally, as they can acquire the same or similar goods and services cheaper in the external market. Kaplan (1982, p. 483) views this as "the essence of the transfer pricing conundrum”.

(3) Dual transfer pricing involves the selling division charging the buying division the marginal cost for the goods and services transferred. The difference between the marginal cost and the market price is then settled by the parent company. As stated by Atkinson et al. (2007) and Tebogo (2011), this arrangement is designed to ensure transfer prices are set at efficient levels so as to motivate intra-organisational interaction between buying and selling divisions. The buying division is motivated to buy from the selling division, since the transfer price is at marginal cost and thus, below the external market price. Similarly, the selling division is motivated to produce and supply to the buying division, since any opportunity cost they forgo by not trading in the external market is reimbursed by the parent company. For the parent company, such transactions make economic sense. Not only do they alleviate "the transfer pricing conundrum”, but they also ensure value is retained within the group and not dissipated by external purchases.

\subsubsection{Negotiated Transfer Pricing}

When it is difficult to identify a market, imperfections exist in the market or interacting divisions cannot agree on a cost-based transfer pricing method, negotiated transfer pricing may be a more practical alternative. Negotiated transfer pricing is defined as a bargaining process between buying and selling divisions and dictates whether intra-company transfers take place, the quantity to be transferred, and the overall transfer payment (Vaysman, 1998). Though the negotiated transfer pricing approach is useful in particular situations, it has a number of weaknesses, including (1) being a very time-consuming process that can make divisional measurement sensitive to the negotiating skills of management; (2) it can lead to inter-divisional conflict, and therefore requires time and effort of top management to oversee the negotiation process and mediate disputes; and (3) it can lead to sub-optimal output levels if the negotiated price is too high (Kaplan \& Atkinson, 1989). Several scholars, including Spicer (1988), Holmström \& Tirole (1991), Wagenhofer (1994) and Ghosh (2000), attest that to understand these weaknesses and manage them effectively involves a thorough consideration of the organisational setting in which transfers occur. 
"In general, a large hierarchical organization is described as a set of systems of simultaneous competition and co-operation which involve managers with diverse preferences" (Ghosh, 2000, p. 664). That is, participants constitute a coalition and must cooperate in pursuit of common organisational goals. In addition, participants often have diverse mutually exclusive interests and objectives, as they have to compete for limited resources, status and career advancement (Kochan \& Verma, 1983). For these reasons, organisational settings are highly important as they affect the behaviour of managers during the negotiation process and any subsequent outcomes (Graham, 1985; Lax \& Sebenius, 1986). Thus, to sufficiently understand and manage the weaknesses associated with negotiated transfer pricing, organisations should ensure their transfer pricing policies recognise the inherent mixedmotive nature of separate interacting divisions (Kochan \& Verma, 1983). This will involve developing transfer pricing policies that (1) focus on notions of fairness and how to mitigate inter-divisional conflict (Eccles, 1985; Emmanuel \& Messaoud, 1994); (2) take into consideration the degree of inter-dependence between profit centres from sourcing (Eccles, 1985; Spicer, 1988); and (3) positively affect the economic outcome measure of firm profit (Eccles, 1985; Chalos \& Haka, 1990; Ghosh, 1994; Ghosh, 2000).

The next section will review literature on transfer pricing in divisionalised health care settings (i.e. between divisions) that has been written over the past two decades.

\subsection{Transfer Pricing and the Health Sector in the 1990s and 2000s}

As stated by Young (1998), one of the key issues linked to health care delivery is the transfer price at which hospital divisions provide materials to patient care departments. Likewise, how the transfer price is determined requires hospital senior management to consider numerous factors. Primarily, they must choose whether or not to include the selling division's variable costs for the materials being transferred or alternatively, the variable costs plus a share of the division's fixed costs. If the latter, senior management also need to decide whether fixed costs should include direct fixed costs or direct fixed costs plus allocated overhead. While it may seem reasonable to supply materials at the actual cost incurred by the selling division (i.e. inclusive of variable costs, direct fixed costs and allocated fixed costs), this can create an issue with the efficiency of transfer prices. If both direct and allocated costs are included, it is highly probable that the transfer price will exceed the price at which the buying division could purchase the materials in the external market. This would not only create a disincentive 
for the buying division to purchase internally, but in effect, would impede the ability of the selling divisions to meet their financial goals and objectives.

Beyond making a decision on the cost categories to include in the calculation of a transfer price, Young (1998) indicates that there are other potential issues associated with transfer pricing in health care organisations. More specifically, the choice of transfer pricing methodology and the chosen payment unit can create a set of dysfunctional incentives for hospital division managers that can result in excessive costs. For example, if senior management elects to use a per diem payment method, this creates an incentive for long inpatient stays. Two reasons for this include the reality that the per diem must cover both fixed and variable costs, and most hospitals have a sizeable base of fixed costs. "Similarly, a per discharge payment (whether diagnosis adjusted or not), encourages providers to increase the number of admissions, shorten inpatient stays, and/or seek a case mix with a high contribution margin” (Young, 1998, p. 58). Efforts to improve cost effectiveness and efficiency by reducing unnecessary admissions or accepting low-margin patients are negatively impacted, as such behaviours will likely result in selling divisions not being reimbursed for their fixed costs.

While these "dysfunctional incentives" can invoke numerous ramifications in health care settings, Young (1998) states that the solution can be found in a two-part transfer price. "A two-part transfer price is based on the idea that fixed costs are time based and variable costs are volume based” (Young, 1998, p. 58). Essentially, this means that each hospital buying division pays its share of a selling division's fixed costs on the basis of time (usually a flat amount paid constantly on a predetermined day) and pays for the selling division's variable costs on the basis of the number and mix of purchased units. Theoretically, two-part transfer pricing occludes the selling division's incentive to charge unnecessarily high prices to buying divisions or to produce superfluous volume. Moreover, two-part transfer pricing promotes greater clinical and administrative efficiency, which may lead to improved overall organisational performance (Young, 1998).

A case study conducted by Kuntz \& Vera (2005) explored the applicability of transfer pricing to health care in a German hospital. The purpose of this study was to investigate how the efficiency of physicians involved in anaesthesia and surgery services can be optimised by the introduction of transfer pricing for anaesthesia services. For the purpose of Kuntz \& Vera's (2005) study, "[t]he relevant transfer price is the one which is paid by the surgery department 
to the anaesthesiology department for providing anaesthesia to the patient” (Kuntz \& Vera, 2005, p. 264). The transfer price is calculated using a relevant time span and the choice of time span (which is used as a reference unit) is extremely important. Not only does the time span have a strong impact on the incentive system of the physicians involved, but it can also influence overall hospital performance. Because the hospital operates as a decentralised organisation, whereby physicians want to maximise the financial performance of their own divisions, "the anaesthesiologist should try to maximize the relevant time span, whereas the surgeon should try to minimize it” (Kuntz \& Vera, 2005, p. 264). To ensure the efficiency of anaesthesia services is optimised across the entire organisation, the most appropriate time span is one that minimises time consumption - the surgeon. Surgically controlled time (SCT) includes the pure surgical time, from incision to closing, plus positioning, preparation and dressing of the patient by the surgeon.

After identifying the most appropriate transfer price and mechanism to calculate it, Kuntz \& Vera (2005) set out to investigate their hypotheses. The first hypothesis proposed "the introduction of a transfer pricing system for anaesthesia services which uses the SCT as reference unit increases the efficiency of the surgeons” (Kuntz \& Vera, 2005, p. 265). Since the transfer price reflects the efficiency of the surgeon (who wants to minimise time consumed), there is a strong incentive for them to keep the SCT as short as possible to improve the financial performance of the surgical department. As postulated, Kuntz \& Vera (2005) observed a positive effect from the introduction of an SCT-based transfer pricing system - surgical time reduced and overall surgical efficiency improved.

The second hypothesis proposed "the introduction of a transfer pricing system for anaesthesia services which uses the SCT as reference unit increases the efficiency of the anaesthesiologists” (Kuntz \& Vera, 2005, p. 265). To test this supposition, Kuntz \& Vera (2005) assumed that anaesthesiologists’ efficiency is reflected by their resource consumption. "Even though the anaesthesiologists were not able to influence the reference unit of the transfer price (the SCT), they reduced their material costs and consequently improved their efficiency too” (Kuntz \& Vera, 2005, p. 267). To elaborate, the anaesthesiology department could not increase the transfer price they received from the surgical department; hence they could only improve their financial performance by making their own processes more efficient. 
Kuntz \& Vera (2005) are cognisant that paying physicians a salary is not an overly inputintensive mechanism, nor does it promote efficiency. Conversely, it fosters a bureaucratic mentality and often leads to poor physician productivity. With regard to anaesthesia services, neither the anaesthesiologist nor the surgeon is incentivised to minimise the time the anaesthesiologist spends with the patient. For these reasons, it is a major task of hospital management to ensure they implement a sophisticated accounting system that serves both as a management planning and a control tool to mitigate this unfavourable incentive characteristic, and improve the efficiency of physicians. Kuntz \& Vera (2005) prescribe transfer pricing as an accounting instrument capable of achieving this aim. Based on the findings of their study, Kuntz \& Vera (2005) state that introducing a transfer pricing system can improve the efficiency of physicians involved in the provision of anaesthesia services. One caveat is the need to ensure payments for anaesthesia treatments are linked to the behaviour of those persons that have a strong incentive to minimise these payments. Kuntz \& Vera (2005) also highlight that decentralised organisations can use transfer pricing to make employees more aware of the financial consequences of their behaviour, particularly relating to costs and overall performance.

Apart from the studies reviewed above, there is no other relevant published literature on transfer pricing in the health sector. Moreover, none of these studies consider transfer pricing from a New Zealand public health sector perspective. This is a cause for concern, as transfer pricing "is of particular importance in decentralized organizations, where top management delegates decision-making authority to the constituent areas or organizational units and where the financial performance of these units is calculated separately” (Kuntz \& Vera, 2005). Furthermore, Ellwood (2009, p. 429) suggests that "further research on accounting technologies including interrelated accounting technologies such as transfer pricing and analysis of cost structure and behaviour could possibly aid public service reform”. As a result, this section of the literature review indicates a greater need for research to explore use of transfer pricing from a holistic organisational perspective (including how and for what purposes), and in a New Zealand public health sector context.

As none of the studies reviewed above relate to transfer pricing in a New Zealand public health sector context, the next two sections (section 2.8 and section 2.9) will review literature on IDFs (an inter-organisational form of transfer pricing) and evaluate the potential usefulness of transfer pricing to DHBs operating in the New Zealand public health sector. 


\subsection{Transfer Pricing and the New Zealand Public Health Sector}

As Ashton et al. (2008), Tenbensel et al. (2011) and Ettelt et al. (2012) note, the New Zealand public health sector was reformed in 2001, which resulted in the decentralisation of some decision-making authority for health service planning and provision. Specifically, DHBs were set up to "undertake periodic assessments of the needs of their populations, plan services for their districts, provide services through their provider arms (public hospitals and related services) and contract for services delivered by non-DHB providers” (Tenbensel et al., 2011, p. 243). One aspect of health service planning and provision that DHBs have delegated authority over is IDFs. There is a process of inter-district co-ordination that takes place between DHBs to plan and provide services via IDFs because most DHBs do not provide a full set of services within their districts. Therefore, patients from one district are often treated in another district. To achieve this, the two engaging DHBs will need to determine both the volume and price at which IDFs for different services occur (Ashton et al., 2008). While it is not clear from the literature reviewed how prices for IDFs are calculated, it is evident that there is an inter-organisational process of transfer pricing that is used to facilitate IDFs between DHBs. The purpose of the next section is to discuss the applicability of transfer pricing literature (which predominantly focuses on transfer pricing at an intra-organisational level) to the inter-organisational process for IDFs.

\subsection{Applicability of Transfer Pricing to the New Zealand Public Health Sector}

Typically, a transfer price is the amount one division of an organisation charges for a product or service transferred to another division of the same organisation (Kaplan \& Atkinson, 1989). While the transfer pricing literature reviewed at section 2.6 and 2.7 ascribes to this definition, and as such, has an intra-organisational emphasis, this study posits that the underlying foundations of transfer pricing are applicable in a New Zealand public health sector context. Specifically, this study posits that transfer pricing rationale is applied by DHBs for the purpose of IDFs. ${ }^{6}$ Based on the conventions of transfer pricing, buying and selling divisions of a decentralised organisation will tend to function separately for the purposes of decision-making and performance. However, they must act in accordance with common overarching organisational objectives, directives and accountability frameworks when making transfer pricing decisions. Similarly, DHBs will function separately for the purposes of decision-making and performance when making IDF decisions (as they have

\footnotetext{
${ }^{6}$ To clarify, as this study will be exploring the process of IDFs, it does not consider the applicability of transfer pricing at the intra-organisational level (i.e. between divisions), but rather, the inter-organisational level (i.e. between DHBs).
} 
delegated authority over service planning and provision), though they must also act in accordance with common overarching objectives, directives and accountability frameworks, as stipulated by the $\mathrm{MOH}$ (Ashton et al., 2008). Based on this logic, the definition of transfer pricing provided by Kaplan \& Atkinson (1989) can be amended for the purpose of IDFs to state that a transfer price is the amount one DHB of the MOH charges for a product or service transferred to another DHB in the New Zealand public health sector (see Figure 5). Based on the literature reviewed, it is unclear precisely what prices would be used by DHBs for IDFs and how these prices would be calculated. However, it is probable that (1) the MOH will have some influence over the price setting process; and (2) DHBs will have some ability to negotiate transfer prices between themselves.

Figure 5: Inter-Organisational Transfer Prices in the New Zealand Public Health Sector

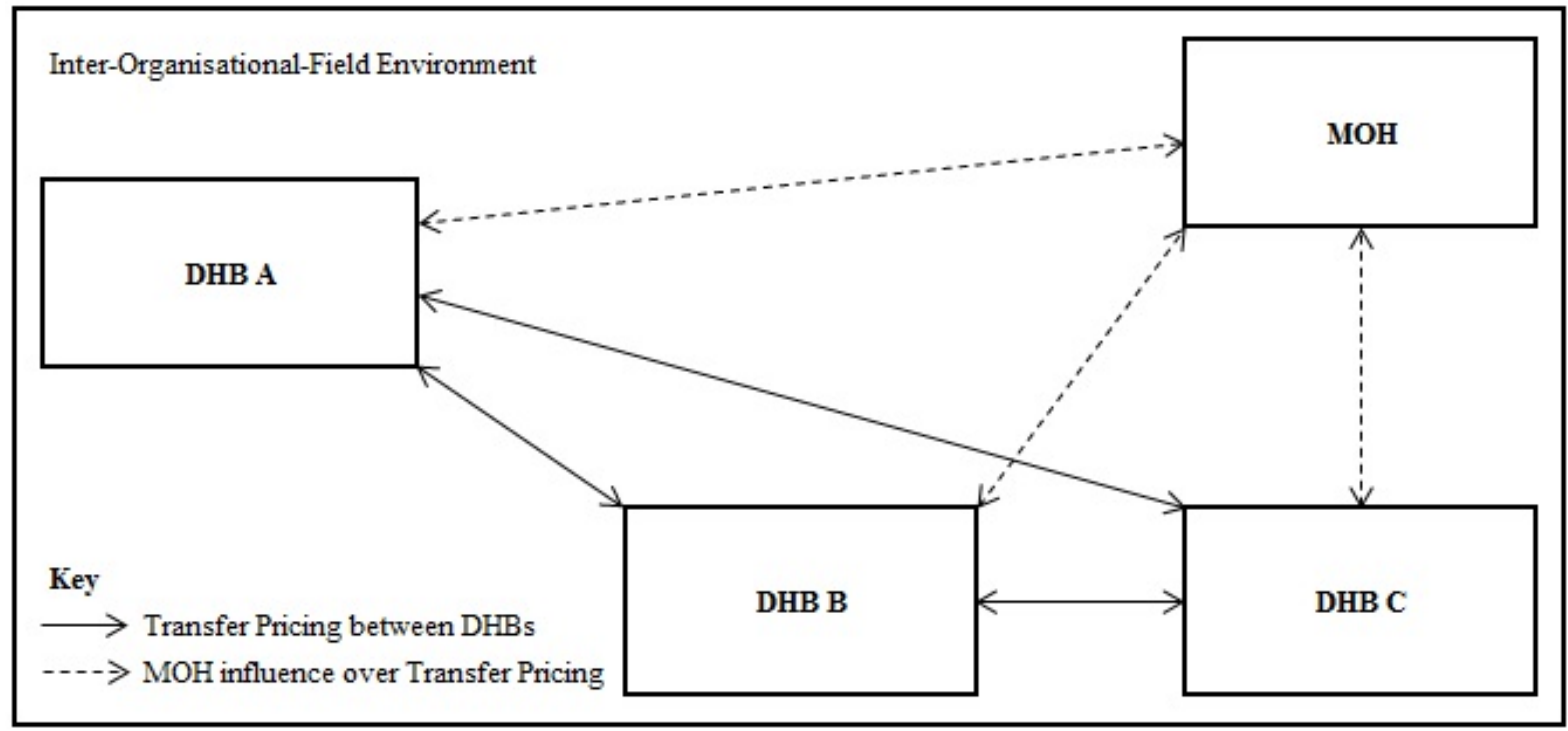

The next section will review literature on the nexus between adoption and use of sophisticated costing systems (as represented by ABC techniques) and intra-organisationalfield transfer pricing in a health care context.

\subsection{Activity-Based Costing and Transfer Pricing}

It is well established in the literature that the way transfer prices are set can seriously affect divisional performance, the success of competitive strategy and overall firm value (see Young, 1998; Baldenius et al., 1999; Ghosh, 2000; Kuntz \& Vera, 2005; Göx \& Schiller, 2007; Dean et al., 2008; Pfeiffer et al., 2011). With globalisation, the challenge of developing effective pricing strategies becomes very complex (Stevenson \& Cabell, 2002). These complexities are particularly salient in situations where the transfer of intangible services or 
component parts is involved because these transfers create internal revenues that impact on divisional performance (Carter et al., 1998). Therefore, management needs high-quality information, so well-informed transfer pricing decisions can be made. More precisely, management need high-quality information to set appropriate and efficient transfer prices that ensure value remains in the organisation.

Colbert \& Spicer (1998); Desheh et al. (1997) and Stevenson \& Cabell (2002) recognise the importance that high-quality information has on transfer pricing and claim that $\mathrm{ABC}$ can be used to provide such information. The major benefit of $A B C$ is its ability to provide an accurate and more complete picture of the costs and profitability of products and/or services. In particular, $\mathrm{ABC}$ has a focus on the level and basis of overhead allocation. Allocation of overheads is a highly important and often contentious issue, which can seriously distort information for decision-making and performance evaluation when done arbitrarily. By using ABC, organisations can identify systematic cause and effect linkages among products, markets, and costs before resorting to across-the-board allocations. "These linkages, called cost drivers, are activities that cause costs to be driven up or down. These costs occur when an activity is performed, so a cost driver is a way of allocating a cost to a particular activity” (Stevenson \& Cabell, 2002, p. 81).

Considering market-based transfer pricing, it is improbable that ABC could be used to inform these. A market-based transfer price is predetermined by prevailing economic conditions within the particular market for a good or services, thus, ABC cannot affect this price. With reference to cost-based transfer pricing, $\mathrm{ABC}$ is unlikely to improve direct variable cost information. Direct variable costs have clear cause and effect links and are not influenced by overhead allocation rates. However, cost-based transfer prices have an overhead component. To elaborate, variable cost transfer prices have a variable overhead component, while full cost-based transfer prices have a variable and fixed overhead component. ABC could be used to provide more accurate understandings of the cause and effect links of these costs, leading to more appropriate overhead allocations. Therefore, ABC could influence variable and full cost-based transfer prices.

The usefulness of ABC when setting transfer prices is emphasised for an organisation that uses a full-cost transfer pricing system (Colbert \& Spicer, 1998). This is mainly because a full-cost transfer price requires overhead costs to be included and allocated to each product and/or service. If an organisation is using a traditional costing system there are likely to be 
information deficiencies, as such systems typically only rely on one or two volume-related cost drivers. Other important cost drivers may be omitted, resulting in inaccurate overhead allocations and distorted individual product and/or service costs. Price distortions can adversely influence transfer prices, and create bias and resourcing inefficiencies (Colbert \& Spicer, 1998). ABC can be deemed a panacea to overcome these issues and improve the transfer pricing process through improved cost understandings and more accurate product and/or service costs (Desheh et al., 1997).

ABC can be invaluable to an organisation that uses a negotiated transfer pricing system too. As Colbert \& Spicer (1998, p. 23) suggest, “ABC-based transfer prices can positively influence negotiations and serve as a basis for more constructive interdivisional working relationships”. Desheh et al. (1997) provides evidence to support this suggestion, finding that transfer prices influenced by ABC information led to a dramatic reduction in conflicts among managers in a pharmaceutical company. Desheh et al. (1997) also found that transfer pricing systems influenced by $\mathrm{ABC}$ not only reduce the strain on managerial relationships, but motivate divisional collaboration to reduce costs and better use organisational assets. Desheh et al. (1997) and Colbert \& Spicer (1998) believe the improved environment for negotiations is predominantly due to enhanced confidence in product and/or service costs reported and greater acceptability of transfer pricing decisions, which flows directly from using ABC.

Colbert \& Spicer (1998) investigate the merits of using ABC as the basis for a transfer pricing system and argue that such a system has a number of desirable features beyond those described above. In addition, it can positively influence organisational decision-making and behaviour. The desirable features of ABC systems linked to transfer pricing include (1) a basis for improved inter-divisional relationships; (2) enlarging the information base between buying and selling divisions; (3) tool for lowering product costs at the supplier-buyer interface; and (4) cost management efforts within the supplier division. The presence of these features then feeds into improved internal decisions and behaviour. Specifically with relation to (1) component design/mix decisions; (2) end product design, mix, and pricing decisions; (3) sourcing decisions (make versus buy); and (4) cost management and asset utilisation.

While there is some literature on the nexus between sophisticated costing systems (such as ABC) and transfer pricing, it is very scant. The studies above only span over the late 1990s to early 2000s and merely discuss the use of ABC and transfer pricing or provide anecdotal evidence. There are no practical examples in the literature, nor have there been any studies on 
ABC and transfer pricing in the New Zealand public health sector. Furthermore, the literature reviewed in this section only considers the applicability of sophisticated costing systems (based on ABC principles) to transfer pricing from an inter-organisational perspective. This study posits that sophisticated costing systems (such as ABC) can also be used to (1) influence decision-making associated with IDFs; and (2) inform prices for the intraorganisational process of IDFs between DHBs.

\subsection{Research Gap}

Based on the review above, several gaps in the literature have been identified. Specifically, there is a substantial gap in the cost accounting literature on (1) adoption and use of costing systems from a New Zealand public health sector perspective; (2) contextual factors that influence adoption and use of sophisticated costing systems; and (3) the dimensions of costing systems used that makes them unsophisticated or sophisticated. Similarly, there is a substantial gap in the transfer pricing literature on (1) use of transfer pricing approaches in the health sector; and (2) transfer pricing in the New Zealand public health sector. Finally, there is a substantial gap in the literature on the nexus between costing systems and transfer pricing, particularly from a health sector perspective.

In recognition of the potential benefits of sophisticated costing systems, and the fact that the New Zealand public health sector is severely underrepresented in the cost accounting literature, this study will explore what costing systems are being used by DHBs (i.e. unsophisticated or sophisticated) and how they are being used. This study will also contribute to cost accounting literature by studying the factors that influence adoption and use of sophisticated costing systems and the dimensions of costing systems used by DHBs in the New Zealand public health sector that makes them unsophisticated or sophisticated. This study sets out to contribute to transfer pricing literature from a New Zealand public health sector context by exploring the processes that underpin IDFs and how prices for IDFs are calculated. To contribute to literature on the nexus between costing systems and transfer pricing from a health sector perspective, this study will explore the extent to which cost information produced by DHBs costing systems influences IDFs (including service planning, provision and IDF prices).

The next Chapter will develop a research objective, a set of research questions and a research framework, all of which are based on the gaps in current costing and transfer pricing literature identified and discussed above and the theory. 


\section{Chapter 3 Theory and Research Framework}

\subsection{Introduction}

The purpose of Chapter 3 is to develop a research objective, a set of research questions and a research framework, all of which are based on the gaps in current costing and transfer pricing literature identified and discussed at section 2.11, and the theory considered throughout Chapter 3. To fill the gap in current literature and contribute to theory, Chapter 3 will begin by considering the theoretical basis of institutional theory - namely organisational legitimacy and the three pillars of institutions (see section 3.2, 3.3 and 3.4). A generic theoretical framework will then be developed based on the main features that underpin organisational legitimacy and the three pillars of institutions at section 3.5. Following this, Chapter 3 will consider organisational legitimacy and the three pillars of institutions in the health sector (see section 3.6, 3.7 and 3.8). A research objective (see section 3.9) and a set of research questions (see section 3.10) will then be developed based on the literature reviewed at Chapter 2, the theory considered throughout Chapter 3, and the organisational environment being studied (the New Zealand public health sector). To facilitate achieving the research objective and answering the research questions, a research framework grounded in institutional theory will also be developed at section 3.11, which will be applied in this research.

\subsection{Institutions, Organisational Change and Institutionalisation}

Scott (2001) describes institutions as social structures that have attained a high degree of resilience; are composed of regulative, normative and cultural-cognitive elements that, together with associated activities and resources, provide stability and meaning to social life; are transmitted by various types of carriers, including symbolic systems, relational systems, routines and artefacts; operate at multiple levels of jurisdiction, from the world system to localised interpersonal relationships; and finally, although by definition institutions connote stability, they are subject to change processes prompted by constant shifts in internal and external organisational environments (institutional stability and change processes are discussed in greater detail in the next paragraph). While this is a relatively dense conception, it gives a clear overall depiction of institutions as "multifaceted, durable social structures, made up of symbolic elements, social activities, and material resources” (Scott, 2001, p, 49).

Institutions intrinsically function to provide stability and coherence in the social world but it is important to appreciate that they themselves undergo change. This is because institutions are possessed objectively yet created subjectively therefore they are socially constructed. 
Typically institutional change is incremental or revolutionary in nature and involves the reshaping of institutions or the taken-for-granted rules and shared norms that constitute institutions (Scott, 2001). According to Dacin et al. (2002), incremental change processes are piecemeal subtle changes that tend to unfold over time. The quintessence of incremental change is the gradual withering of an accepted norm or social convention, or the gradual adoption of a new norm or social convention, as the nature of political, social, and/or economic exchanges gradually change. In contrast, revolutionary change tends to be extensive, as it can present large discontinuities with former patterns, and it occurs rapidly. Oliver (1992) emphasises the discontinuous nature of revolutionary change, stating that it can be termed deinstitutionalisation, which refers to the erosion or discontinuity of an institutionalised organisational practice. There are numerous factors, both internal and external, that drive organisational change (Scott, 2001; Lounsbury, 2008). The most notable internal environmental factors include intra-organisational shifts in political ideologies and heterogeneous/discordant beliefs and practices. The imposition of change can also eventuate through external factors such as regulation; legislation; economic conditions; technological advancements; societal expectations and political emphases (Scott, 2001; Greenwood et al., 2002; Dacin et al., 2002; Deegan 2006).

When confronted with changing environmental demands, organisations can adopt or adapt a range of institutions to ensure survival (Scott, 2001; Kostova et al. 2008). This generally involves the weakening or occasionally even the disappearance of certain institutions or taken-for-granted rules and norms, and the strengthening or emergence of other institutions or taken-for-granted rules and norms (Scott, 2001; Lounsbury, 2008). This occurs through institutionalisation, the process "by which social processes, obligations or actualities come to take on a rule like status in thought and action” (Meyer \& Rowan, 1977, p. 341). That is, they become established as a convention or norm within an organisation. Often institutions can be in conflict during the process of institutionalisation and will compete with each other by prescribing "varying forms and activities for participants, with the winners and losers to be sorted out over time” (Scott, 2001, p. 189). This process can potentially be problematic as it may undermine the legitimacy of an organisation. To elaborate, institutions competing for ascendency will generate internal tensions and conflicts. These tensions and conflicts, if strong enough, can jeopardise "perceived consonance with relevant rules and laws, normative support, or alignment with cultural-cognitive frameworks” (Scott, 2001, p. 59). The result of 
which can be resistance to new ideas and ways of doing things, and an overall reduction in the success and legitimacy of an organisation.

\subsection{Organisational Legitimacy and Social Obligations}

Legitimacy is a theory that explicitly considers organisations as part of the broader social system and it seeks to describe or explain behaviour rather than prescribe how organisations should behave. According to Lindblom (1994), legitimacy is a condition or status that exists when an organisation's value system is congruent with the value system of the larger social system of which it is a part. For congruence to exist, an organisation must give explicit consideration to the expectations of society, and comply with these relevant social expectations (Deegan, 2006). Since legitimacy is socially constructed, that is, it reflects congruence between the behaviours of the legitimated organisation and the shared beliefs of society; it can only be understood in the context of a particular setting at a particular time. As Suchman (1995, p. 574) states, "Legitimacy is a generalized perception or assumption that the actions of an entity are desirable, proper or appropriate within some socially constructed system of norms, values, beliefs, and definitions". When a disparity, actual or potential, exists between the two value systems (the organisational system and the larger social system), there is a threat to the organisation's legitimacy.

According to Shocker \& Sethi (1974) any organisation operates in society via a social contract, expressed or implied, whereby its survival and growth are based on two fundamental outcomes. The first being the delivery of socially desirable ends to society in general; the second being the distribution of economic, social, or political benefits to groups from which it delivers its power. As Deegan (2006, p. 170) explains "organizations are expected to comply with the terms (expectations) embodied within the social contract. The explicit terms of a social contract tend to be legal requirements, while other non-legislated societal expectations embody the implicit terms of the contract". "By designing a formal structure that adheres to the norms and behaviour expectations in the extant environment, an organization demonstrates that it is acting on collectively valued purposes in a proper and adequate manner” (Dillard et al., 2004, p. 509).

If an organisation does not design a formal structure that adheres to norms and behaviour expectations the by-product will inevitably be a legitimacy gap. The impact of a legitimacy gap can vary and is largely dependent on the extent to which society deems an organisational form to deviate from what is considered normal or expected (Dillard et al., 2004). Typically a 
legitimacy gap will lead to the reduction of organisational legitimacy, with two potential outcomes/responses (Scott, 2001; Deegan 2006). If the reduction in legitimacy is gradual, in terms of timing and intensity, there will also be a gradual change in the organisation's institutions and taken-for-granted norms as it attempts to parry the negative effects and maintain survival (Scott, 2001; Kostova et al. 2008; Lounsbury, 2008). If the reduction is sudden and sizable this will lead to the destruction of organisational legitimacy, as the damage will be irreparable (Deegan, 2006).

As this section has emphasised, "Organizations require more than material resources and technical information if they are to survive and thrive in their social environments. They also need social acceptability and credibility” (Scott et al., 2000, p. 237). To gain and retain social acceptability and credibility organisations must observe and adhere to social expectations and applicable legal and political frameworks (Deegan, 2006; Dillard et al., 2008). Organisations must also consider their established conventions and norms, which form organisational institutions, to ensure their behaviour (perceived or actual) is in line with stakeholder's expectations. $^{7}$ Ultimately, these considerations form the basis of the organisational environment and through congruence/adherence organisational legitimacy is created. As the organisational environment changes over time organisations are required to constantly review and make ongoing amendments to their practices to maintain organisational legitimacy, with the aim of ensuring long-term survival. As Scott (2001, p. 59) states, organisational legitimacy is "not a commodity to be possessed or exchanged but a condition reflecting perceived consonance with relevant rules or laws, normative support, or alignment with cultural-cognitive frameworks” (Scott, 2001, p. 59). These rules or laws, normative support, and cultural-cognitive frameworks form the three pillars of institutions, which elicit three related but distinguishable bases of legitimacy (Scott, 2001).

\subsection{Organisational Legitimacy and the Three Pillars of Institutions}

The three pillars of institutions are regulative, normative and cultural-cognitive systems (see Table 2 for further details). According to Scott (2001, p. 51), each of the three pillars "has been identified by one or another social theorist as a vital ingredient of institutions". This is

\footnotetext{
${ }^{7}$ As Deegan (2006, p. 169) states, "institutional theory provides an explanation of how mechanisms through which organisations may seek to align perceptions of their practices and characteristics with social and cultural values (in order to gain or retain legitimacy) become institutionalized in particular organisations. Such mechanisms could include those proposed by legitimacy theory, but could conceivably also encompass a broader range of legitimating mechanisms. This is why these theoretical perspectives should be seen as complementary rather than competing”.
} 
corroborated by Hoffman (1997, p. 36), who describes the pillars as three elements that form a continuum moving "from the conscious to the unconscious, from the legally enforced to the taken-for-granted”. Furthermore, D’Andrade (1984) argues that an integrated conception of the three pillars of institutions creates the appearance of institutions as overdetermined systems. "Overdetermined in the sense that social sanctions plus pressure for conformity, plus intrinsic direct reward, plus values, are all likely to act together to give a particular meaning system its directive force” (D’Andrade, 1984, p. 98). With these outlooks in mind, the theoretical framework for this study will consider the three pillars of institutions both independently and interdependently, the aim of which is to highlight important differences between each of the three pillars before amalgamating them into one research framework to apply to the New Zealand public health sector. ${ }^{8}$

Table 2: The Three Pillars of Institutions

\begin{tabular}{|l|l|l|l|}
\hline & \multicolumn{3}{|c|}{ Pillar } \\
\hline $\begin{array}{l}\text { Theory Element } \\
\text { compliance }\end{array}$ & \multicolumn{1}{|c|}{ Regulative } & \multicolumn{1}{c|}{ Normative } & \multicolumn{1}{c|}{ Cognitive } \\
\hline Basis of order & Regulative rules & $\begin{array}{l}\text { Binding } \\
\text { expectations }\end{array}$ & $\begin{array}{l}\text { Taken-for-grantedness } \\
\text { Shared understandings }\end{array}$ \\
\hline Mechanisms & Coercive & Normative & Mimetic \\
\hline Indicators & $\begin{array}{l}\text { Rules } \\
\text { Laws } \\
\text { Sanctions }\end{array}$ & $\begin{array}{l}\text { Certification } \\
\text { Accreditation }\end{array}$ & $\begin{array}{l}\text { Common beliefs } \\
\text { Shared logics of action } \\
\text { - Prevalence } \\
\text { - Isomorphism }\end{array}$ \\
\hline & Legally sanctioned & Morally governed & $\begin{array}{l}\text { Comprehensible } \\
\text { Recognisable } \\
\text { Culturally supported }\end{array}$ \\
\hline
\end{tabular}

(Source: Scott, 2001, p. 52)

\subsubsection{The Regulative Pillar}

The regulative pillar is concerned with the idea that institutions constrain and regularise behaviour. "In this conception, regulatory processes involve the capacity to establish rules, inspect others' conformity to them, and as necessary, manipulate sanctions - rewards or punishments - in an attempt to influence future behavior” (Scott, 2001, p. 52). Typically "force, fear and expedience are central ingredients of the regulatory pillar, but they are often

\footnotetext{
${ }^{8}$ This approach is supported by Scott (2001, p. 51) who proposes that "[o]ne possible approach would be to view all of these facets as contributing, in interdependent and mutually reinforcing ways, to a powerful social framework, one that encapsulates and exhibits the celebrated strength and resilience of these structures”.
} 
tempered by the existence of rules, whether in the guise of informal mores or formal rules and laws” (Scott, 2001, p. 53). These informal mores or formal rules and laws are devised and espoused by the societies in which organisations exist or by those whom organisations depends on, and they create what several authors have referred to as coercive pressure (DiMaggio \& Powell, 1983; Covaleski \& Dirsmith, 1988; Carruthers, 1995; Carpenter \& Feroz, 2001; Scott, 2001; Delmas \& Toffel, 2004). The regulative pillar as a stable system of rules (either formal or informal), which is backed by surveillance and sanctioning power, is one prevailing view of institutions. However as Scott (2001) reveals, the regulative pillar is by no means a perfect view. "[R]ules must be interpreted and disputes resolved; incentives and sanctions must be designed and will have unintended effects; surveillance mechanisms are required but will prove to be fallible, not fool proof; and conformity is only one of many possible responses by those subject to regulative institutions” (Scott, 2001, p. 54). ${ }^{9}$

\subsubsection{The Normative Pillar}

The normative pillar underscores systems comprising shared values and norms that are internalised by individuals and imposed on others (Scott, 2001). ${ }^{10}$ Normative systems are archetypically seen to impose constraints on social behaviour because they establish rules that introduce a prescriptive, evaluative and obligatory dimension into social life. Normative systems do however empower and enable social action. "They confer rights as well as responsibilities, privileges as well as duties, licenses as well as mandates” (Scott, 2001, p. 55). The normative conception stresses a deeper moral base for assessing legitimacy and the successful imposition of values and norms as a normative system of social behaviour is supported by normative pressure to conform. Conformity can be roused by various carries including symbolic systems, relational systems, routines and artefacts (Scott, 2001). “In exchange for appearing to conform to such normative institutional pressures [the organisation] obtains rewards, such as increased legitimacy” (Krishnan \& Yetman, 2011, p. 1006). This increased legitimacy (typically observed through certification and accreditation) can benefit the organisation by allowing it to appeal to its stakeholders for more resources

\footnotetext{
${ }^{9}$ North (1990, p. 54) also calls attention to problems that can arise because "enforcement is undertaken by agents whose own utility functions influence outcomes”. Numerous institutional theorists stress this potential eventuality. One such theorist is Skocpol (1985), who argues that the state develops its own interest and operates somewhat autonomously from other societal actors. In this and other ways, attention to the regulative aspects of institutions creates renewed interest in the role of the state: as rule maker, referee and enforcer.

${ }^{10}$ Values are "conceptions of the preferred or the desirable, together with the construction of standards to which existing structures or behaviour can be compared and assessed. Norms specify how things should be done; they define legitimate means to pursue valued ends” (Scott, 2001, p. 55).
} 
and subjecting it to lower regulatory and behavioural scrutiny by internal and external constituents (Scott, 2001; Bansal \& Clelland, 2004).

\subsubsection{The Cultural-Cognitive Pillar}

The cultural-cognitive pillar postulates that institutions are shared understandings and common beliefs that constitute the nature of social reality and the frames through which meaning is made. According to Scott (2001), as meanings emerge through social interactions they are attributed to objects and activities, and are subsequently maintained and transformed to make sense of the ongoing stream of happenings. Over time these meanings are deemed to be the orthodox structure in society and are adopted as either a common frame of reference or definition of a situation (a constitutive schema). This is because they are not simply treated "as subjective beliefs but also as symbolic systems perceived to be objective and external to individual actors” (Scott, 2001, p. 57). That is, they become prevalent isomorphic structures for shared logics of action. This leads to their becoming institutionalised as cognitive and preconscious taken-for-granted assumptions and shared understandings that form "templates for particular types of actors and scripts for action” (Scott, 2001, p. 58). Consequently, mimetic pressure results as organisations identify and imitate culturally supported structures or practices used by other entities that are perceived to be successful or legitimate.

\subsection{Theoretical Framework}

The previous three sections (including section 3.2, 3.3 and 3.4) have considered and discussed the theoretical underpinnings of institutional theory, which will be applied to this study - namely organisational legitimacy and the three pillars of institutions. Using the main features that underpin organisational legitimacy and the three pillars of institutions, a theoretical framework has been developed (see Figure 6), which forms the foundations of the research framework. As the theoretical framework is only a generic framework, it is necessary to consider and discuss institutional theory in the organisational-field being studied (the health sector). The purpose is to determine the applicability of institutional theory in the research context and to provide a substantive framework that will be used to assist the research process (specifically to achieve the research objective and answer the research questions). Thus, the next three sections (including section 3.6, 3.7 and 3.8) consider and discuss institutional theory in a health care setting. 
Figure 6: Organisational Legitimacy and the Three Pillars of Institutional Theory

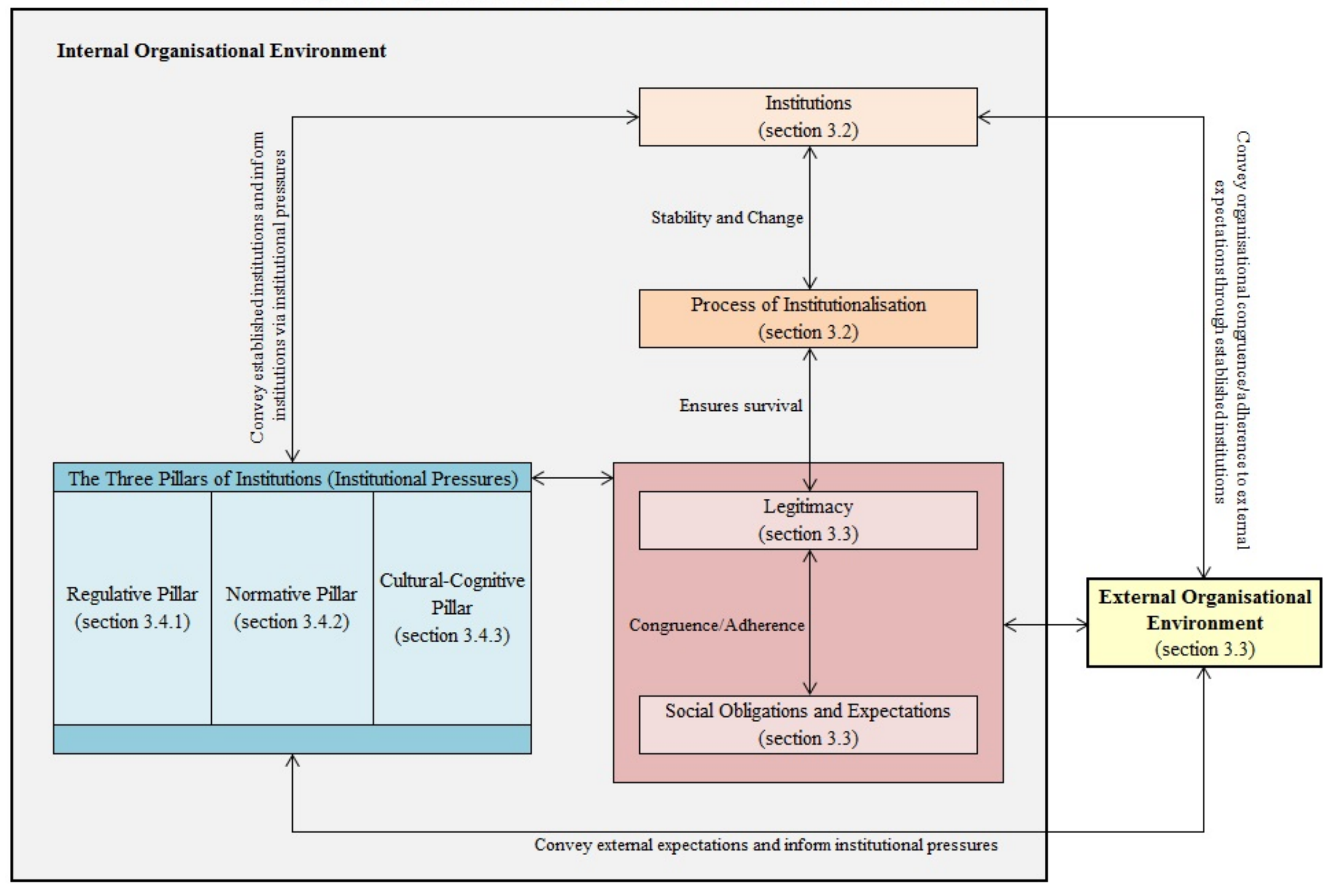




\subsection{Institutionalisation in Health Care}

Conventional wisdom asserts that use of case-mix accounting systems based on Diagnosis Related Groups (DRG) faithfully represent the economic or technical reality of health care organisations (Fetter et al., 1991). The foremost issue with this view is the fact that it establishes a general theory of organisational rationality. However, "one cannot understand such organizational and regulatory practices as the DRG framework and case-mix accounting merely with reference to the general rationality of their structural properties" (Covaleski et al., 1993, p. 76). "Organizations are inextricably embedded in a dynamic system of interrelated economic, institutional, and ecological processes” (Dacin, 1997, p. 47). Therefore a general theory of rationality is not sufficiently qualified to comprehend or explain the complexities of such a dynamic system and its multiple influences on organisational action (and the basis for such action). Organisational action is an indeterminate outcome of substantive struggles between different agencies with varying levels of influence, all of which serve a role in shaping action. Failure to give due consideration to these influences is to neglect "the actual complex and contingent conditions under which organizational action occurs” (Clegg, 1989, p. 105). Accordingly, “one can more accurately characterize such practices as the DRG framework and case-mix accounting as social in nature, practices whose principal purpose is at once to express and demonstrate conformity with institutionalized rules and expectations" (Covaleski et al., 1993, p. 76).

Several institutional theorists, including Scott et al. (2000); Lounsbury (2001); Scott (2001); Dillard et al. (2004) and Lounsbury (2008) offer compelling insights to support the perception that institutional theory can be used to understand the various social and behavioural facets of health care practices, which would otherwise be ignored. These institutional theorists also concur with Covaleski et al. (1993, p. 66) “that an organization's survival requires it as much to conform to societal norms of acceptable practice as to achieve high levels of production efficiency and effectiveness”. Many aspects of an organisation’s formal structure, policies and procedures are founded in this dual requirement, thus they not only serve to reaffirm organisational efficacy internally, but they also serve to demonstrate conformity with the institutionalised rules and expectations expressed by external constituents (Clegg, 1989; Covaleski et al., 1993; Scott et al., 2000; Scott, 2001; Dillard et al., 2004; Lounsbury, 2008). Based on this premise, the adoption and use of costing systems may be expected to play heightened, though ritualistic roles in the heavily institutionalised environment of health care, with the fundamental goal of adhering to institutional pressures. 
This essentially means "they may be treated as ceremonial systems for creating and affirming order and meaning, for executing procedures in sanctioned ways, and for providing accounts of activities in terms that make them seem reasonable and acceptable to external constituents” (Covaleski et al., 1993, p. 66).

\subsection{Institutional Pressures in Health Care}

As noted at section 3.3, there are three institutional pillars (regulative, normative and cultural-cognitive), which provide stability and meaning to social behaviour (Scott, 2001). The three pillars also elicit three separate bases of institutional pressure, which impose moral and cultural boundaries around appropriate organisational and managerial behaviour. The bases of institutional pressure that emanate from these pillars are regulatory, political and social agencies (Child \& Tsai, 2005). ${ }^{11}$ Regulatory agency pressures are authorities, such as state and local bodies, which impose rules on organisations and monitor and sanction organisational behaviour; political agency pressures are the actions of other organisations within the same reference group; and social agency pressures are the general societal expectations of how an organisation should behave (Greenwood \& Hinings, 1996; Scott, 2001; Dacin et al., 2007).

As argued by Covaleski et al. (1993); Ruef \& Scott (1998); Scott (2001); Covaleski et al. (2003); Eldenburg \& Krishnan (2003) and Krishnan \& Yetman (2011), institutional pressures are particularly salient in hospitals, especially public and non-profit hospitals. "An additional complicating factor in hospitals is that one set of institutional pressures may conflict with other sets of pressures” (Krishnan \& Yetman, 2011, p. 1006). Specifically, one set of institutional pressures can require hospitals to reduce costs by being economically and programmatically efficient (Dranove, 1998; Covaleski et al., 2003; Eldenburg \& Krishnan, 2003). These types of institutional pressures are typically imposed by government through fiscal policy because of poor economic conditions or changes to strategic emphases. Conversely, an alternative set of institutional pressures can constrain managers from pursuing opportunities to reduce costs and increase economic value, particularly if such opportunities diminish the range and/or quality of health services to sections of society (Krishnan \& Yetman, 2011). These types of institutional pressures are typically imposed through societal expectations, legal obligations and regulatory oversight.

\footnotetext{
${ }^{11}$ Goodstein (1994); Goodrick \& Salancik (1996) and Hitt et al. (2004) recognise that, in addition to economic factors, institutional pressures can affect organisational behaviour.
} 


\subsection{Organisational Legitimacy and the Notion of Social Contract in Health Care}

Numerous authors in health care, such as Rodwin (1993); Morreim (1995); Spencer et al. (2000) and Dacin et al. (2002), have voiced concerns that changes to the organisational environment may prompt significant moral implications in health care settings. Specifically, these authors have "considered how these changes have influenced the character of professionals delivering health care services and their loyalties, commitments, and perceptions of their ethical obligations to patients” (Dacin et al., 2002, p. 52). At the core of many exploratory studies that have looked at the correlation between changing organisational environments and professional morality is a concept Toulmin (1990, p. 25) identified as “demoralisation”. The foundations of this concept bring forth the argument that changing institutional environments and heightened budgetary pressures can erode a particular way of defining the moral calling associated with physician roles. This is a particularly pertinent issue because physicians "must consider the social, political and economic framework within which human life takes place” (Gray et al., 1996, p. 47). To elaborate, physicians need to adhere to political and financial pressures (along with legal and regulatory structures that monitor and sanction organisational behaviour), but equally they must also consider their social and moral obligations to the general public.

Society (which comprises patients, donors and other community members) will tend to hold a set of expectations about how a health care organisation should conduct its operations (Ruef \& Scott, 1998). These expectations are central to organisational legitimacy and form the notion of a social contract between the organisation and the general public (Scott, 2001). In an organisational environment where patient welfare primacy is a prominent socially constructed expectation, the existence of de-moralisation (or the perceived existence thereof) can severely impact on the legitimacy of a health care organisation. This is largely because the presence of de-moralisation implies that physicians are defecting from their responsibility to deliver high quality health care services to the public (to some extent), instead focusing their attention on adhering to politically imposed directives and/or meeting budgetary constraints. As a result, confidence in the public health sector will reduce and a legitimacy gap will be created between society's expectations and the actions (perceived or actual) of the organisation (Deegan, 2006).

In summary, health care organisations face a unique challenge in balancing institutional pressures imposed on them by various constituents. According to Clegg (1989), in order for 
hospitals to survive they should conform to those interests that are the most influential. Based on the literature reviewed, relating to institutional theory in health care, this would involve hospitals reaffirming organisational efficacy internally while demonstrating conformity externally. With the intention of preserving organisational legitimacy, health care organisations will use institutions as ceremonial processes to create and affirm conformity with regulatory, political and social agencies. For example, the institutionalisation of costing systems "as ongoing processes appears to be profoundly political and potentially complicit in a shift in the balance of power from the practitioner to the administrative components of the hospitals” (Covaleski et al., 1993, p. 77). Power shifts from the physician to the hospital administrator in the sense that expertise becomes encoded within the organisational structure (with respect to those institutional pressures that are the most influential) rather than the individual providing the health services.

\subsection{Research Objective}

Changes in the New Zealand public health sector in recent years, such as heightened social, political and economic pressures to manage and reduce costs while improving the quality of care in conjunction with stringent health care guidelines, have forced DHB's nationwide to reassess their approach to health care provision. With the intention of preserving legitimacy, this has chiefly involved evaluating current practices or institutions; revising health care systems, including locality of treatment; and assessing established accounting systems and mechanisms (or lack thereof) to understand the source of costs and resource consumption (OAG, 2013). Acknowledging that patient welfare has always held pre-eminence in the New Zealand public health sector, balancing the dual pressures to enhance the utilisation of limited resources and adhere to social expectations to provide sustained high quality health services has been a difficult exercise for DHBs (OAG, 2013).

As a result, this study will assess the influence of the NHB and the twenty DHBs it monitors, using a twofold consideration. The first consideration is adoption and use of costing systems by DHBs operating in the New Zealand public health sector. As current cost accounting literature indicates (Cooper \& Kaplan, 1992; Drury \& Tayles, 1995; Hussain \& Gunasekaran, 2001; Abdallah \& Li, 2008), more sophisticated costing systems provide higher quality cost information compared to traditional costing systems, which leads to more informed and effective decision-making. Thus, bearing in mind the MOH's directives, desired outcomes and the recent issues observed by the OAG (discussed at section 1.1), it is expected that 
DHBs operating in the New Zealand public health sector will adopt and use more sophisticated costing systems, such as ABC, to plan and provide health services. Based on this expectation, there is a need to ascertain whether or not DHBs adopt and use costing systems (including their level of sophistication), how well DHBs understand their costs and cost structures for effective service planning and provision, and how DHB's contribute to effective regional and national service planning and provision using information provided by their respective costing systems.

The second consideration is how service planning and provision is effectuated by interdistrict co-ordination and IDFs, and the impact costing systems adoption and use have on these processes. As Ashton et al. (2008) notes, most DHBs do not provide a full set of services within their districts; therefore around one in six admissions are for patients from other districts. Thus, there is a process of inter-district co-ordination that takes place to plan and provide services via IDFs. Ashton et al. (2008) expressed concerns about deficiencies in payments for IDFs. Specifically, there are concerns regarding poor quality data on the numbers and types of flows, inaccurate pricing and late payments. There is also a belief that mechanisms used to inform prices unfairly affect smaller secondary DHBs compared to larger tertiary DHBs due to the excessive influence tertiary DHB's supposedly have over the price setting process, which is done at national level. As there is no published literature on IDFs in the New Zealand public health sector, this study will set out to determine how National Prices for IDFs are calculated, how costing systems information is used to inform these prices, how effective these prices are for inter-district trading, and to what extent DHBs are in collaboration with each other to plan and provide health services.

In recognition of the potential benefits of sophisticated costing systems, and the fact that the New Zealand public health sector is severely underrepresented in current cost accounting and transfer pricing literature, the objective of this study is as follows:

To examine the costing systems used by DHBs to plan and provide health services, and to evaluate how the use of such costing systems influence service planning and provision (at the district, regional and national level) in accordance with the outcomes outlined by the MOH.

In particular, the study will explore how more sophisticated costing techniques, such as $A B C$, are being used by DHBs to (1) enhance the utilisation of limited resources; and (2) adhere to social expectations to provide sustained high quality health services. The study also sets out 
to contribute to transfer pricing literature from a New Zealand public health sector context by exploring the processes that underpin IDFs, including (1) how National Prices for IDFs are calculated; and (2) to what extent the cost information produced by DHBs costing systems influences this calculation.

\subsection{Research Questions}

To achieve the overall research objective outlined at section 3.9 a series of research questions are posed. The specific research questions, which are based on the research objective, literature reviewed and theory considered are set out below:

RQ 1: What determines and guides the costing systems used in New Zealand DHBs?

RQ 2: How are costs calculated in DHB costing systems?

RQ 3: How is cost information produced by cost systems used to plan and provide services?

RQ 4: How and for what other purposes is cost information used in the public health sector?

RQ 5: How are the transfer prices to be charged for inter-DHB trading determined?

RQ 6: How and for what purposes do DHBs collaborate with each other?

\subsection{Research Framework}

The research framework, developed to achieve the research objective outlined at section 3.9 and answer the research questions posed at section 3.10, is an organisational-field focused research framework based in the New Zealand public health sector (see Figure 7). According to DiMaggio \& Powell (1983, p. 148) an organisational-field is defined as a set of "organizations that, in the aggregate, constitute a recognized area of institutional life; key suppliers, resource and product consumers, regulatory agencies, and other organizations that produce similar services or products”. The research framework for this study posits that institutionalisation is deeply embedded in the New Zealand public health sector, and will endeavour to contribute to literature and theory by identifying, with particular emphasis on costing and IDFs, (1) how institutional pressures impact on the organisational environment in which DHBs operate; and (2) the institutions New Zealand DHBs adopt.

Based on the literature reviewed at section 3.6, 3.7 and 3.8, which relates to institutional theory in health care, hospitals face a unique challenge in balancing institutional pressures 
imposed on them by various constituents. With the intention of preserving organisational legitimacy, health care organisations will use institutions as ceremonial processes to create and affirm conformity with regulatory, political and social agencies. Moreover, health care organisations will tend to conform to those pressures that are the most influential. Acknowledging the fact that there are three agencies which institutional pressures can emanate from, the research framework for this study posits that the pressures placed on a health care organisation (i.e. DHB A, the Main Case Site) include (1) regulatory and political agency pressures from authorities such as the $\mathrm{MOH}$, the $\mathrm{NHB}$ and associated costing and pricing groups (i.e. the Supplementary Case Site); (2) political pressures from other DHBs operating in the New Zealand public health sector (i.e. the Confirmatory Case Sites); and (3) social agency pressures from the external organisational environment about how the organisation should behave (i.e. the general public expecting DHBs to provide sustained high quality health services).

While the research framework does not suggest the extent to which a DHB will implement any one institution, it does posit that these institutions (which are based on the twofold consideration documented at section 3.9) will include costing practices, costing systems, costing rules and procedures, the provision of cost and volume information for decisionmaking, pricing mechanisms, and product/service mix. Moreover, the research framework suggests that a DHB which conforms to institutional pressures is likely to possess greater organisational legitimacy and be subjected to lower regulatory and behavioural scrutiny by internal and external constituents. This suggestion is justified by the fact that conformity to institutional pressures will lead to less public outcry that DHBs are reneging on their duty (i.e. their social contract) to the general public to provide high quality health services.

\subsection{Chapter Summary}

To fill the gap in current literature and contribute to theory, Chapter 3 has considered the theoretical basis of institutional theory - namely organisational legitimacy and the three pillars of institutions. A generic theoretical framework was then developed based on the main features that underpin organisational legitimacy and the three pillars of institutions. Following this, Chapter 3 considered organisational legitimacy and the three pillars of institutions in the health sector. A research objective and a set of research questions were then developed based on the literature reviewed at Chapter 2, the theory considered throughout Chapter 3, and the organisational environment being studied (the New Zealand 
public health sector). To facilitate achieving the research objective and answering the research questions, a research framework grounded in institutional theory was also developed, which will be applied in this research.

The purpose of the next chapter is to outline the main methodology that will be used to conduct this study. Chapter 4 will then identify the data types required to (1) make inferences with respect to the research objective; (2) respond to the resultant research questions; and (3) assess the research framework. Chapter 4 will also set out the tools and techniques that will be used to collect and analyse the data required to answer the research questions and achieve the overall objective of the study. 
Figure 7: Public Health Sector Organisational-Field Research Framework

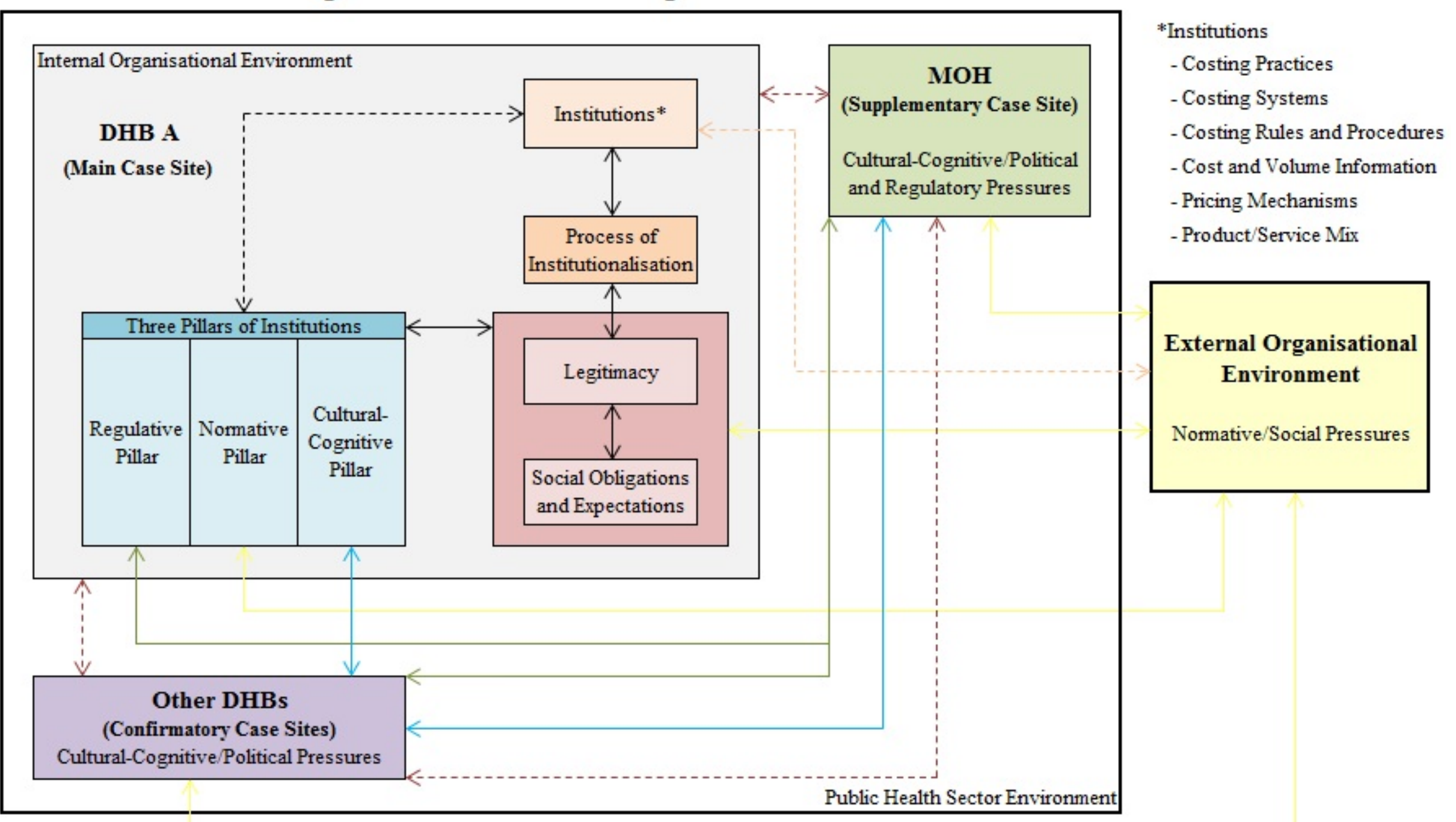

Key

Regulatory Pressures

Cultural-Cognitive/Political Pressures

Normative/Social Pressures $-\cdots$ Cost and Pricing Information

Convey congruence/adherence to external expectations through established institutions

$--->$ Convey established institutions and inform institutions via institutional pressures 


\section{Chapter 4 Methodology}

\subsection{Introduction}

This study explores the nexus between sophisticated costing systems use (as represented by ABC techniques) and IDFs in the New Zealand public health sector. In particular, the study considers adoption and use of sophisticated costing systems to disseminate cost information to inform transfer prices for inter-DHB trading. To guide the study, Chapter 3 developed a research objective (at section 3.9), six research questions (at section 3.10) and a research framework (at section 3.11). The purpose of Chapter 4 is to identify the data types required to (1) make inferences with respect to the research objective; (2) respond to the resultant research questions; and (3) assess the research framework. Chapter 4 also explains the tools and techniques that will be used to collect and analyse the data required to answer the research questions and achieve the overall objective of the study.

The rest of the chapter is organised as follows. The next section outlines the main methodology used in the study, a MCS approach, and its applicability with respect to the research purpose stated above. Section 4.3 discusses the benefits of a MCS approach over alternative approaches. Section 4.4 outlines the potential limitations of case study research grounded in a qualitative paradigm and discusses the verification strategies employed to mitigate such limitations (specifically replication, reflection and triangulation). Section 4.5 details the procedures for data collection, including methods of data collection and demographics of data collected. Section 4.6 details the procedures for interpretation and analysis of the data. And finally, section 4.7 summarises this chapter.

\subsection{A Multi-Site Case Study Approach}

To achieve the research objective stated at section 3.9, answer the six research questions posed at section 3.10 and assess the research framework developed at section 3.11, this study employs a MCS approach. A MCS approach is defined as an empirical inquiry that investigates a defined, contemporary phenomenon that is common to two or more real-life or naturalistic settings (Bishop, 2010). A MCS “offers a means of understanding an individual, event, policy, program, or group via multiple representations of that phenomenon” (Bishop, 2010, p. 587). To elaborate, a MCS enables wider understandings about a phenomenon by illuminating the experiences, implications, or effects of a phenomenon in more than one setting (Bishop, 2010). The research design through which MCS research is conducted is typically the same across all sites. Thus, the same phenomenon or unit(s) of analysis is 
studied with respect to the same key research questions (i.e. the research objective discussed at section 3.9 and research questions posed in section 3.10). "In addition, the same or similar data collection, analysis, and reporting approaches are employed across the sites” (Bishop, 2010, p. 587).

\subsubsection{Applicability of the Multi-Site Case Study Approach}

The adoption of a MCS approach is appropriate for the purposes of this study for three reasons. Firstly, the study explores a contemporary phenomenon, the nexus between sophisticated costing systems (as represented by ABC techniques) and IDFs in the New Zealand public health sector. Secondly, the phenomenon is common to more than one setting, as the New Zealand public health sector comprises multiple DHBs. Thirdly, a single-site case study approach is not appropriate because DHBs which operate in the New Zealand public health sector come from varying backgrounds, have differing organisational structures and characteristics (i.e. tertiary and secondary DHBs vary in size and nature), and serve their respective communities with consideration for specific and often dissimilar objectives and needs. Therefore, a MCS research approach is more suitable for purposes of this study because it allows individual DHBs to be explored within the organisational environment in which they operate.

\subsection{Benefits of the Multi-Site Case Study Approach}

A MCS approach has a number of benefits over alternative research methods, such as a single-site case study and cross-sectional surveys. The benefits of a MCS approach, compared to a single-site case study approach, are discussed below at section 4.3.1. The benefits of a MCS approach, compared to a cross-sectional survey approach, are discussed below at section 4.3.2.

\subsubsection{Multi-Site Case Studies versus Single-Site Case Studies}

A single-site case study can yield in-depth findings about the structure and characteristics of an organisation (including the historical, cultural and situational nature of an organisation). However, it is unable to provide cross-site patterns that can potentially enhance the internal and external validity of the study (Lillis \& Mundy, 2005). Moreover, a single-site case study has limited generalisability to other organisations and industries due to its single-site focus (Miller, 1998). As Bishop (2010) states, criticisms about single-site case studies tend to reflect concerns about the uniqueness or artifactual conditions surrounding the case. Conversely, a MCS approach has the capacity to elicit common findings from across different 
settings, but with respect to a single phenomenon. Hence, as well as eliciting site-specific findings that can be unique to an individual site, a MCS has the potential to enable valid cross-site syntheses and generalisable insights into a phenomenon. "As a result, richer and deeper understandings of a phenomenon are revealed” (Bishop, 2010, p. 578).

\subsubsection{Multi-Site Case Studies versus Cross-Sectional Surveys}

According to Lillis \& Mundy (2005) a cross-sectional survey can provide a wide breadth of findings. In particular, a cross-sectional survey can provide patterns of relationships between investigated factors and insights into the impacts of external factors, such as industry; regulation; legislation; economic conditions; technological advancements; societal expectations and political emphases. Though a cross-sectional survey can provide breadth of findings, it is unable to provide contextual explanations for occurrences within an organisation due to multiple respondents (Lillis \& Mundy, 2005). Moreover, survey instruments are inherently flawed because they often use weak measures for dependent and independent variables; leave fundamental terms to be interpreted in a subjective manner by respondents; allow respondents to self-specify; provide inconsistent findings; and finally, rely on a particular response rate (without which the survey becomes unusable) (Al-Omiri \& Drury, 2007). In contrast, a MCS approach allows the researcher to define fundamental terms and ascertain what such terms mean to the participant; facilitate constructive in-depth discussions on relevant topic areas; interact face-to-face with key members of an organisation to gain clearer insights on a phenomenon; and provide consistent findings through verification strategies (which are discussed in the follow section) (Al-Omiri \& Drury, 2007).

In summary, though a MCS approach does not have the same depth as a single-site case study; it has more breadth due to its multi-site analysis. In addition, though a MCS approach has less breadth than a cross-sectional survey, it has more depth by investigating the structure and characteristics of individual organisations (Lillis \& Mundy, 2005). The next section discusses the general limitations of qualitative research and outlines the specific mechanisms to be used in this research to mitigate such limitations.

\subsection{Mitigating Potential Limitations of Qualitative Research}

While the case study approach as a method to conduct qualitative research has numerous benefits (as per section 4.3), it is frequently criticised for having limited generalisability, validity and reliability. According to Zimmerman (2001) and Ahrens \& Chapman (2006), the shortcomings of case study research are ascribed to a failure to follow research protocols 
originally designed within an economics-based quantitative paradigm. As a means to mitigate the shortcomings of case study research grounded in the qualitative paradigm, numerous scholars, including Ahrens \& Dent (1998), Morse et al. (2002) and Lillis (2006), have suggested that case study researchers need to demonstrate that they are both rigorous and unbiased in their approach to research. This can be achieved by employing various verification strategies.

Acknowledging the inherent shortcomings of qualitative research, the study mitigates these by employing a MCS study approach. Using a MCS approach improves the degree of generalisability, validity and reliability of findings by obtaining data from multiple sites (Lillis \& Mundy, 2005; Bishop, 2010). Furthermore, several verification strategies are employed to add rigor and demonstrate impartiality to the research process and findings (Morse et al., 2002). The verification strategies employed in this study are replication logic (discussed at section 4.4.1), reflection (discussed at section 4.4.2) and triangulation (discussed at section 4.4.3).

\subsubsection{Choice of Case Sites and Replication}

According to case-focused literature, including Yin (1984); Eisenhardt (1989); Yin (2003); and Lillis \& Mundy (2005), a MCS research approach should make use of replication logic, which involves a non-random and purposive choice of case sites. To gain a wider breadth of understandings about a phenomenon and strengthen analytical generalisations, the sites chosen should also vary in organisational structure and characteristics (Yin, 2003). This approach to site selection is supported by Pettigrew (1988), who notes that given the limited number of cases which can usually be studied; it makes sense to choose sites that are both antithetical and transparently observable, the aim of which is to gain insights from additional case sites that corroborate, qualify and/or extend the findings of the first site. As Yin (2003) notes, the underlying logic of replication is to treat a series of cases as a series of experiments with each case serving to confirm or disconfirm the hypotheses. Case sites that confirm emergent findings enhance confidence in the validity of the findings. In contrast, case sites that disconfirm emergent findings can often provide an opportunity to refine and extend theory (so long as findings can be explained logically).

This study employs replication logic by choosing case sites that operate within the same organisational-field environment but vary in their organisational structure and characteristics. The sites selected for the purposes of this study all operate in the New Zealand public health 
sector and include a combination of tertiary and secondary DHBs and the MOH (particularly representatives from costing and pricing groups). This combination of case sites was selected so as to maximise case diversity and to gain deeper insights on the use of costing systems and transfer prices for IDFs in the New Zealand public health sector from multiple perspectives. These sites were also chosen to demonstrate rigor; to mitigate the potential for selection bias; and to gather findings that are valid, reliable and potentially generalisable with respect to DHBs operating in a New Zealand public health sector context.

To add further rigor to the research process, this study also makes use of reflection. Reflection as a form of verification strategy and its application in this study are discussed below at section 4.4.2.

\subsubsection{Reflection Methods}

According to Ahrens \& Chapman (2006), reflection is a flexible and ongoing process in which different stages of the qualitative inquiry interact and influence each other, the aim of which is to ensure the research problem, theoretical framework and data collected are appropriately linked. The process of reflection is particularly important in conducting a research exploration (whether it is qualitative or quantitative in nature) because defining the research problem, choosing appropriate theoretical perspectives to underpin the study, and collecting and analysing relevant data to address the research problem are core to a study. In addition to linking the main components of a study together, reflection can be used to validate the research framework, provide additional insights on a phenomenon and add richness to the findings of a study. That is, reflection can be used to validate ideas and findings from earlier data collection/analysis by identifying like terms or similar findings or alternatively it can be used to identify dissimilarities or obscurities in findings that require further explanation (Covaleski \& Dirsmith, 1988).

With consideration for the prospective uses of reflection aforementioned, this study makes use of an interactive pattern in its research process, whereby the preliminary findings inform decisions about future data collection (Covaleski \& Dirsmith, 1988; Miller et al., 2004). To elaborate, reflection is employed during the process of data collection and analysis. It is also employed to establish and check links between the data collected, the data analysed and the research framework developed at section 3.11. 
The process of reflection associated with data collection that is used in this study is split into three phases to enable reflectivity and interaction between the research problem, theoretical framework and data collected and analysed (Covaleski \& Dirsmith, 1988). The first phase is collection of data from one case site, so as to gain a general understanding of the research field and to develop the main research agenda. This phase is important as it serves to substantiate the research context and research purpose. The second phase of data reflection is initial analysis of data collected from the first case site, the aim of which is to discern key trends and patterns, and to evaluate their compatibility to the proposed theory and research framework (Covaleski \& Dirsmith, 1988; Ahrens \& Chapman, 2006). Phase two is also important as it provides insights into the most significant or interesting issues in the particular context, and can be used to revise the research purpose and/or research questions. The third phase involves using the findings from the first case site to inform the interview questions and choice of documents (which are relevant to the study's finalised research purpose), which will be collected from supplementary case sites and analysed to form the study's main results.

The overall purpose of reflection is to provide validity, reliability and richness to the study's results. Another verification strategy that is used for these purposes is triangulation. Triangulation as a form of verification strategy and its application in this study are discussed below at section 4.4.3.

\subsubsection{Triangulation}

Triangulation is defined by Flick et al. (2004, p. 178) as "observation of research from (at least) two different points”. There are four main points research can be observed from and they can be used separately or in conjunction with each other. The points include findings gathered from different methods, data, theories or investigators and they represent four distinct types of triangulation - methodological triangulation, data triangulation, theoretical triangulation and investigator triangulation (Flick, 1992; Flick et al., 2004; Hopper \& Hoque, 2006). The main benefits of triangulation are in its ability to reveal additional insights that may be neglected by a single method, data source, theory or researcher. Moreover, triangulation can enhance the credibility of explanations and capture richness and complexity of a phenomenon (Flick et al., 2004; Hopper \& Hoque, 2006).

Of the four types of triangulation outlined above, this study makes use of data triangulation. According to Flick (1992), the purpose of data triangulation is to determine patterns or reoccurring and consistent instances in the data collected. This process allows a researcher to 
confirm the validity and reliability of a particular explanation, theory or argument. In addition, Flick et al. (2004) note that data triangulation is used to provide richer more indepth understandings about a particular event, people, context or community. To achieve this data triangulation draws on data from several different sources (specifically people and places) at different times (Flick, 1992).

For the purposes of this research, data triangulation is used by drawing insights from several data sources (case sites and documents) relevant to the New Zealand public health sector (particularly DHBs and the $\mathrm{MOH}$ ). Data from each case site is analysed and compared through data triangulation to determine whether or not findings cohere. Data from case sites is also compared to documents acquired during the data collection process to determine whether or not findings from different sources cohere. The success of this process is crucial to the results of the study (and overall richness of results) as it dictates whether ideas and findings are valid and reliable. This is done by identifying like terms or similar findings. Data triangulation is also used to identify dissimilarities or obscurities in findings that require further explanation, which can add richness to the study's overall results (Covaleski \& Dirsmith, 1988). As Bishop (2010) notes, analysing data can be particularly challenging for multi-site case researchers. The sheer volume of data can be overwhelming and identifying patterns and themes among data can prove difficult. "However, when what a researcher hears, observes, and reads at a site is consistent, the triangulated data can be sturdy and helpful” (Bishop, 2010, p. 588).

As section 4.4 has discussed, three verification strategies are used in the study, replication (discussed at section 4.4.1), reflection (discussed at section 4.4.2) and triangulation (discussed at section 4.4.3). These strategies are employed with the intention of adding rigor to the study, demonstrating impartiality of the research process and to gather findings that are valid, reliable and add richness. The data collected and analysed with consideration for the verification strategies is described in the next section. Specifically, the next section describes the data sources and methods employed to select and collect data.

\subsection{Data Collection}

The two primary sources of data collected in the study are interviews (with site visits and assisted access to organisational costing and information systems) and primary and archival documents (acquired during the interview process and from electronic sources recommended by interviewees). As noted above at section 4.1, the sources of data are selected and collected 
to make inferences with respected to the research objective stated at section 3.9, to respond to the resultant research questions posed at section 3.10 and to assess the research framework developed at section 3.11. According to Yin (2003), reliance on interview data supplemented by extensive analysis of documents is a popular and recommended practice in case study research. Specific methods employed to recruit interviewees and conduct interviews, as well as methods used to select and collect primary and archival documents are discussed below.

\subsubsection{Methods of Data Collection}

\subsubsection{Interviews}

A semi-structured interview approach is adopted to conduct interviews and serves as the main method to collect data for the purposes of the study (Yin, 2003). A semi-structured interview approach typically comprises a set framework of themes that the researcher wants to explore with specified questions, however the interview process is open and flexible (Warren, 2002). To elaborate, the researcher will ask set questions that the interviewee is free to respond to in an unrestricted manner based on their own experiences and perceptions (Schram \& Steen, 2001). The researcher can then tailor follow-up questions to the interview context based on the interviewee and their previous responses. The benefits of a semi-structured interview approach are in its ability to yield a wider breadth and depth of responses compared to a structured interview process (which has a rigorous set of questions that yield standardised responses). In addition, a semi-structured interview approach allows the researcher to comprehend the interview context, which is particularly useful as it provides a means to understand the bases for statements made and views expressed by interviewees (Yin, 2003).

The sites chosen to conduct semi-structured interviews are New Zealand public health sector organisations (i.e. tertiary and secondary DHBs and the $\mathrm{MOH}$ ) and a desired sample size between 5-10 participants was anticipated and attained. For the purposes of the study, all participants were expected to have a detailed knowledge of their organisational environment, the costing systems used by DHBs and IDF processes. To guarantee validity of findings and ensure appropriate conclusions were made it was essential that participants meet these characteristics (Warren, 2002). The method of selection that was used to approach potential participants involved email and telephone correspondence with suitable personnel from chosen DHBs and the $\mathrm{MOH}$. Contact details were obtained from applicable organisational websites, by email contact with organisational administrators and through the snow-balling technique. The snow-balling technique involves previous interview participants suggesting 
further contacts who may be useful to the interview process (Arksey \& Knight, 2002). Emails were subsequently sent to each potential participant with an information sheet attached (included as Appendix III). This email was followed up by a telephone call two days later. If potential participants deemed themselves to be unsuitable for the study they were asked to give notification via email or telephone before 30 September 2012. They were then asked to provide contact details of other organisational personnel who may be more appropriate to assist during the interview process. All participants were given until 31 January 2013 to withdraw from the study.

Consistent with the underlying characteristics of the semi-structured interview approach, all interviews were conducted in an informal and flexible manner. Though the interview process was structured with consideration for a set framework of themes, questions were customised to reflect the interview context and interviewees were given the opportunity to discuss areas that most interested them (Warren, 2002). Customised interview questions were designed to fit each organisation's structure, roles and functions in relation to costing and IDF's in the New Zealand public health sector (for a sample of interview questions asked to $\mathrm{MOH}$ representatives refer to Appendix I and for a sample of interview questions asked to DHB representatives refer to Appendix II). The interview questions were initially formulated based on prior literature with the aim of fulfilling the research objective documented at section 3.9 and answering the research questions posed at section 3.10. During the interview process the interview questions were continuously revised to reflect new understandings and insights gained from the analysis of prior interviews. This was done using the reflection strategy described at section 4.4.2.

\subsubsection{Documentation}

As noted at section 4.4.3, this study makes use of data triangulation as a verification strategy. Therefore, all documentation is acquired to complement and/or supplement the findings of interviews conducted at the case sites. The purpose is to ascertain the validity and reliability of interview data, and to improve the overall richness of the study's findings. The documents acquired during data collection are primary and archival documents that relate to DHB Costing, National Pricing, Population-Based Funding and IDFs in the New Zealand public health sector. All documents are either provided by interviewees during the interview process or sourced electronically as per interviewee's recommendations (specifically the National Service Framework Library (NSFL), which is on the MOH website). 


\subsubsection{Demographics of Data Collected}

\subsubsection{Interviews}

A total of six case sites were chosen for the purposes of the research, including one main case site (DHB A), one supplementary case site (MOH) and four confirmatory case sites (DHB B, DHB C, DHB D and DHB E). Five of the case sites chosen were DHBs operating in the New Zealand public health sector and a total of six interviews were conducted at these sites with Chief Financial Officers (CFO) and Planning and Funding Analysts (PFA). The interviews were all conducted in accordance with the interview process described at section 4.5.1.1 and interviewees were chosen because of their expertise and knowledge of the organisational environment (i.e. costing systems adoption and use and IDF processes at their respective DHBs). The remaining case site was the $\mathrm{MOH}$ and two interviews were conducted at this site with representatives of the costing and pricing groups ( $\mathrm{MOH}$ Interviewee $\mathrm{A}$ and $\mathrm{MOH}$ Interviewee B). The interviews were conducted in accordance with the interview protocol described at section 4.5.1.1 and interviewees were chosen because of their expertise and knowledge of DHB costing processes and IDF processes.

All interviews were conducted between 1 June 2012 and 30 November 2012 and conducted on a one-on-one basis. Interviews conducted with representatives of DHB A, DHB B and the $\mathrm{MOH}$ were face-to-face. Interviews conducted with representatives of DHB C and DHB D were phone interviews. The time and location of each interview was agreed with the interviewee at their convenience and each interview took approximately one to two hours to conduct. The interviews were all recorded (with consent from the interview participant) and transcribed at a later date. Notes were also taken by the researcher during and after each interview to supplement the interview transcript.

\subsubsection{Documentation}

A total of 18 documents were acquired during the process of data collection. As noted above (at section 4.5.1.2) the documents were primary and archival in nature. The documents that were sourced from interviewees during the interview process include costing system guidance documents and IDF technical reports prepared by New Zealand DHBs; and discussion documents issued by the NHB related to the MOH costing and pricing groups. These documents were acquired to gain an understanding of the organisational environment in which DHBs operate, including the costing systems they use, and how the MOH impacts on that environment through Population-Based Funding and the calculation of National Price 
for IDFs. The documents acquired from electronic sources (specifically the NSFL) recommended by interviewees include the Common Chart of Accounts; Common Costing Guidelines; Common Costing Standards; Common Counting Standards; Crown Funding Agreement; Full-time Equivalent Counting Specification; IDF Forecast Methodology; National Costing Collection and Pricing Programme 2013 DHB Provider Arm Data Request; National Service Framework Data Dictionary; National Service Framework Service Specification; New Zealand Casemix Framework; Operational Policy Framework; Tertiary and National Paediatric Adjuster Pool. These documents were acquired to ascertain the validity and reliability of interview data, and to improve the overall richness of findings.

As section 4.5 has discussed, the two primary sources of data collected are interviews (with site visits and assisted access to organisational costing and information systems) and primary and archival documents (acquired during the interview process and from electronic sources recommended by interviewees). The next section discusses how the two sources of data are interpreted and analysed using qualitative procedures and techniques.

\subsection{Data Analysis}

The study makes use of qualitative procedures and techniques to interpret and analyse the data, which was obtained in accordance with the data collection processes outlined at section 4.5. Firstly, the data from each interview was transcribed using Express Scribe Transcription Software and subsequently analysed to identify key terms and findings. Analysis of the transcribed interviews was performed with a coding system (i.e. a list of important words and phrases), which was initially devised based on literature reviewed, theory considered and background knowledge of the organisational environment being studied (Malina \& Selto, 2001). During the process of analysis new words and phrases were added to the coding system based on their relevance and importance to the purposes of the research. The key terms and findings were then interpreted to discern the meanings and rationale that underlie the opinions, statements and explanations given by interviewees, and through which practical and theoretical explanations can be achieved (Silverman, 2006). In instances where more than one interview was conducted at a particular case site, patterns and relationships in the data were revealed by identifying like terms and similar findings. The patterns and relationships revealed in one case site (the main site) were then compared to those in other case sites (the supplementary and confirmatory case sites). To corroborate interview findings the documentation acquired during data collection was also analysed to identify key terms and 
findings, the purpose of which was to reveal patterns and relationships between the two sources of data (i.e. interviews and documentation) to enhance confidence in the validity and reliability of findings and to improve the overall richness of findings. Subsequent to data interpretation and analysis, the findings are to be presented as direct quotations, references to points made by interview participants or references to points made in relevant documentation (all of which are documented in the results at Chapter 5 to Chapter 8).

\subsection{Chapter Summary}

This study employs a MCS approach to explore adoption and use of sophisticated costing systems to disseminate cost information to inform transfer prices for inter-DHB trading in a New Zealand public health sector context. The resulting sample of six case sites comprises one main case site (DHB A), one supplementary case site (MOH) and several confirmatory sites (DHB B, DHB C, DHB D and DHB E). Interviews are conducted with key organisational personnel currently working in the New Zealand public health sector. Specifically, six interviews are conducted at New Zealand DHBs with CFOs and PFAs. Two interviews are also conducted at the $\mathrm{MOH}$ with representatives of the costing and pricing groups. All interviews are transcribed using Express Scribe Transcription Software and a total of 18 documents are collected (primarily from electronic sources) to supplement the interview data. To add rigor to the study, demonstrate impartiality of the research process and gather findings that maximise validity, reliability and richness verification strategies are used. The verification strategies, which include replication, reflection and triangulation, are used throughout the processes of sample selection, data collection and data analysis.

Applying the research approaches and techniques described above, a qualitative MCS is conducted, which explores costing systems and IDFs in the New Zealand public health sector. Findings of the study are documented below at Chapter 5 to Chapter 8 . Chapter 5 provides an overview of the New Zealand public health sector, including a summary of Population-Based Funding, the costing group, the costing standards and the costing guidelines. Chapter 6 presents the semi-structured interview evidence of costing systems adoption and use in New Zealand DHBs. Chapter 7 discusses the pricing group cost and volume data request and presents the data submission requirements for Service-Level and Event-Level DHBs. Chapter 8 discusses the calculation of National Price and presents the semi-structure interview evidence of how National Price influences IDFs. 


\section{Chapter 5 DHB Funding, Purchasing and Costing: An Organisational Overview}

\subsection{Introduction}

There are twenty DHBs in the New Zealand public health sector, which have been established based on geographic location. ${ }^{12}$ The specific objectives of each DHB, as outlined by the $\mathrm{MOH}$, include improving, promoting and protecting the health of people and communities; promoting the integration of health services, especially primary and secondary care services; seeking the optimum arrangement for the most effective and efficient delivery of health services in order to meet local, regional, and national needs; and promoting effective care or support of those in need of personal health services or disability support. DHBs are also expected to show a sense of social responsibility, to foster community participation in health improvement, and to uphold the ethical and quality standards commonly expected of providers of services and public sector organisations. The MOH has outlined several more general objectives for DHBs as well. These include promoting inclusion and participation in society and the independence of people with disabilities; reducing health disparities by improving health outcomes for Māori and other population groups; and reducing (with a view toward eliminating) health outcome disparities between various population groups (Ministry of Health, 2014).

To achieve these objectives each DHB, which is also described as the DHB of Domicile, must plan to provide or fund the provision of health services in their geographic area. This involves making decisions on the most suitable location for the delivery of health services to their respective DHB populations (which are based on Statistics New Zealand consensus area units) while considering regional and national needs. To make these types of decisions each DHB must evaluate their local health needs (based on demographics) and how they can meet such needs using funding provided by the $\mathrm{MOH}$. Consequently, the rest of this chapter is organised as follows. Section 5.2 discusses how funding is distributed to each DHB using Population-Based Funding; Section 5.3 discusses how DHB's provide/purchase health services to meet the needs of their respective DHB populations; and Section 5.4 discusses the Common Costing Group (CCG) and its associated functions.

\footnotetext{
12 The DHBs operating in the New Zealand public health sector are Northland DHB, Waitemata DHB, Auckland DHB, Counties Manukau DHB, Waikato DHB, Bay of Plenty DHB, Lakes DHB, Tairawhiti DHB, Taranaki DHB, Hawke's Bay DHB, MidCentral DHB, Whanganui DHB, Capital \& Coast DHB, Hutt Valley DHB, Wairarapa DHB, Nelson Marlborough DHB, West Coast DHB, Canterbury DHB, South Canterbury DHB and Southern DHB.
} 


\subsection{DHB Funding}

According to sector knowledge provided by the Ministry professionals interviewed, the $\mathrm{MOH}$ distributes funds to all twenty DHBs that operate in the New Zealand public health sector through the Crown Funding Agreement (CFA). The CFA is an output agreement between the Crown (aka the $\mathrm{MOH}$ ) and DHBs, which specifies that the Crown will provide funding to DHBs in return for service provision. To receive annual appropriations from the Crown, all DHBs are required to prepare accountability and planning documents. The documents, which are an Annual Plan that incorporates a Statement of Intent and a Regional Plan, should address local, regional and national needs for health services; how health services can be properly co-ordinated to meet those needs; and the optimum arrangement for the most effective and efficient delivery of health services.

Crown funding is integral to the New Zealand public health sector as it contributes more than two-thirds to total spending on public health (for a breakdown of other sources of Revenue and Cost Recoveries refer to Schedule 6 at section 5.4.2.6). Due to the significance of Ministry funding, it is distributed to DHB's methodically using an approach called Population-Based Funding that aims to distribute funds fairly according to the relative needs of DHB populations and the costs of providing health services to meet those needs. This is achieved by distributing funds according to the demographic characteristics of each DHB population (Cost Weights) and certain unavoidable costs in providing services to rural and non-resident populations (Adjusters). Thus, the population-based funding is effectuated using a formula that comprises these two main constituents - (A) Cost Weights and (B) Adjusters.

\section{(A) Cost Weights}

Cost Weights represent the expected costs per person of a DHB population and are modelled using historical expenditure according to four demographic characteristics. These characteristics, which are known as the population-based funding formula variables, are the key capitation components and include (1) Age; (2) Gender; (3) Ethnicity; and (4) Deprivation. (1) Age is based on date of birth and recognised in 5-year increments (i.e. 0-4, 5-9, 10-14, ...85+); (2) Gender is separated between male and female; (3) Ethnicity is selfidentified and prioritised as 1) Māori, 2) Pacific and 3) Other; and (4) Deprivation is derived by linking patient address information/domicile code to the corresponding New Zealand Deprivation Index 2006 quintile value. To calculate cost weights, patient data is collected for each of the aforementioned characteristics. All data related to date of birth, gender and 
prioritised ethnicity is obtained from the National Minimum Data Set (NMDS) and crosschecked against the National Health Index (NHI) database. ${ }^{13}$ The NHI is also used to acquire address information to determine where each patient is situated on the deprivation index.

The data for each combination of the characteristics described above creates a population group, which when aggregated, forms a cost weight matrix. The cost weight matrix outlines the expected cost per person within each service area and is created by calculating total expenditure in the previous year divided by the total population count for each age, gender and deprivation quintile group. To ensure cost weights are accurate the average expected expenditure per person for every age-gender-deprivation cell is multiplied by the number of people belonging to that cell within each ethnic group. The expected costs for each cell group are then added together to determine the overall expected expenditure for each ethnic group.

Once expected expenditure for each ethnic group is calculated it is compared to actual expenditure. Typically, the expected expenditure model underestimates actual expenditure in Māori and Pacific groups as these groups tend to need more health services than other groups but do not necessary consume these services upfront (Penno et al., 2012). If the model does under predict expenditure in one group an adjustment needs to be made to all three ethnic groups. This will usually involve cost weights for Māori and Pacific groups being adjusted up and cost weights for other groups being adjusted down.

To provide a hypothetical example, assume that the expected expenditure model predicts that Māori expenditure was $\$ 10$ million. However, actual expenditure may be $\$ 12$ million. This creates an adjustment factor of $20 \%$ (being the percentage difference between the expected expenditure model and actual expenditure). This adjustment factor is then applied as a single adjustment across all cells in that particular ethnicity group (i.e. all age-gender-deprivation cost weights in Māori ethnic group are increased by 20\%). Because the adjustment uses the entire national population as a base an adjustment is made to all three ethnic groups. Where a group is adjusted up another group(s) must be adjusted down (i.e. where the model under predicts expenditure in one group it must have over predicted expenditure in another) (Penno et al., 2012). This means that Pacific groups or other groups (or a combination of both) are adjusted down by $\$ 2$ million.

\footnotetext{
${ }^{13}$ The NMDS is a national collection of hospital discharge information, including clinical information, for inpatients and day patients. The NHI is a unique identifier assigned to each person using health services and includes demographic details.
} 
After cost weights for each individual service are calculated (and adjusted where necessary) they are aggregated within their respective service groups. There are five major service groups (MSG), which are (1) Personal Health Primary (primary health, immunisation, pharmaceutical and laboratory); (2) Personal Health Other (inpatient, outpatient, maternity and other); (3) Health of Older People (aged residential care, home support and inpatient assessment, treatment and rehabilitation); (4) Mental Health; and (5) Psychogeriatric Services. Aggregated cost weights for each of the five service groups are combined to derive total expected annual expenditure for each population group. Total expected annual expenditure for each DHB is then multiplied by their respective population projection to determine their share of population-based cost-weighted funding for the year.

(B) Adjusters

Adjusters are designed to compensate DHBs for unavoidable differences in costs associated with the provision/funding of services to their respective populations. The funding adjusters include (1) Unmet Needs Adjuster; (2) Rural Adjuster; and (3) Overseas Adjuster:

(1) The Unmet Needs Adjuster is required to ensure highly deprived populations and specific ethnicities (i.e. Māori and Pacific Islander) that underutilise services related to their health needs have access to all essential services.

(2) The Rural Adjuster is required to ensure rural communities have equal access to health services, regardless of any additional costs to provide health care in remote areas which may result (e.g. Inter-DHB Transfers; Community Services; Small Hospital Facilities; Governance Costs; Offshore Islands; Rural General Practitioner Costs; and Travel and Accommodation).

(3) The Overseas Adjuster is required to cover costs incurred by DHBs of providing health services to eligible overseas visitors (i.e. New Zealand citizens visiting temporarily; overseas visitors covered by reciprocal agreements with Australia and the United Kingdom; nonresident citizens from Niue, Tokelau and Cook Islands; visitors covered by the Accident Compensation Corporation; and refugees).

Once the MOH has finalised populated-based funding, the twenty DHBs nationwide will use their individual funding packages to plan, purchase and provide health services that they are contracted to provide through the CFA. 


\subsection{DHB Purchasing or Service Provision}

The Planning and Funding Unit (PFU) of each DHB will choose to provide health services or purchase health services from multiple other providers based on local need and availability of resources. The main health service provider for each district is the DHB hospital (aka Public Hospital), which is owned and funded by the DHB. Each DHB hospital is called the Provider Arm and mainly provides hospital-related services. Examples of Provider Arms in the New Zealand public health sector include Hutt Valley Hospital, which is run by Hutt Valley DHB, Auckland City Hospital, which is run by Auckland DHB (and is the largest Provider Arm in New Zealand), Christchurch Hospital, which is run by Canterbury DHB (and is the largest Provider Arm in the South Island) and Dunedin Hospital, which is run by Southern DHB. For selected health care activities DHB's will contract directly with other providers besides the main Provider Arms, such as private hospitals, primary care, mental health, disability and community services. The Provider Arms themselves can also subcontract to these other agencies where necessary.

In addition, DHBs purchase services from other DHB's Provider Arms through IDFs. As all appropriations provided through the CFA include funding for IDFs, DHBs are required to reimburse each other for IDFs from this funding. When a DHB wants to purchase services from another DHB the purchaser is the "DHB of Domicile" and the provider is the "DHB of Service”. To facilitate IDFs between DHBs the National Cost Collection and Pricing Programme (NCCPP) sets National Prices, which become the default prices (refer to Chapter 7 for full discussion on work performed by the NCCPP and Chapter 8 for full discussion on National Price). The main motivation for developing these prices is effective and efficient inter-DHB trading within the sector. While DHBs are permitted to negotiate their own prices, the hope is that they will trust the efficiency of National Prices and save resources, which can otherwise be expended on lengthy price and volume negotiations (refer to Chapter 8 InterDistrict Flows for full discussion on IDFs).

To assist the NCCPP in setting National Prices for IDFs the MOH has developed a set of DHB Costing Standards that serve as common standards for the costing of health services. The standards apply to all DHBs operating in the New Zealand public health sector, in particular the DHB's Provider Arms, and are very important to the efficiency of IDFs as they determine the quality of information to be used by the NCCPP for National Pricing work (refer to Chapter 7 for full discussion on work performed by the NCCPP and Chapter 8 for 
full discussion on National Price). The DHB Costing Standards and the Group responsible for developing, reviewing and updating the Standards are discussed in greater detail below.

\subsection{The Common Costing Group}

The Common Costing Group (CCG or “the Group”) is a group of New Zealand public health sector experts comprising representatives from DHBs and the MOH. The CCG was set up in 2005 and is responsible for developing, reviewing and updating the DHB Costing Standards and the DHB Costing Guidelines to be used by New Zealand DHBs.

\subsubsection{The Common Costing Standards: An Overview}

The DHB Costing Standards, known as the Common Costing Standards (CCS or "the Standards”) hereafter, are rules that establish requirements for recognising, measuring and disclosing financial and non-financial information. The CCS also set out specific rules to be used in a DHB's costing system when they have a material impact. ${ }^{14}$ The CCS are based on the principle that when determining the cost of a patient event, it must be fully absorbed (i.e. any cost that is caused by the delivery of health care, whether it is direct or indirect in nature, should be allocated to activities associated with a patient event in order to have a complete cost for the event). To achieve this fundamental directive, the CCG has specified that ABC methodologies be applied when costing patient events. In instances where information is not available to use ABC methods to allocate overheads the Group has prescribed alternative more simplistic methods for cost allocation (refer to section 5.4.2.4 for Schedule 4 of the CCS on Overhead Allocation Methodology, section 6.3.1.1 for discussion on the application of Schedule 4 and section 7.2 for discussion on the requirements of service-level DHBs and the application of prescribed overhead allocation bases).

The Standards are intended for application to all cost reports and any limitation in their application is made clear in the text of each particular Standard. When making disclosures and preparing cost reports, the CCG advises that DHBs should maintain a balance between benefits and costs. Concordant with Cooper (1988), the CCG stresses that the benefits derived from information should meet or exceed the costs of providing the information. ${ }^{15}$ Any and all cost reports should be based on accurate information and DHB's should

\footnotetext{
${ }^{14}$ According to the CCG (2012, p. 7) “A statement, fact or item is deemed material if it is of such a nature or amount that its disclosure is likely to influence the users of the report in making decisions or assessments". Additionally, a statement, fact or item is deemed to have a material impact when it is $2 \%$ of the cost of the product or product-line being measured.

${ }^{15}$ While a cost/benefit consideration is important, the CCG concedes that such an evaluation is highly subjective and cost/benefit margins will differ on a DHB-by-DHB basis.
} 
demonstrate a transparent methodology for the preparation of cost reports. These expectations are emphasised to ensure information usefulness, reporting comparability, and to provide the Group with the opportunity to assess whether DHBs are complying with the Standards. As an additional expectation, where DHBs do not comply with the Standards, full disclosure is required to permit comparative assessments of DHB information.

The main purposes of the Standards, as outlined by the Group, are to:

1) Ensure consistency in costing and cost allocation within the DHB sector

2) Improve the quality of cost reporting

3) Improve operational decision-making within DHBs and hospitals

4) Provide better data for DHB benchmarking

5) Provide a sound basis for IDF pricing

\subsubsection{DHB Costing Schedules 1-7}

As noted above, the CCS are based on the principle that when determining the cost of a patient event it must be fully absorbed and the CCG has outlined that ABC methodologies should be applied to achieve this. Where ABC methods are not possible, the Standards have prescribed alternative methods to be used (see Schedules below for preferred and alternative costing methods). The Standards comprise seven schedules, each of which is outlined next:

\subsubsection{Cost Centre Categories (Schedule 1)}

The purpose of Cost Centre Categories Schedule 1 is to provide guidance for common classification of cost centres in DHB costing systems. The CCG has defined cost centres as divisions, departments or units that perform functional activities at a DHB Provider Arm and it has identified five cost centre categories to be used in DHB costing systems. The cost centre categories, which are discussed in greater detail below, are (1) Patient Care and Patient Support Cost Centres; (2) Overhead Cost Centres; (3) Non-core Cost Centres; (4) DHB Governance Cost Centres; and (5) Planning and Funding Cost Centres. In instances where a cost centre comprises costs attributable to more than one category, it is recommended that the costs be split and assigned to the appropriate cost centre category. For example, Laundry provides services to hospital and private organisations; therefore hospital costs should be allocated to Patient Care and Patient Support Cost Centres while private costs should be separated out to a Cost Centre. 
(1) Patient Care and Patient Support Cost Centres

Patient Care Cost Centres are defined as cost centres directly involved in the care of patients and include (but are not limited to) Allied Health; Palliative Care; and Renal Dialysis. Patient Support Cost Centres are defined as cost centres that are indirectly involved in the care of patients and include (but are not limited to) Laundry; Patient Administration, such as medical typists; and Ward issues, such as pharmaceutical dispensation. As per the CCS, Patient Care and Patient Support Cost Centres should associate an identified product with a specific patient, either when the patient consumes the product (e.g. lab test) or on an assignment basis (e.g. pharmacy cost). While both Patient Care and Patient Support costs typically vary with patient volume, only Patient Care costs are individually linked to patient events, meaning Patient Support costs are always associated with a specific patient on an assignment basis. Furthermore, DHBs with an unsophisticated costing system are required to assign all Patient Care and Patient Support costs to Patient Care Cost Centres, which is the lowest level of costing for monitoring purposes (unless Patient Support costs relate to a commercial venture (e.g. private laundry services), in such case they will not be assigned to a patient event).

\section{(2) Overhead Cost Centres}

Overhead Cost Centres are defined as cost centres that provide a supporting role to the organisation, but cannot be traced to identifiable products consumed by publicly funded patients, nor are they readily affected by changes in patient or volume mix. Overhead Cost Centres include (but are not limited to) Asset Costs, such as clinical equipment depreciation; Chief Executive Office (CEO) Costs, such as public relations; and Medical Records. Full details pertaining to the allocation of overhead costs to other cost centres are outlined in Overhead Allocation Methodology Schedule 4 (section 5.4.2.4).

\section{(3) Non-core Cost Centres}

Non-core Cost Centres cover any costs that do not provide products or services directly or indirectly (as an infrastructure) to patients, and as such should be excluded from patient costs. Non-core costs include research and commercial ventures, such as Laundry services provided to private organisations.

\section{(4) DHB Governance Cost Centres}

DHB Governance Cost Centres are defined as cost centres that relate to any governance functions at a DHB. Governance Cost Centres include (but are not limited to) CEO Costs; Human Resources; and Risk Management. Governance Cost Centres may receive costs 
allocated from Overhead Cost Centres and may allocate costs to the Patient Care and Patient Support Cost Centres where appropriate according to usage using the Overhead Allocation Methodology described in Schedule 4 (section 5.4.2.4).

\section{(5) Planning and Funding Cost Centres}

Planning and Funding Cost Centres are defined as cost centres that provide a population health planning function or health service funding function. Planning and Funding Cost Centres may receive costs allocated from Overhead Cost Centres where appropriate and should not be allocated to any Patient Care and Patient Support Cost Centres.

\subsubsection{Cost Groups (Schedule 2)}

The purpose of Cost Groups Schedule 2 is to provide guidance for the aggregation of costs in the General Ledger (GL) into higher-level cost groups, as categorised by the Common Chart of Accounts (CCoA). In accordance with Schedule 2, all costs recorded in the GL need to be assigned to cost groups, as the cost groups are tracked when allocating costs and determining product and service costs. As per the CCoA there are several mandatory expense categories, which include (but are not limited to) Medical Personnel; Non-Clinical Supplies; and Outsourced Services. When costs are assigned to specific cost groups a major distinction between direct and indirect costs is required. Schedule 2 does not however permit a distinction between variable and fixed costs. According to the CCG, the range of possible subjective judgements is too great to provide a single set of common guidelines for such a distinction. This is supported by the fact that DHBs have historically split costs into variable and fixed categories, which tended to result in different categorisations by each DHB. Direct costs are costs that are directly attributable to patient activities and fall into the category “Cost Groups with Direct Patient Activity”. Direct Cost Groups include (but are not limited to) Nursing Labour; Implants; and Patient Support Costs. Indirect costs are costs indirectly allocated to patient activities and fall into the category "Cost Groups with no Direct Patient Activity” (also identified as “Overheads”). Indirect Cost Groups include (but are not limited to) Costs of Capital, which are related to DHB financing; Governance and Administration, which are organisation-wide overheads; Building Depreciation; Leases and Rents.

\subsubsection{Cost Centre Allocation Order (Schedule 3)}

The purpose of Cost Centre Allocation Order Schedule 3 is to outline the most logical and appropriate order for allocating costs from Cost Centres (Schedule 1, section 5.4.2.1) to Cost Pools (Schedule 7, section 5.4.2.7). Schedule 3 provides an illustration to show the order in 
which Non-clinical Overhead Cost Centres, Patient Support Service Cost Centres and Patient Care Cost Centres should be allocated to Product Cost Pools (see Figure 8). Schedule 3 also illustrates the flow of certain Non-Clinical Overhead Cost Centres (e.g. vehicle expenses) and Patient Support Service Cost Centres (e.g. laundry-related commercial ventures) to Non-core Cost Centres, which are not allocated to patient events and are generally dead-ended (i.e. not captured as a part of any product in the costing of patient events) in accordance with Schedule 5 (section 5.4.2.5).

Figure 8: Cost Centre Allocation Order

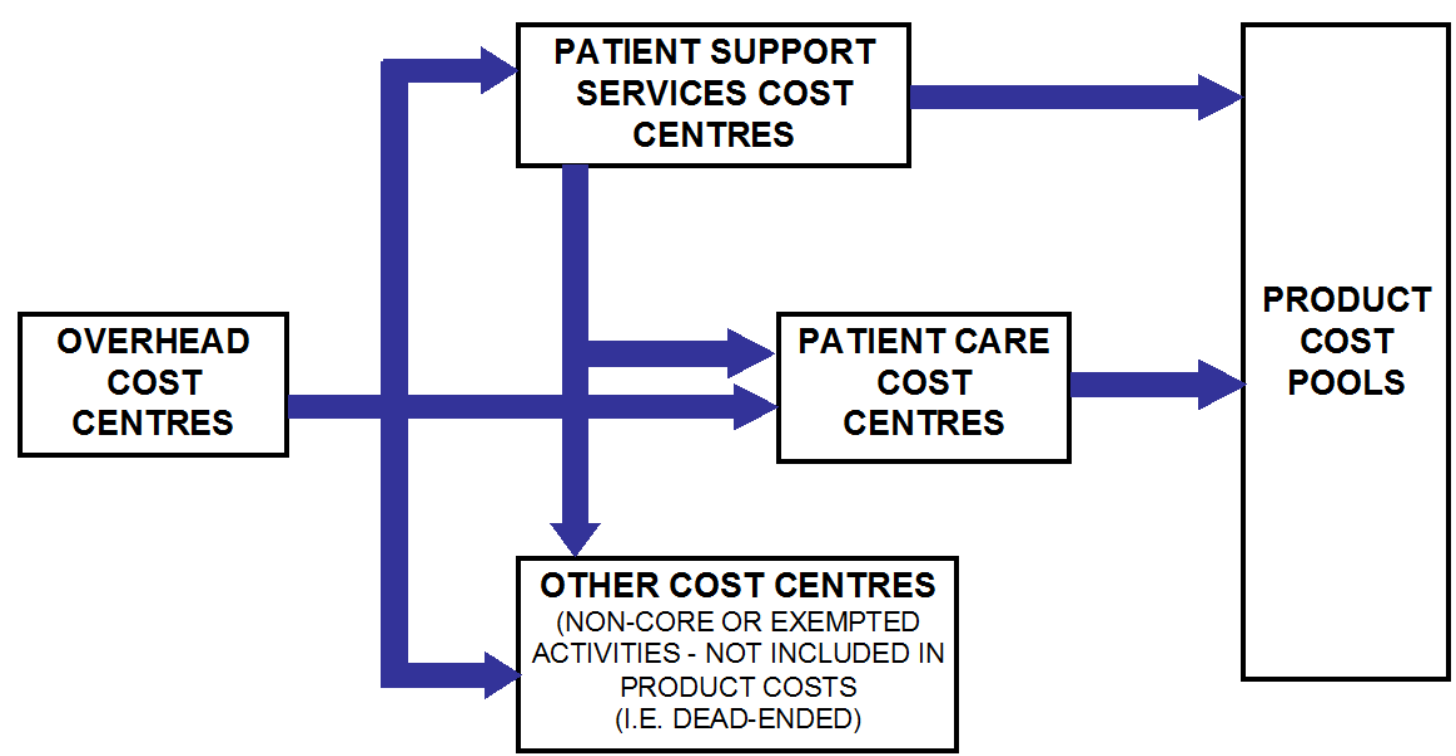

(Source: Common Costing Group, 2012, p. 28)

- Overhead Cost Centres are fully allocated to Patient Support Services Cost Centres, Patient Care Cost Centres and Other Cost Centres (using cost drivers defined in Schedule 4, section 5.4.2.4).

- Patient Support Cost Centres and Overhead Cost Centres allocated thereto are allocated to Patient Care Cost Centres, Product Cost Pools and Other Cost Centres.

- Patient Care Cost Centres are fully allocated to Product Cost Pools.

- All Cost Centres allocated to Other Cost Centres are non-core or exempted as per Schedule 5 (section 5.4.2.5) and as such do not require further allocation.

The CCG emphasises that the order in which Cost Centres are allocated is vital to ensure consistency and comparability across all DHBs operating in the New Zealand public health sector. To preserve consistency and comparability, Schedule 3 requires all Cost Centres to be 
allocated on the basis of the output activity of the subsequent Cost Centre. Schedule 3 offers four separate approaches to fulfil this requirement, which include the Step-Down, Internal Recharging, Iterative and Simultaneous approaches.

In the step-down cost allocation system, backward allocation of costs is not permitted, as this practice would result in Cost Centres with unallocated costs. The internal recharging method is used when a Cost Centre charges its costs to another Cost Centre within the DHB. In an internal recharging cost allocation system, costs should be allocated from Cost Centres to Cost Pools after the calculation of each Cost Centres allocated costs and this should be done on the basis of resource usage. The value of the allocated costs may be based on full, partial or shared use of a particular resource. In the case of partially used or shared resources, costs should be allocated in the order as shown in Figure 8. In an iterative cost allocation system some backward allocation of costs is permitted, as cost allocations will clear after a number of cost allocation iterations (assuming all overhead Cost Centres allocate to other Cost Centres). If DHBs use the simultaneous model, they are exempted from applying Schedule 3 (section 5.4.2.3) as the CCG considers this to be the mathematically preferred approach.

\subsubsection{Overhead Allocation Methodology (Schedule 4)}

The purpose of Overhead Allocation Methodology Schedule 4 is to outline the most appropriate method for allocating Non-Patient Cost Centre costs (overhead) to Patient Care Cost Centres. To elaborate, the Overhead Allocation Methodology identifies an appropriate cost driver for the outputs of each Cost Centre. Costs should then be allocated to other dependent Cost Centres and Cost Pools on the basis of "unit cost per cost driver".

Schedule 4 provides several common bases for cost drivers, which are used to allocate overhead. In instances where a cost driver is not measured or a DHB is unable to apply the preferred cost drivers, Schedule 4 offers alternate cost drivers (typically Full-Time Equivalent (FTE) or Total Cost, as all DHBs should have access to this information) to allocate overhead costs. A breakdown of typical functions performed by a Provider Arm with preferred and alternate allocation cost drivers is provided below in Table 3 (note this breakdown is not exhaustive): 
Table 3: Cost Centre Allocation and Recommended Cost Drivers

\begin{tabular}{|c|c|c|}
\hline \multirow{2}{*}{ Function } & \multicolumn{2}{|c|}{ Allocation Cost Driver } \\
\hline & Preferred & Alternate \\
\hline Asset Costs & NBV by Cost Centre & Total Costs \\
\hline CEO & FTE & Total Costs \\
\hline Cost of Capital & Asset Value & Total Costs \\
\hline Director of Nursing & Nursing FTE & Total Costs \\
\hline Facilities & Area occupied in square metres & Total Costs \\
\hline Finance Department & Transactions & FTE \\
\hline General Support Services & FTE & Total Costs \\
\hline Governance & Revenue & Total Costs \\
\hline Human Resource Costs & FTE & Total Costs \\
\hline Information Systems & Number of PC's & FTE \\
\hline Insurance - Assets & Asset Value & Total Costs \\
\hline Mgmt. Support - Corp & FTE & Total Salary Costs \\
\hline Mgmt. Support - Service & FTE & Total Salary Costs \\
\hline Medical Support & Medical FTE & Medical Salary Costs \\
\hline Nursing Support & Usage & Nurse FTE \\
\hline Payroll & FTE & Total Salary Costs \\
\hline Purchasing & Usage & Total Costs \\
\hline Quality/Accreditation & FTE/Headcount & Total Salary Costs \\
\hline Risk Mgmt./Legal & FTE/Headcount & Total Salary Costs \\
\hline
\end{tabular}

Where a DHB cannot apply the preferred or alternate cost drivers for costs that are deemed to be material (i.e. costs that are at least $2 \%$ of total costs) the Group has requested that this be disclosed and details of the allocation basis used be provided. The purpose of this disclosure is to give the Group an opportunity to consider alternative overhead allocation bases not currently provided in the Standards to determine their appropriateness and potential inclusion in future versions of the Standards.

\subsubsection{Cost Exclusions/Inclusions (Schedule 5)}

Cost Exclusions/Inclusions Schedule 5 provides guidance regarding the items to exclude and include when determining the cost of products consumed by patient events. The objective of Schedule 5 is commonality of cost information, which is used by the NCCPP to set National 
Prices. Commonality of information also allows the MOH to assess DHB performance and set achievable benchmarks for DHBs to strive towards. The general guidance set out in Schedule 5 states that only costs incurred in every day operations and core business restructuring (as a normal part of DHB activity) should be allocated to products. Costs incurred as part of organisational wide restructuring, provisions for bad and doubtful debts, and all expenses from research and commercial ventures should not be allocated to individual products as they do not form part of the infrastructure linked to the delivery of patient care.

\subsubsection{Treatment of Revenue (Schedule 6)}

Treatment of Revenue Schedule 6 provides recommendations for the treatment of each revenue account from the CCoA. To foster homogenous applications across the Sector, the Schedule offers twenty-one recommendations with additional guidance for the treatment of revenue items - seventeen of which relate to Cost Recovery and four of which relate to Revenue. Revenue that should be treated as “Cost Recovery” includes (but are not limited to) Gain on Sale of Fixed Assets; General Rents; and Professional and Consultancy Fees. Revenue that should be treated as "Revenue" includes Rental Income from Investment Property; Bequests; and Donations. In instances where a DHB cannot apply the guidelines provided in Schedule 6 (i.e. when information is not available to permit compliance), the CCG has provided additional commentary that all DHBs should disclose any departures from the prescribed revenue treatments. The purpose of this disclosure is to provide the Group with information to better understand when and why the prescribed treatments are not applied, and where alternative treatments are applied instead. This information is subsequently used to facilitate continual development of the Standards, as alternative revenue treatments are evaluated for appropriateness and potential inclusion in future versions of the Standards.

\subsubsection{Intermediate Products (Schedule 7)}

The purpose of Intermediate Products Schedule 7 is to facilitate consistent treatments of cost pool and product information in DHB costing systems so accurate unit costs per product can be formed. The CCG (2012, p. 47) defines an intermediate product as "a product or service provided to a patient that contributes to the final total cost of a patient's [visit]". To encourage consistent treatments Schedule 7 provides standardised methodologies to be used when allocating fully absorbed costs in Patient Care and Patient Support Cost Centres to Intermediate Product Cost Pools (see Figure 8). "Greater standardisation of Cost Pools allows for the comparison of DHBs at a higher level of detail than possible at the group level” 
(CCG, 2012, p. 48). The CCG also contends that the sophistication of costing systems used by each DHB determines the level of product specificity. The level to which products are specified within a Cost Pool then determines the level of detail at which comparative and benchmarking work can be performed. The methodologies outlined in Schedule 7 include the Cost Pools to which fully absorbed costs are allocated; levels of detail for products that make up those pools; and costs that will be included and excluded from the pools. The Intermediate Product Cost Pools offered in the Schedule include (but are not limited to) Anaesthetists; Pharmaceutical Cancer Treatment; and Obstetrics.

\subsubsection{DHB Costing Schedules 1-7: Sophisticated versus Unsophisticated Application}

Based on the summary of the seven DHB Costing Schedules above (section 5.4.2.1 to section 5.4.2.7), there are two distinct approaches to costing that are accepted by the CCG. One is full use of the CCS by DHBs with sophisticated costing systems, the other, partial use by DHBs with unsophisticated costing systems (costing systems adoption and use is discussed at Chapter 6). To illustrate how the Schedules interrelate from a sophisticated costing approach and an unsophisticated costing approach, a comparison is provided at Figure 9.

Figure 9: Sophisticated versus Unsophisticated Costing

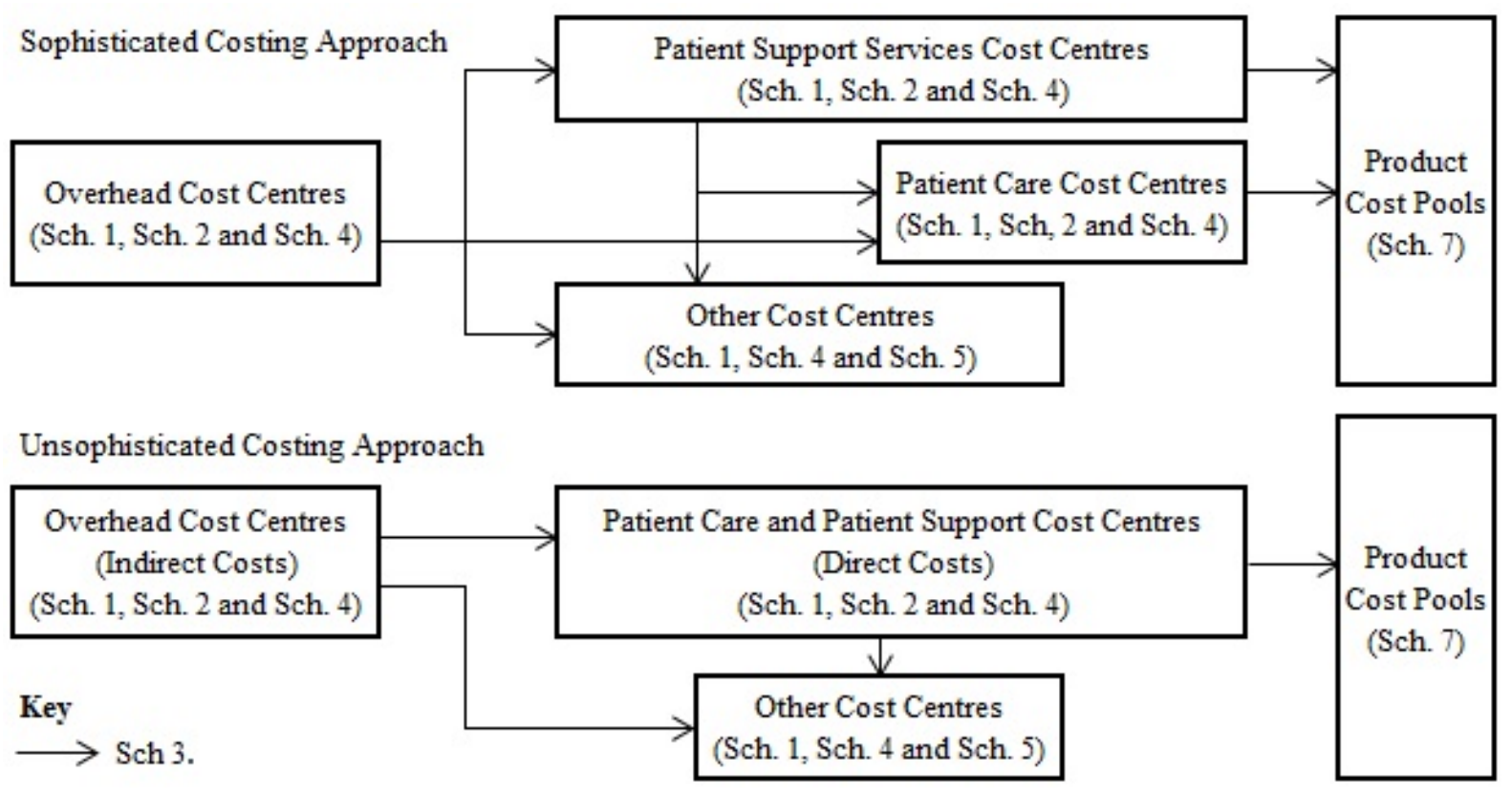




\subsubsection{The Common Costing Guidelines: An Overview}

The DHB Guidelines, known as the Common Costing Guidelines (CCGL or "the Guidelines”) hereafter, demonstrate how DHBs apply the Standards to Intermediate Products (Schedule 7, section 5.4.2.7). In particular, the Guidelines demonstrate how DHBs allocate costs to patient events and the type of costs that are allocated to each product. There are five guidelines and they have been developed based on information obtained from members of the CCG. Each guideline provides details of the DHBs that have contributed information towards its creation and the date this information was obtained. The Guidelines include:

1) Guideline 1: Critical Care

2) Guideline 2: Emergency Department (ED)

3) Guideline 3: Theatre/Procedure Rooms

4) Guideline 4: Wards

5) Guideline 5: Oncology and Haematology

The main purposes of the Guidelines are to (1) Assist DHBs when they are implementing an event-level costing system; (2) Enable DHBs to assess their costing methodology in comparison to other DHBs; (3) Assist the interpretation of event-level costing data; and (4) Improve development of the Common Costing Standards

\subsubsection{Maintaining Common Costing Standards and Common Costing Guidelines}

The CCG assembles every three months (four times a year) to discuss the application of the CCS and interpretation of the CCGL. The main motivation for these quarterly meetings is to determine whether or not the Standards and the Guidelines are fulfilling their main purposes, and to ensure they are appropriate for the wider business group (the DHBs collectively). As the CCGL are a support document to the CCS, specifically Schedule 7 (section 5.4.2.7), it is essential that the documents function jointly with a high level of efficacy to meet their main purposes (predominantly uniform treatments of cost pools and product information so eventlevel cost information is comparable for analysis and benchmarking).

The CCS and the CCGL are considered living documents and are continually developed and amended as needs change. Needs may change for any number of reasons, which include (but are not limited to) regulatory, legislative, political, economic, social and demographic changes. With the intention of sustained overall effectiveness, there are several processes used by the CCG to maintain the CCS and the CCGL. These processes include: 
- The CCG uses benchmarking to audit each DHB to ensure they are generally following the CCS. The CCG also uses other methodologies, such as surveying, to determine whether or not the standards are being followed, and if not, the CCG will enquire to (1) understand why they are not being followed; (2) ascertain what methods are used instead.

- To enhance overall functionality of the CCS, they are updated annually based on feedback from members of the CCG. Specifically, if any DHB has issues applying the standards to their particular costing system and/or finance system, this will be discussed by the CCG and the CCS may be amended. The CCG will tend to amend the standards to reduce ambiguity and make them more accommodating for all users. While this can be disruptive to DHBs when they apply the CCS, wholesale changes are typically only made when the CCG and DHBs agree that a change needs to be made to improve costing.

- As the CCGL are used in conjunction with the CCS, it is vital that the guidelines are interpreted clearly and consistently with reference to the standards. To maintain synergy between the two documents, the CCG comes together to discuss any discrepancies relating to the application of the CCS and/or the interpretation of the CCGL. If there are any concerns, the CCG may make amendments to the CCS based on these concerns and will redevelop the guidelines according to the amended standards.

\subsubsection{Linking Documents}

The CCG insists that a robust definition base is crucial to the effectiveness of costing systems to produce and disseminate quality information for use in areas such as the NCCPP. Accordingly, the CCG has developed several companion documents that underpin the CCS. These documents include:

- The Common Chart of Accounts

The purpose of the CCoA is to provide a nationally consistent GL coding system for the recording of transactions by DHBs. Specifically, the CCoA allows common presentation, interpretation and use of financial information produced by DHBs. The CCoA also supports and provides a stable platform for the CCS and all cost reporting, comparative analysis and benchmarking.

- Full-time Equivalent Counting Specification

The purpose of the FTE Counting Specification is to set out the framework for measuring staff resources. Three separate measures have been developed for the framework, which are "Accrued” FTE, “Worked” FTE and “Contracted” FTE. Hours are the basic building 
block for all three FTE types and are converted to FTE units on the basis of a 40-hour working week for Accrued and Worked FTEs and the number of hours defined as "fulltime” (for example 37.5 hours, 40 hours) for Contracted FTEs. The Accrued FTE measure is the core measure for forecasting and reporting.

- The National Service Framework (NSF) Data Dictionary

The purpose of the NSF Data Dictionary is to provide a breakdown of all purchase unit (PU) costs, their unit of measure, data definitions, GL codes and output classes.

- The Common Counting Standards

The purpose of the Common Counting Standards is to outline how health activity should be defined, measured and counted to support the planning of health and disability services. The main objectives of the Common Counting Standards are to ensure consistency in measuring health sector activity; provide consistent data for comparing and benchmarking; to ensure that similar health activities can be meaningfully counted and compared across the health sector; consolidate the definitions for each set of counting rules within each visit type (i.e. inpatient, outpatient and diagnostic); and to identify the areas where there is a lack of definitional clarity.

- NSF Service Specification

The purpose of the NSF Service Specification is to outline how services should be provided to meet health needs. Whenever a DHB enters into a new service agreement, or when a DHB is varying or rolling over existing service agreements, the latest service specification and their PUs must be used. Each DHB must also comply with the quality requirements in the Service Specifications and include non-discretionary quality requirements in their agreements with funded service providers. Service Specifications tend to include (but are not limited to) a service definition; service objectives; service users and access criteria; service component descriptions; quality requirements; PU code(s) and reporting requirements.

- Operational Policy Framework

The Operational Policy Framework (OPF) is a set of business rules, policy and guideline principles that outline the operating functions of DHBs. The OPF comprises several sections that detail the requirements DHBs are expected to adhere to. The sections include DHB Governance; Planning and Accountability; Service Change; Service Planning and Policy; Improving Māori Health; IDFs; Dispute Resolution; Quality; Workforce; 
Information Technology; Financial and Capital Operations; and Monitoring and Reporting.

Though the linking documents are important components in the costing process, and assist DHB's in providing information to the NCCPP, these documents will not be discussed further as it is beyond the scope of this exploratory study.

\subsection{Chapter Summary}

As Chapter 5 has discussed, the $\mathrm{MOH}$ distributes funds to all twenty DHBs operating in the New Zealand public health sector through the CFA. To distribute funds to the DHBs, the $\mathrm{MOH}$ uses a mechanism called population-based funding. The Population-Based Funding approach aims to distribute funds fairly according to the relative needs of DHB populations and the costs of providing health services to meet those needs. This is achieved by distributing funds according to the demographic characteristics of each DHB population (Cost Weights) and certain unavoidable costs in providing services to rural and non-resident populations (Adjusters). Once the $\mathrm{MOH}$ has finalised populated-based funding, the twenty DHBs nationwide will use their individual funding packages to plan, purchase and provide health services that they are contracted to provide through the CFA. The PFU of each DHB will choose to provide health services through the DHB hospital (aka main Provider Arm) or purchase health services from multiple other providers (such as other DHB Provider Arms and Private Hospitals) based on local need and availability of resources. If a DHB decides to purchase health services from another DHB, they will do so via IDFs. To facilitate IDFs between DHBs, the NCCPP sets National Prices, which become the default prices. The main motivation for developing these prices is effective and efficient inter-DHB trading within the sector. To assist the NCCPP in setting National Prices for IDFs, the MOH has developed a set of DHB Costing Standards that serve as common standards for the costing of health services. The standards apply to all DHBs operating in the New Zealand public health sector, in particular the DHB's Provider Arms, and are very important to the efficiency of IDFs, as they determine the quality of information to be used by the NCCPP for National Pricing work. For an illustration of the overall process of DHB Funding, Purchasing and Costing in the New Zealand public health sector, which has been described in Chapter 5, refer to Figure 10. 
Figure 10: DHB Funding, Purchasing and Costing

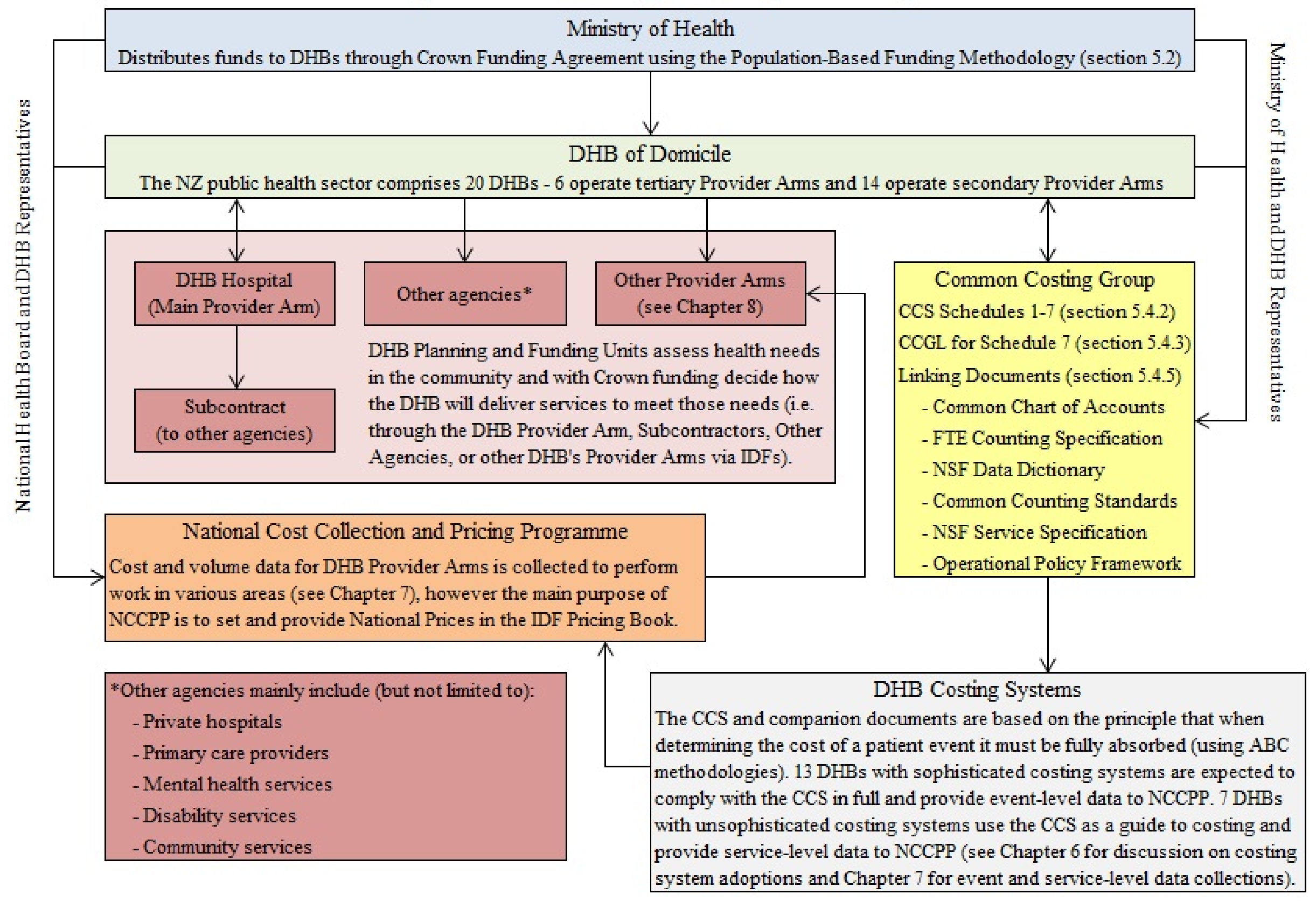




\section{Chapter 6 The Common Costing Standards and Costing Systems Adoption}

\subsection{Introduction}

As documented by the CCG (2012, p. 8), "DHBs are encouraged to implement and continue developing costing systems that adhere to the common costing principles described in [the CCS]”. The CCG also recommends that all cost reports be prepared using the same basic building blocks described in the Standards, as this practice benefits the wider good of the New Zealand public health sector (specifically DHBs). In particular, reporting information in consistent and comparable forms allows users (such as DHB PFAs and the NCCPP) to discern and analyse how costs are structured, differ by geographic region, change based on demographics and move between DHBs via IDFs.

Though the CCS have been developed thoroughly with clear purposive aims, their capacity to provide information for effective decision-making can be diminished (especially for those users aforementioned) by dissimilarities in the way DHBs utilise costing systems and apply the Standards. Expanding on the point above, not all DHBs that operate in the New Zealand public health sector have recognised or formal costing systems. Furthermore, costing system adoptions vary in sophistication. Results of this study indicate that DHBs tend to operate costing systems at one of three levels: (1) unsophisticated costing systems that are not formally recognised (section 6.2); (2) moderately sophisticated costing systems that are formally recognised (section 6.3); and (3) sophisticated costing systems that are formally recognised (section 6.4).

\subsection{Unsophisticated Costing Systems Not Formally Recognised}

Based on the findings gathered at the supplementary case site $(\mathrm{MOH})$, there are six secondary DHBs and one tertiary DHB that do not currently make use of formally recognised costing systems. Furthermore, five of the six secondary DHBs are relatively small in comparison to the rest of DHBs operating in the sector. Therefore, the conclusion can be drawn that smaller secondary health care providers tend not to institutionalise formally recognised costing systems. One secondary health care provider (DHB C), which was explored as part of this study, currently uses an "in-house cost allocation system, which is adequate for a small DHB” but they do not recognise this as a formal costing system. The DHB acknowledges that they use simple techniques and practices to provide service-level cost information to the NCCPP, but they do not have a sophisticated costing system to facilitate the provision of this information at a more detailed event-level. Furthermore, the secondary DHBs explored as 
part of this study (DHB C, DHB D, DHB E) note that they currently fulfil two of the four characteristics typified by Cooper (1988) as major qualities warranting use of more sophisticated costing systems, but they are not currently making use of such systems. The characteristics are (1) provision of numerous products and services; and (2) organisational operations are multi-faceted and complex.

The sixth secondary DHB (DHB E) does not make use of a formally recognised costing system because "they recently turned their sophisticated costing system off" (DHB E interviewee A). DHB E is one of the largest secondary DHBs operating in the New Zealand public health sector and acknowledges that they provide numerous products and services, and their operations are multi-faceted and complex. However, they do not believe the costs of running a sophisticated costing system are justified at their DHB (the costing system previously implemented was PowerPerformance Manager (PPM), which is discussed at section 6.4). The decision by DHB E to review their current institutions, which led them to turn off their sophisticated costing system, was largely motivated by a push from the MOH to manage their costs more effectively and reduce their overall deficit. This is reiterated by $\mathrm{MOH}$ Interviewee A, who stated "there was a lack of funding to support the use of that system and pay operational staff”.

While DHB E “turned a deficit into a surplus after disabling their costing system”, the longterm impact of their decision to revert to a more cost effective albeit unsophisticated costing approach is not yet clear. Specifically, how the decision will impact on the DHB's ability to plan and provide health services to meet the needs of its DHB population. Though DHB E "still has the benefit of access to other DHBs cost data through the data cube, they are flying blind about how their own costs stack up against other [DHBs]". ${ }^{16}$ For a large DHB to turn off their sophisticated costing system they need "a good understanding of how the sector functions and to trust the efficiency of National Price” (MOH Interviewee A). Trust has to be placed in the efficiency of National Price because the DHB is not contributing cost information to the NCCPP at an event-level to influence price setting for IDFs. This type of decision will always be based on internal analysis and requires considerable trust in a DHB's knowledge of the sector and their own cost structures.

\footnotetext{
${ }^{16}$ The National Event-level Cost Data Cube (also referred to as the "data cube") is a data bank managed by the MOH that stores event-level DHB's historical cost and volume data. The data stored in the data cube is available to all DHBs to use for various purposes, including cost comparisons and service planning.
} 


\subsection{Formally Recognised Moderately Sophisticated Costing Systems}

Aside from the six secondary DHBs discussed above, which do not make use of recognised or formal costing systems, the findings gathered at the supplementary case site (MOH) revealed that the remaining eight secondary DHBs make use of formal costing systems. Specifically, these DHBs tend to use an ABC-based costing system called CostPro. As DHB A Interviewee A stated, "The CostPro costing system is used by a number of small to medium sized DHBs very effectively and provides good value for money. The developers of CostPro are active in the health sector so have an in-depth knowledge of DHB systems”. While CostPro is not the most sophisticated costing system available, it is financially preferred by small DHBs. It only costs around \$20,000 per annum for software licensing and unlike other more sophisticated costing systems, it is not resource intensive to run (i.e. it does not consume numerous operational staff FTEs). Furthermore, “it provides a really wide breadth of information that allows [DHBs] to contribute event-level costing data to the NCCPP, perform individual product work and understand [their] billing processes in much greater detail” (DHB A Interviewee A).

\subsubsection{Main Case Study Results: CostPro Costing System Adoption and Use}

Discussions with DHB A Interviewee A (i.e. the main case site), identified their DHB implemented the CostPro Costing System in 2007 (which is still currently in use). "This costing system was chosen because [the DHB] already had the CostPro patient activity data mart, which holds patient information sourced from the Patient Management System” (DHB A Interviewee A). Therefore, the DHB could use both systems in tandem for costing purposes. The CostPro Costing Systems brings through all patient volumes from the Patient Management System and all unprocessed cost data from the Finance System (also referred to as the GL financials), which are used jointly to calculate unit costs at the end of every month. Using data from these information systems, CostPro can calculate costs by patient, procedure, department and health specialty group.

According to DHB A Interviewee B, “The system has primarily been used for NCCPP data collections, which are run by the NHB every November" (the NCCPP and its related functions are discussed in greater detail in section 7). Though this is the main driver behind the adoption of CostPro at the DHB, it is not the sole motivation driving ongoing use of the costing system. Over time DHB A has broadened its foci for collecting cost information beyond the NCCPP national data submission to consider various strategic emphases 
associated with planning and funding the provision of health services, both to their own DHB population and across regional boundaries. This is due to two main events. Firstly, DHB A "has got used to [their] own data" and secondly, they "are starting to gain access to the national data set”, which stores all DHBs submitted cost and volume data (DHB A Interviewee B). These two events have given the DHB greater opportunities to compare and analyse cost information to make decisions associated with planning and funding of health services. Specifically, the DHB has started exploring their costs and volumes to make decisions associated with product and service mix - the goal of which is to maximise utilisation of their constrained capacity.

To illustrate the types of capacity decisions now being made, DHB A Interviewee A discussed a hypothetical situation whereby the DHB was evaluating the potential to take on hip replacement volumes for another DHB in the region. In this instance, if the DHB took on the volumes and their staffing mix remained constant, they could calculate the marginal cost of performing each additional hip replacement. To elaborate, the average price of a hip replacement in the sector is approximately $\$ 6,500$ plus any additional costs associated with clinical supplies and infrastructure such as electricity. As the orthopaedic surgeon who will be performing the procedures is already employed (and their salary remains constant) the only additional costs are the marginal components. The CostPro Costing System, with its emphasis on $\mathrm{ABC}$, is able to break down the patient event into specific detailed activities and show the disaggregated cost of the DRG event (including the marginal costs of taking on each additional volume). This level of detail is vital for the types of decisions described above, as it highlights (1) whether or not the DHB can take additional volumes given its spare capacity; and (2) whether or not it is cost-effective to actually take on the volumes. ${ }^{17}$

DHB A Interviewee A indicates their costing system works by allocating financials through Departments to Cost Pools, which are then applied to patient activity volumes to get a cost per unit. The next section expands on the process of costing that has been institutionalised at DHB A, and an illustration of how costs and volumes flow through the CostPro Costing System at the DHB is provided below (see Figure 11).

\footnotetext{
${ }^{17}$ An interesting element that emerges from this example is the capacity to which the orthopedic surgeon can actually work at and if the volumes are taken on whether or not this will require an additional surgeon. Moreover, orthopedic surgeons will not all work to the same level of efficiency, therefore it is difficult to ascertain to what capacity a surgeon can actually be gauged before another surgeon is required. While this is an intriguing research avenue, it is beyond the scope of this study and as such cannot be explored more thoroughly.
} 
Figure 11: DHB Costing Flow Chart

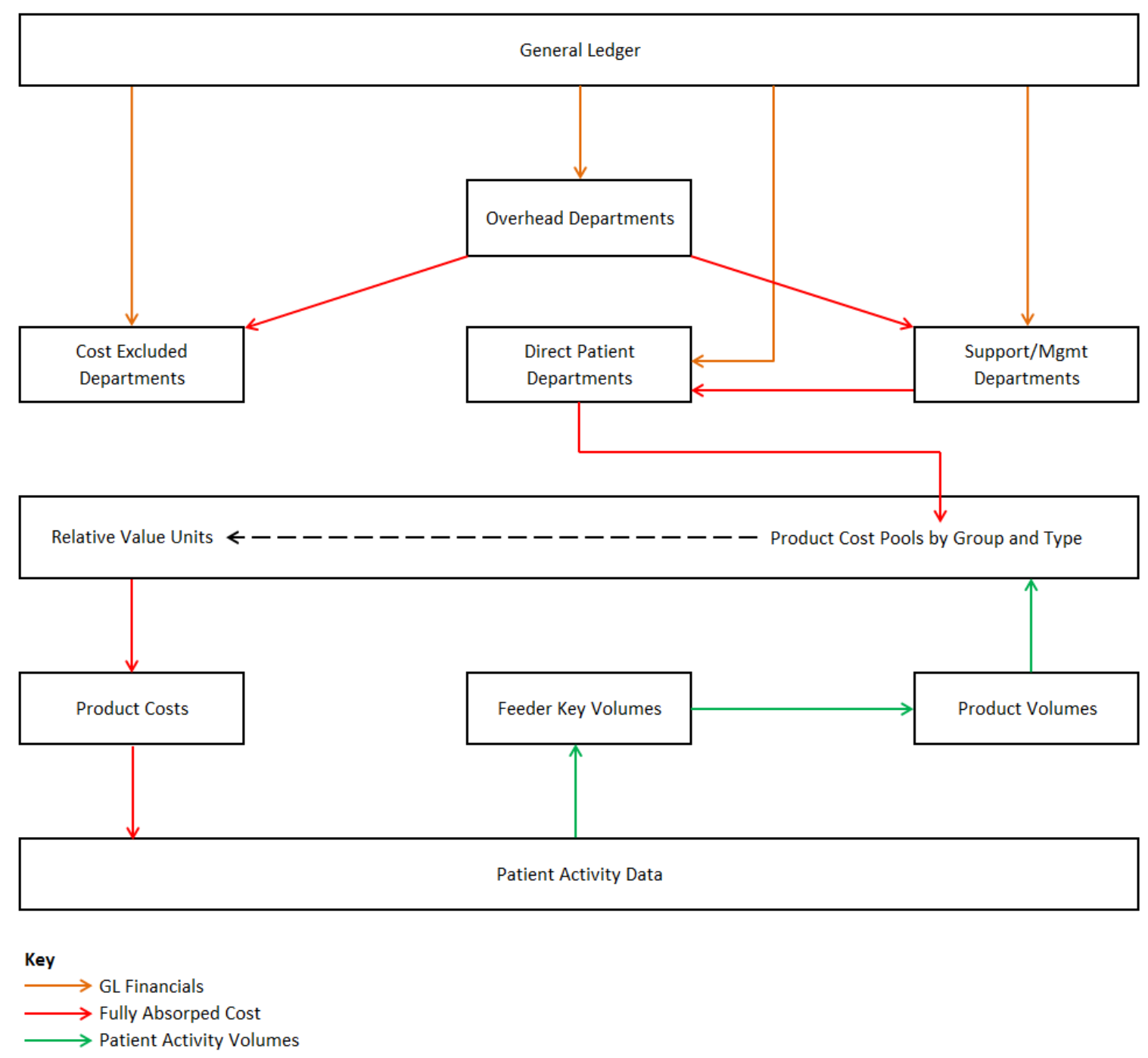

\subsubsection{Overhead Allocation}

The first step involved in costing patient events at DHB A is allocation of overhead department costs. Overhead costs are grouped into overhead departments and allocated to Direct Patient Departments, Support/Management Departments and Cost Excluded Departments using the allocation bases outlined in the CCS. With reference to the Overhead Allocation Methodology (Schedule 4, section 5.4.2.4), the DHB uses a mix of preferred and alternate cost drivers to allocate overhead. The DHB applies area occupied in square metres for infrastructure (e.g. Maternity ward) and number of PCs for IT systems, which are the preferred allocation bases prescribed in the Standards. For all other areas within the DHB, including Management, Administration, Governance, and Planning and Funding, the DHB applies the alternate cost driver FTEs (which is also labelled as the default). Though the DHB acknowledges they do not use a variety of overhead allocation bases, particularly more 
sophisticated bases, they note that their current costing system has functionality to distinguish overhead departments. Specifically, the costing system can distinguish costs that can be included in costing patient events from costs that should be excluded. "There are some overhead departments that create overhead costs that are not assigned to patient events and are dead-ended” (DHB A Interviewee A), as they do not relate to patient events nor do they have any impact on the Provider Arms. Consistent with the overhead methodology prescribed by the CCG, “[DHB A's] current costing system filters overhead costs to Overhead Departments, which are then allocated to Direct Patient Departments, Support/Management Departments or Cost Excluded Departments" (DHB A Interviewee A) (refer to Figure 11 for full illustration of the DHB's costing processes).

Though the DHB is costing at an event-level, they recognise that their ability to allocate overheads to patient events is inhibited by the limitations of their current costing system. Specifically, there is an inability to understand the true drivers of overhead costs. As DHB A Interviewee A stated, "You need $80 \%$ of your costs to have true drivers for [the costing system] to be a pure ABC system. We would probably be under 50\%”. This is clearly a disadvantage of CostPro, as inaccurate overhead allocations are an impediment to the usefulness of costing information for cost comparisons, benchmarking and price setting. However, the weaknesses of the current costing system used by DHB A exemplifies both the complex nature of public health sector organisations and the level of detail DHBs can go down to when allocating overheads to patient events.

Once overhead costs are allocated to the appropriate departments (Direct Patient, Support/Management and Cost Excluded) the next stage of the costing process institutionalised at DHB A is to cost Direct Patient Departments, which will form the cost basis of patient events. The process of costing Direct Patient Departments is described by the DHB as Product Mapping.

\subsubsection{Product Mapping}

When costing a direct department (i.e. a department that is not an overhead, but may include allocated overhead) the DHB evaluates what products can be captured from the department by assessing feeder keys. Feeder keys (which are an institutionalised costing process that is specific to DHB A) are the code combinations that are created for all different types of activity, such as ED Triage 1 through to ED Triage 5. Activity is captured from the Patient Management System by mapping the feeder key to a product created in the costing system 
under each specific department. If a product mapping has changed for a feeder key it will need to be recast. This can be performed in CostPro simply by accessing the Data Warehouse and entering the feeder keys that require changes. When a feeder key is remapped, a fiscal year for the change to occur must also be entered in the Data Warehouse. Once this is done the final step is to run the stored procedure "Recast Patient Utilisation", which will extract the records with those feeder keys and recast them with their new products.

A product will have a unit of measure (i.e. Minutes, Bed Days, Visits, Lab Test), which is necessary to determine the relativity between each product within a department. Once the process of mapping products to departments is complete the next step is cost type mapping.

\subsubsection{Cost Type Mapping}

The purpose of cost type mapping is to create and map the cost types required to accurately cost products. This is done by classifying costs into cost types based on the GL account they come from and then mapping these through to cost type groups, which are disclosed in Schedule 7 (section 5.4.2.7). Many account combinations will map to the same department and cost type and a few of these will need to be split so that a portion is allocated to multiple departments and cost types. The DHB's CostPro Costing System makes this process very easy, as it provides a list of similar account combinations and shows what departments and cost types these were mapped to. The DHB's costing system also simplifies the process of setting up defaults, as it will suggest cost types when new account combinations are added at each GL update. Once product and cost types have been created, relative value units (RVU) are required to cost products correctly.

\subsubsection{Relative Value Unit Allocation}

A RVU is a relativity weighting given to show how costs from the Cost Pools should be allocated to the products. For example, when applying RVUs to doctors costs across ED products, it is assumed triage 1 cases require 100, triage 2 require 90, triage 3 require 40, triage 4 require 20 and triage 5 require 10 units of a Senior Doctors time in comparison to each other. The RVU assignments are based on the rationale that triage 1 events have the highest severity and triage 5 events have the lowest severity, thus triage 1 events require more Senior Doctors time than triage 5 events. Total doctors costs pushed down to the ED are subsequently allocated to each individual type of triage event based on the RVU assignments (i.e. if an RVU of 100 units has a cost of $\$ 10.00$ then triage 1 events will get a unit cost of 
$\$ 10.00$, triage 2 events will get a unit cost of $\$ 9.00$, triage 3 events will get a unit cost of $\$ 4.00$, and so on and so forth).

\subsubsection{Costing Calculation}

To determine product cost per volume the DHB uses a relatively basic costing calculation. To demonstrate the process used by the DHB to cost products a hypothetical costing example has been set out below for Doctors costs associated with IT Systems (see Table 4). Firstly, the DHB takes the value of the GL account (A in Table 4) and divides it by the total adjusted volume for the department/cost type (B in Table 4). To calculate the cost per volume the DHB then multiplies the result by the products RVU (C for RVU and D for final cost per volume, in Table 4). Therefore, for example, the calculation for Doctors Theatre Minutes would be $(\$ 25,272 / 19,678,130) \times 10=\$ 0.0128$.

Table 4: Costing Calculation Example for Doctors Costs Associated with IT Systems

\begin{tabular}{|c|c|c|}
\hline \multicolumn{2}{|l|}{ Cost Types: } & IT Systems \\
\hline \multicolumn{2}{|l|}{ GL Amount: (A) } & $\$ 25,272$ \\
\hline Volumes: & $\underline{\text { Product Codes }}$ & \\
\hline Doctors Inpatient Visits & DOC_INP & 32,198 \\
\hline Doctors Outpatient Clinic Mins & DOC_OUTP & 479,089 \\
\hline Doctors Theatre Mins & DOC_THT & 208,566 \\
\hline \multicolumn{3}{|l|}{ RVUs: (C) } \\
\hline Doctors Inpatient Visits & DOC_INP & 100 \\
\hline Doctors Outpatient Clinic Mins & DOC_OUTP & 30 \\
\hline Doctors Theatre Mins & DOC_THT & 10 \\
\hline \multicolumn{3}{|l|}{ RVU x Volumes: } \\
\hline Doctors Inpatient Visits & DOC_INP & $3,219,800$ \\
\hline Doctors Outpatient Clinic Mins & DOC_OUTP & $14,372,670$ \\
\hline Doctors Theatre Mins & DOC_THT & $2,085,660$ \\
\hline RVU x Volumes Total: (B) & & $\underline{19,678,130}$ \\
\hline \multicolumn{3}{|l|}{ Cost Per Volume: (D) } \\
\hline Doctors Inpatient Visits & DOC_INP & $\$ 0.1284$ \\
\hline Doctors Outpatient Clinic Mins & DOC_OUTP & $\$ 0.0385$ \\
\hline Doctors Theatre Mins & DOC_THT & $\$ 0.0128$ \\
\hline
\end{tabular}

Once the unit cost (or cost per volume) of each product consumed by a patient event is determined, the DHB can then calculate the cost of a single patient event using DRGs and Caseweights (these are discussed further in section 7.3). 


\subsubsection{CostPro Costing System Volume Data}

To expand on the example used in section 6.3.1.4, there are several feeder keys for ED products. The ED products include ED Attendance Triage 1 Medical; ED Attendance Triage 1 Surgical; ED Attendance Triage 2 Medical; ED Attendance Triage 2 Surgical; ED Attendance Triage 3; ED Attendance Triage 4 and ED Attendance Triage 5. The CostPro Costing System gives DHB A's PFA access to the volumes that come through for each triage level every month from the Patient Management System via the Data Warehouse tab. As an example, the costing system indicates that the DHB had 316 people admitted as triage 5 in July 2012 and 204 in August 2012. This information is very useful as it facilitates decisionmaking associated with the planning and funding of services. Specifically, the DHB is able to analyse patient volumes year-on-year and forecast future volumes by using volume data from prior periods, which is collected by the $\mathrm{MOH}$ and stored in a data cube.

While the CostPro Costing System is able to facilitate decisions associated with product and service mix to a certain extent, it will not always provide the most valuable information for decision-making. This is largely because CostPro is not the most advanced costing system available, and as such it cannot go down to the same level of detail as more sophisticated costing systems. As an example, using their current costing system, DHB A has identified 10 different products in ED, meaning they have identified and manage 10 groups of patients with different cost profiles. This is in stark contrast to another secondary health care provider that has identified and manages roughly 40 groups of patients with different cost profiles in their ED (DHB A Interviewee A). Though the second DHB has more patient volumes, which justifies the need for a more sophisticated costing system (such as PPM) to facilitate clearer patient differentiation, the DHB also has 3 staff solely devoted to costing and has been labelled a costing "flagship” within the sector. The adoption and use of more sophisticated costing systems is discussed next.

\subsection{Formally Recognised Sophisticated Costing Systems}

Findings gathered at the supplementary case site (MOH) and DHB B indicate that larger tertiary DHBs tend to institutionalise more sophisticated formally recognised costing systems. Of the six tertiary DHBs operating in the New Zealand public health sector, five currently have and make use of sophisticated costing systems (one tertiary DHB based in the South Island uses an unsophisticated costing system to provide service-level data). Specifically, tertiary DHBs tend to institutionalise a costing system called PPM. PPM is a 
sophisticated costing system developed specifically for use in the health sector that focuses on the activity-based environment of health care. The main advantages of PPM include:

(1) PPM has inbuilt flexibility to allow costing to any level, depending on how much data is available from external feeder systems;

(2) PPM allows the use of weights to create patient level activity data for areas without a feeder system, based on any coding classification system;

(3) Costs can be assigned down to the service and patient level based on duration, standard cost or actual charge. In addition, costs can be spread across all services equally, or unequally using user-defined/industry-specific RVUs;

(4) Costing can be performed at the fine-grained activity level (e.g. chest X-ray) and results can then be consolidated up to patient, DRG, service, or divisional level;

(5) Adverse events can be quantified by comparing them to similar DRG encounters without adverse events;

(6) The cost of delivery for each patient encounter can be determined, and gains and losses can be measured against National Price;

(7) The GL can be repurposed for Patient Costing, enabling users to easily move amounts between cost centres, create dummy cost centres and account codes, offset revenue against expenditure, and define how corporate overheads should be treated; and

(8) PPM has a built-in reconciliation and audit-reporting tool that allows DHBs to reconcile each process performed back to the original GL. The convenience of this tool is in the fact that DHBs can present accurate and consistent costing results and volumes in line with Schedule 7 of the CCS and the NCCPP national data request.

One tertiary DHB (DHB B) currently using PPM stated that the costing system is "very good" as it enables them to "identify opportunities for cost savings and improved clinical resource efficiency”. DHB B identified several main motivations that drive the use of the current costing system in their large tertiary DHB setting. Drivers of 'Highest Motivation' are to identify value-add and non-value add activities to reduce product and service costs; provide data to NCCPP (to influence National Price); to make and/or support IDF decisions; and to support funding decisions in non-standard services. Drivers of 'High Motivation' are to measure performance for the purpose of performance appraisal. Drivers of 'Moderate Motivation’ are to evaluate business cases for new/changed services. 
To indicate the extent to which their current costing system uses ABC, DHB B stated that implementation is complete and $\mathrm{ABC}$ information is commonly used by their DHB for cost management and decision-making purposes. "ABC is considered a normal part of the information system” (DHB B Interviewee A). The DHB also provided additional commentary stating, "Clinical costing systems in use in New Zealand are not pure ABC but actually cost at a fine, more targeted grain than $\mathrm{ABC}$ (i.e. a nurse is a nurse in $\mathrm{ABC}$ but in clinical costing a theatre nurse is not the same as a ward nurse or a clinic nurse)" (DHB B Interviewee A). This comment highlights the complex nature of ABC adoptions in the public health sector, and reaffirms the DHB's own admission that they fulfil two of the four characteristics typified by Cooper (1988) as major qualities warranting the adoption of more sophisticated costing systems, that make use of ABC. These characteristics are (1) the provision of numerous products and services; and (2) organisational operations are multifaceted and complex.

\subsection{Chapter Summary}

As Chapter 6 has discussed, DHBs are encouraged to adopt and use costing systems that adhere to the common costing principles described in the CCS (i.e. sophisticated costing systems). However, they tend to operate costing systems at one of three levels: (1) six secondary DHBs and one tertiary DHB currently use unsophisticated costing systems that are not formally recognised. Furthermore, five of the six secondary DHBs are relatively small in comparison to the rest of DHBs operating in the sector. Thus, the conclusion can be drawn that smaller secondary health care providers tend not to institutionalise formally recognised costing systems; (2) eight secondary DHBs currently use moderately sophisticated costing systems that are formally recognised. Specifically, these DHBs have tended to institutionalise an ABC-based costing system called CostPro, which is the preferred option for secondary DHBs because it is affordable and provides a wide breadth of information that enables them to contribute event-level costing data to the NCCPP, perform individual product work and understand their billing processes; and (3) five tertiary DHBs currently use sophisticated costing systems that are formally recognised (one tertiary DHB based in the South Island uses an unsophisticated costing system to provide service-level data). Specifically, tertiary DHBs have tended to institutionalise a costing system called PPM, which is described as "very good” because it allows DHBs to identify opportunities for cost savings and improved clinical resource efficiency, provide data to the NCCPP, make and/or support IDF decisions, measure performance for the purpose of performance appraisal, and evaluate business cases. 


\section{Chapter 7 National Cost Collection and Pricing Programme Data Submission}

\subsection{Introduction}

The NCCPP is a series of work programmes performed conjointly by DHB representatives and the MOH NHB on an annual basis. When the NCCPP was originally established its main purpose was to work out National Price for IDFs. Since such time its role has expanded beyond this main purpose to include:

- $\quad$ Updating the price book for IDF prices (refer to Chapter 8)

- $\quad$ Setting the tertiary adjuster pool (refer to Chapter 8)

- Developing casemix caseweights (refer to section 7.3.1 and Chapter 8)

- Populating the National Event-level Cost Data Cube

- Reviewing priority areas in non-casemix pricing

- $\quad$ Supporting work on pricing mental health and elective services

- $\quad$ Supporting the Common Costing Standards (refer to section 5.4)

- $\quad$ Producing key pricing information for DHB comparisons by the NCCPP

- Contributing to the strategic review of pricing in the $\mathrm{MOH}$

- $\quad$ Supporting service planning

- Re-producing data to allow DHBs and other key groups to undertake further analysis (predominantly benchmarking and productivity evaluations)

To run the work programmes outlined above, the NCCPP has requested that all DHBs provide cost, revenue and volume information from their Provider Arms every November. ${ }^{18}$ As per the OPF, which is a set of business rules, policies and guiding principles to be used in the public health sector, all DHBs are required to provide information in line with the NCCPP data request at either service-level or event-level (section 5.4.5). According to $\mathrm{MOH}$ interviewee $\mathrm{A}$, there are 7 DHBs in the New Zealand public health sector with unsophisticated costing systems, and they provide data at the service-level (discussed at section 7.2). There are also 13 DHBs in the New Zealand public health sector that have adopted and currently maintain sophisticated costing systems, and they provide data at the event-level (discussed at section 7.3).

\footnotetext{
${ }^{18}$ Currently data collection is carried out annually but the NCCPP is considering collecting more frequently to facilitate requests made by DHBs to have greater access to event-level costing data throughout the year. Collecting data more frequently will require a year-to-date collection rather than a year-end collection (with cost data reconciliations with DHB annual accounts continuing to occur at year-end). According to a representative of the NCCPP, fulfilling this request will require a significant change to how cost information is collected to ensure the process is effective and efficient for DHBs, the CCG and the NCCPP.
} 


\section{2 Costing Systems and the NCCPP Data Request}

As stated above, the NCCPP requires DHBs to provide information on costs incurred, revenues received and volumes delivered by their Provider Arms every financial year as at 31 March. There are seven major files that DHBs may need to submit to the NCCPP annually depending on the costing system they use, which are summarised in Table 5:

Table 5: Summary of File Submission Requirements for Service and Event-Level DHBs

\begin{tabular}{|c|c|c|}
\hline File Type & File Description & Relevant DHBs \\
\hline $\begin{array}{l}\text { Reconciliation } \\
\text { Template }\end{array}$ & $\begin{array}{l}\text { Contains a Compliance Statement, High } \\
\text { Level Summary, Financial Reconciliation, } \\
\text { Volume Reconciliation MSG Mapping and } \\
\text { Outlier Events }\end{array}$ & All \\
\hline Activity File & $\begin{array}{l}\text { All activity } \\
\text { (i.e. all event, PU and MSG level activity) }\end{array}$ & All \\
\hline Event Cost File & Event-level costs only & Event-level DHBs \\
\hline $\begin{array}{l}\text { Non-event Cost File } \\
\text { (Summary File) }\end{array}$ & $\begin{array}{l}\text { PU and/or MSG costs broken down to CS2 } \\
\text { and CS7 cost codes } \\
\text { Mental Health PU level costs broken down to } \\
\text { CS2 cost codes }\end{array}$ & 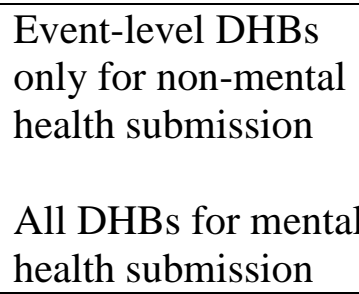 \\
\hline CS2 Cost File & $\begin{array}{l}\text { Costs broken down by MSG and CS2 cost } \\
\text { code }\end{array}$ & Service-level DHBs \\
\hline CS7 Cost File & $\begin{array}{l}\text { Costs broken down by MSG and CS7 cost } \\
\text { code }\end{array}$ & Service-level DHBs \\
\hline $\begin{array}{l}\text { Supplementary } \\
\text { Casemix File }\end{array}$ & $\begin{array}{l}\text { Casemix data request for specific costs } \\
\text { E.g. the } 2012 \text { data request was for additional } \\
\text { information and confirmation of costs for } \\
\text { patients receiving cardiac defibrillators }\end{array}$ & Event-level DHBs \\
\hline
\end{tabular}

\subsubsection{Common File Submission Requirements}

Of the seven major file requests outlined above, there are three that all DHBs need to submit irrespective of their costing system. The files are the Reconciliation Template, an Activity File and Non-Event (summary level) Mental Health Data:

\section{1) The Reconciliation Template}

The purpose of the Reconciliation Template is to ensure all DHB's cost and volume data is prepared in accordance with the CCS and that this data is collated accurately at summary level. The template is highly detailed and comprises several individual components:

(1) A Compliance Statement, which should include a disclosure statement and declaration of areas of non-compliance with the CCS (particularly Schedule 7, section 5.4.2.7) and the NCCPP data request; 
(2) High-level summary checks, the purpose of which are to pre-detect and correct errors prior to data submission. The summary checks should include a comparison of derived revenue to costs, a comparison of current year total costs to the previous year, a comparison of reconciled volume to raw file volume and NCCPP volume submissions versus national data collection alerts;

(3) A financial reconciliation of submitted costs to DHBs' audited annual costs, which illustrates cost and revenue items that are not related to provision of Provider Arm health services; and

(4) A volume reconciliation, which is used for quality assurance purposes and does not replace the need to provide a full Activity File. The volume reconciliation should include summarised activity file data by agency, code, MSG and PU, and it should reconcile to the Activity File provided in accordance with the NCCPP data request.

Along with the common requirements aforementioned, event-level DHBs must provide a file for Outlier Events. This file is intended to provide event-level DHBs an opportunity to check and identify extreme high/low cost per caseweight events prior to submission. Specifically, the file should include the top twenty and bottom twenty Cost per Caseweight Inpatient events. As the information provided by event-level DHBs is used to inform National Prices for IDFs (refer to Chapter 8 for discussion on National Price and IDFs), this file is of high importance as it allows the NCCPP to assess and remove outlier events from the data used for pricing work that may potentially reduce the efficiency of National Prices.

\section{2) Activity Data Files}

All DHBs are required to submit a file for activities provided by or through their respective Provider Arms. In addition, the request covers only those services provided by the Provider Arm and should not include other services funded by the DHB Funder Arm but not undertaken by the DHB's Provider Arm. Specifically, services provided by non-government organisations and other primary providers. The activity file submission should be provided on the basis of funder, agency, facility, MSG, PU, patient management system unique identifier (PMSUID) and total units. Furthermore it should include all activities that correspond to a Cost Groups (Schedule 2, section 5.4.2.2) cost file, an Intermediate Products (Schedule 7, section 5.4.2.7) cost file and a non-event cost file for mental health services. 


\section{3) Non-Event (summary level) Mental Health Data}

In accordance with the non-event (summary level) cost file specifications, all DHBs are required to provide a cost file for all mental health services, broken down by PU. This file should be provided on the basis of PU by funder, agency, facility, MSG, PU, cost and Cost Groups (Schedule 2, section 5.4.2.2) cost code.

Whether or not DHB's need to adhere to the remaining four file submissions (which include an Event Cost File, CS2 Cost File, CS7 Cost File and Supplementary Casemix File) is contingent on the sophistication of their respective costing systems. "DHB CEO's collectively agreed in October 2008 that all medium and large DHBs should have event-level costing systems” (MOH Interviewee B). Though the NCCPP accepts that small DHBs may not find it cost-effective to maintain event-level costing systems, the NCCPP believes all DHBs should have local or regional costing systems and contribute cost information at an event-level. The purpose is "to further improve the accuracy of prices and adjusters, as well as the overall value of the National Cost Collection" (refer to Chapter 8 for discussion on National Price and adjusters). Notwithstanding this belief, only 13 of the 20 DHBs nationwide have adopted and currently maintain sophisticated event-level costing systems. As $\mathrm{MOH}$ interviewee A stated, "[those] DHBs with unsophisticated costing systems cannot justify the costs of running a more sophisticated costing system”. Specifically, the DHBs (which are typically small DHBs) believe the operational costs and high level of system support required to adopt and use more sophisticated costing systems, such as ABC, are not sufficiently offset by potential information benefits of running these systems.

All DHBs with unsophisticated costing systems are expected to submit files in accordance with the requirements of a service-level DHB. Service-Level Costing and NCCPP file submissions are explored below. All DHBs with sophisticated costing systems are expected to submit files in accordance with the requirements of an event-level DHB. Event-Level Costing and NCCPP file submissions are explored at section 7.4.

\subsection{Service-Level Costing and the NCCPP}

As indicated at Chapter 6, DHBs with unsophisticated costing systems have very limited means to access information about their costs. In many instances these DHBs can identify where their direct costs originate, but they are severely disadvantaged when it comes to understanding, monitoring and controlling their indirect costs (section 5.4.2.2). Specifically, there is an inability to ascertain what drives the incurrence of indirect costs and where/how 
they should be allocated. For DHBs in this situation, Schedule 4 (section 5.4.2.4) offers alternate cost drivers (typically FTE or Total Cost, as all DHBs should have access to this information) to allocate overhead. Using FTE or Total Cost to allocate overhead makes it virtually impossible to cost down to a patient level, as there is not the depth of knowledge to accurately trace causal relationships between indirect costs and individual patient events (which utilise activities from multiple services both directly and indirectly). With consideration for this lack of understanding for how indirect costs are incurred, the CCG and the NCCPP requires all DHBs with unsophisticated costing systems to cost at service-level.

DHBs that make use of unsophisticated costing systems, and thus cost down to service-level, are required to allocate all costs of health care (i.e. direct patient care, clinical support and overhead) to activity reported in a MSG, with the exception of mental health services, where DHBs are required to allocate all costs of health care down to PU level. According to $\mathrm{MOH}$ interviewee B, MSG’s include “ED, Maternity, Neonatal, Community, Surgical, Disability Support, Health of Older People or any other palliative services”. To allocate direct patient care and clinical support costs at the MSG is relatively straightforward, as these costs are directly associated with the delivery of a specific service. However, to allocate overhead is more difficult as these costs generally cannot be directly associated with the provision of a specific service. To allocate overhead, service-level DHBs tend to use a single arbitrary DHB-wide overhead allocation rate based on FTEs or total cost. Though allocating indirect costs using FTEs or total cost is the most suitable approach for DHBs that have unsophisticated costing systems, this can impact on the quality of cost information for decision-making. Specifically, service planning can be less effective as DHBs with an unsophisticated costing system do not have an accurate understanding of the costs associated with service provision, and cost comparisons between DHBs with unsophisticated and sophisticated costing systems is severely limited as service costs for DHBs with an unsophisticated costing system can often be inconsistent, incomparable or incomplete.

\subsubsection{Service-Level File Submissions}

The NCCPP requires all DHBs with unsophisticated costing systems to submit five major files for activity and cost data. Three of the file submissions include a Reconciliation Template, an Activity File and Non-Event (summary level) Mental Health Data (section 7.1.1). Service-level DHBs are also required to submit two cost files, the purpose of which is to provide the NCCPP with high-level summary data to construct a sector wide view of DHB 
Provider Arm costs and volumes. The first file is a Cost Groups (Schedule 2, section 5.4.2.2) cost file and the second is an Intermediate Products (Schedule 7, section 5.4.2.7) cost file for all non-mental health services. Both these cost file submissions should be provided on the basis of MSG by funder, agency, facility, cost and Cost Groups (Schedule 2, section 5.4.2.2) cost code.

\subsection{Event-Level Costing and the NCCPP}

Unlike service-level DHBs, in which many of the CCS are offered as a guideline to costing, event-level DHBs are expected to follow the Standards and ABC methodologies specified therein rigorously. To use the CCS congruously with their respective costing systems, eventlevel DHBs should apply the principle of full absorption to determine the cost of a patient event. This means that any cost that is caused by the delivery of health care, whether it is direct or indirect in nature, should be allocated to activities associated with a patient event in order to have a complete cost for the event. As MOH Interviewee B stated, "it is imperative that all event-level DHB's co-operate with the NCCPP's data requests thoroughly to ensure smooth running of the New Zealand public health sector in various crucial functions”. Eventlevel costing data contributes substantially to the development of casemix caseweights, benchmarking, cost and volume comparisons, pricing work, service planning and funding. Thus, significant regulatory and political pressures are placed on DHBs to adopt and use sophisticated costing systems, as the information they provide to the NCCPP is essential to the functionality of the New Zealand public health sector as an efficient and effective means to deliver sustained high quality health services.

While the CCS are not mandated, and as such, event-level DHBs are not obliged to follow them precisely as they are set out, this does not raise concerns over inconsistent applications. As MOH Interviewee B stated, “we are comfortable that those DHBs costing at the eventlevel are allocating costs in a very consistent manner. This is because all DHBs are actively involved in the CCG and as a member of the Group they all strive to reduce discrepancy”. That is, there is sufficient cultural-cognitive/political pressure on DHBs to apply the CCS appropriately. Furthermore, the Group has been working together for a number of years (the CCG was established in 2005) and "members are constantly reviewing information of DHBs within the Group to ensure each member's information is consistent with their own” (MOH Interviewee B). If there are inconsistencies between DHBs that have a similar demographic or hospital structure, the Group will consult the CCS to ascertain how they were applied and 
why there are such inconsistencies. Often the Standards are applied dissimilarly because they "were not described well enough to accommodate some scenarios or the description may not be clear enough, which creates opportunities for misinterpretation” (MOH Interviewee B). To mitigate misinterpretation of the CCS "the CCG and NCCPP constantly offer training sessions and forums to provide better visibility for how to cost, how costs are derived and how costing information impacts on National Pricing work”. This can be viewed as a direct response to normative/social pressures, as the $\mathrm{MOH}$ seeks to align perceptions of $\mathrm{DHB}$ practices and characteristics with social and cultural values (in order to gain or retain organisational legitimacy). In addition, significant regulatory pressures are placed on DHBs, as the $\mathrm{MOH}$ has the authority to withhold funding, to impose a management regime, and in extreme cases, replace a Board if it finds a DHB under-performing. In practice, these powers are rarely used, as they are seen as drastic measures and are likely to produce unwanted effects, such as running a DHB into deficit and reduced public confidence in the New Zealand public health sector (which can have the effect of reduced organisational legitimacy).

\subsubsection{Event-Level File Submissions}

The NCCPP requires all DHBs with sophisticated costing systems to submit six major files for activity and cost data. Three of the file submissions include a Reconciliation Template, an Activity File and Non-Event (summary level) Mental Health Data (section 7.1.1). Event-level DHBs are also required to submit two cost files plus one supplementary casemix file.

The two cost files event-level DHBs submit to the NCCPP provide the costs associated with their Provider Arms. The first file is an event-level cost file to capture cost data for any activity performed at patient event-level. This cost file should be provided at event-level by cost, Cost Groups (Schedule 2, section 5.4.2.2) cost code, Intermediate Products (Schedule 7, section 5.4.2.7) cost code and PMSUID. Where activity is not costed at patient event-level, DHBs are required to provide cost information by PU. If PU cost information is not available, event-level DHBs are required to provide this information by MSG. The second cost file event-level DHBs are required to submit is a non-event (summary level) cost file to capture costs at the MSG and PU level. This file should be provided on the basis of MSG and PU by funder, agency, facility, cost, Cost Groups (Schedule 2, section 5.4.2.2) cost code and Intermediate Products (Schedule 7, section 5.4.2.7) cost code.

In addition to the core data request, event-level DHBs are required to provide casemixspecific data. This data is requested by "The Casemix Cost Weights Group (CCWG), a work 
stream operating under the NCCPP responsible for reviewing the caseweights used for casemix funding” (NCCPP, 2012, p. 48). ${ }^{19}$ Caseweights reflect the costs of treatment for individual DRGs and allow comparisons across DRGs as well as a means of aggregating volumes. The CCWG use data provided by event-level DHBs to perform work in various areas associated with caseweights. Some of these areas include reviewing the level of weighted inlier equivalent separation (WIES) weights for DRGs and assessing the adequacy of cost weights for DRGs. ${ }^{20}$

\subsection{Chapter Summary}

As Chapter 7 has discussed, the NCCPP requests cost, revenue and volume information from DHBs for their Provider Arms every November. The purpose is to run various work programmes, such as updating the price book for IDF prices; setting the tertiary adjuster pool; developing casemix caseweights; supporting service planning and populating the National Event-level Cost Data Cube. As per the OPF, all DHBs are required to provide information in line with the NCCPP data request at either service-level or event-level. There are 7 DHBs in the New Zealand public health sector with unsophisticated costing systems, and they provide data at service-level. Specifically, they submit five major files for activity and cost data, including a Reconciliation Template, an Activity File, Non-Event (summary level) Mental Health Data, a Cost Groups cost file and an Intermediate Products cost file for all non-mental health services. There are also 13 DHBs in the New Zealand public health sector that have adopted and currently maintain sophisticated costing systems, and they provide data at eventlevel. Specifically, they submit six major files for activity and cost data, including a Reconciliation Template, an Activity File, Non-Event (summary level) Mental Health Data, an event-level cost file to capture cost data for any activity performed at patient event-level, a non-event (summary level) cost file to capture costs at the MSG and PU level, and casemixspecific data.

\footnotetext{
${ }^{19}$ Casemix focuses on the demographic characteristics of the population served by a health care system. Typically the characteristics considered include age, gender, ethnicity, deprivation and health status.

${ }^{20}$ WIES provide a relative measure of resource use for each event within a DRG. A patient's WIES is determined according to their DRG, length of stay, copayments for mechanical ventilation and copayments for certain conditions such as scoliosis. Per Penno et al. (2012, p. 43), a DRG "is a system which classifies patients into clinically meaningful groups according to the severity of their illnesses and the intensity of resources required to treat them".
} 


\section{Chapter 8 Inter-District Flows and the NCCPP}

\subsection{Introduction}

When a DHB wants to purchase services from another DHB's Provider Arm to treat patients in their own geographic region they do so through IDFs. To facilitate IDFs between DHBs operating in the New Zealand public health sector, the NCCPP sets National Prices for services, which become the default prices. The main motivation for developing these prices is efficient and effective inter-DHB trading (purchasing and service provision) between DHBs in the sector. While DHBs are permitted to negotiate their own prices, the hope is that they will trust the efficiency of National Prices and save resources, which can otherwise be expended on lengthy price and volume negotiations. The calculation of National Price is discussed next.

\subsection{National Price}

To foster a health system in which efficient and effective inter-DHB trading occurs, the NCCPP should provide National Prices that are well-informed and equitable. That is, National Prices should be formed in such a way that the DHB of Domicile is not overcharged and the DHB of Service is sufficiently reimbursed for costs associated with the provision of services to other DHBs. In an attempt to provide National Prices grounded in the qualities described above, the NCCPP collects cost and volume data from all DHBs operating in the sector and uses this information as the basis for National Prices (as discussed in Chapter 7). "The calculation of National Prices is predicated on the expectation that all DHBs will comply with the NCCPP's data request” (MOH Interviewee B). However, as Chapter 6 reveals, DHBs operate costing systems with varying levels of sophistication, and as Chapter 7 reveals, this impacts on the quality of cost and volume data submitted to the NCCPP (i.e. costing system sophistication dictates whether a DHB provides service-level or event-level cost information).

Though the NCCPP's annual data collection is a very resource-intensive process for DHBs, it should be noted that the number of DHBs that submit cost and volume data at event-level determines how well informed and equitable National Prices are for IDFs. Therefore, the onus is on DHB's to adopt and make use of sophisticated costing systems to ensure they contribute to the NCCPP's National Pricing work. The process used by the NCCPP to calculate National Prices, including how service-level and event-level data is used to inform these prices, is described below. 
As per discussions with $\mathrm{MOH}$ Interviewee A and B, who are both directly involved in the NCCPP National Pricing work, all cost and volume data for service-level and event-level DHBs is collected, stored and processed in the IDF Price Book. The IDF Price Book is an Excel workbook that comprises two large spreadsheets - one of which is a Summary File of all cost and volume data that is used to calculate (1) Relativities and Scaled Prices, and the other is where all macro driven processes are performed to calculate (2) Adjusters. Once scaled price relativities and adjusters are calculated, the NCCPP can provide the IDF Price Book. The basic equation that is used as the basis for pricing in the IDF price book is:

$$
\text { Efficient Cost }=\text { Scaled Price } x \text { Volumes }+ \text { Adjusters }
$$

(1) Relativities and Scaled Prices

The NCCPP generates a set of Price Relativities for all non-casemix PUs (i.e. the price of individual products) and casemix cost weights (i.e. the price of typical DRG events) using event-level cost and volume data submitted in accordance with the NCCPP's data request. The Price Relativities for non-casemix PUs and casemix cost weights are calculated using the normal distribution within a specific inlier bound standard weight (previously referred to as WIES in section 7.3.1). Fundamentally, this means that all event-level cost and volume data is combined for individual PUs and casemix cost weights and appropriate price benchmarks are determined based on that data. The benchmarks then become the basis for National Price for each non-casemix PU and standard casemix cost weight.

Subsequent to the calculation of Price Relativities for all non-casemix PUs and casemix cost weights the NCCPP then scales them. The first step involved in scaling is to revise Price Relativities by excluding all outlier events. The logic behind this step is to remove any incentive for event-level DHBs retaining patients for longer than necessary, thus promoting efficient resource use. Once outlier events are removed, the NCCPP brings together all cost and volume data (being service-level and event-level cost data combined) to scale Price Relativities in accordance with total costs for the sector. This is done to ensure (1) the average price-weights multiplied by volumes do not exceed the total costs submitted by all DHBs; and (2) the relativities are based on total costs.

\section{(2) Adjusters}

Casemix funding assumes that a Provider Arm will (on average) receive the right amount of funding for each class of discharge, as defined by the DRGs. However, there are instances 
where casemix funding does not sufficiently recognise the costs incurred by a DHB for providing services. Similarly, there are instances where casemix funding does not take into consideration the efficiencies/inefficiencies of particular DHBs. Consequently, the NCCPP calculates adjusters in an attempt to alleviate the shortcomings of casemix funding and improve equitability of IDFs between DHBs. The IDF Price Book adjusters include (1) The Tertiary Compensator; (2) National Paediatric Adjuster; (3) Efficiency Adjuster; and (4) Inflationary Adjuster.

(1) The Tertiary Compensator is required because casemix prices do not reflect the actual costs to tertiary facilities of providing services. Even though the tertiary service casemix unit price is calculated through the price book a facility-related increment is calculated (using actual cost evidence) and is added to base funding for tertiary DHBs to cover their additional costs of service. ${ }^{21}$

(2) The National Paediatric Adjuster is an adjustment for national paediatric services. This payment is made to DHBs of Service to recognise the additional cost margin paediatrics has over comparable adult services.

(3) The Efficiency Adjuster is based on the principle that the DHB of Domicile should not be required to pay for the inefficiencies of the DHB of Service. To calculate the efficiency adjuster, which is usually around 2\%, the NCCPP compares costs (inputs) and volumes (outputs) of each DHB against others in the sector to estimate relative levels of efficiency.

(4) The Inflationary Adjuster is required because the NCCPP works with retrospective data to calculate National Prices for the following year. Thus, an adjustment to all price work is required to account for inflationary changes. In a similar vein, there is also a predicted demographic growth adjustment to account for changes in the DHB population.

\subsubsection{National Price Domination}

Discussions with $\mathrm{MOH}$ and $\mathrm{DHB}$ representatives indicate there is widespread agreement that National Price is dominated by tertiary DHBs. This point of view is substantiated by several pieces of evidence. As MOH Interviewee A stated, “all tertiary DHBs, with the exception of [one in the South Island], operate sophisticated costing systems and provide event-level data

\footnotetext{
${ }^{21}$ There are a number of reasons why casemix prices may predict costs for tertiary facilities inadequately. Two prominent examples include (1) technological advancements to service provision, with tertiary facilities tending to implement such changes first; and (2) the fact that tertiary services are more likely to maintain 24-hour accessibility, with a consequential increase in capacity costs.
} 
to the NCCPP”. The five tertiary DHBs that contribute cost information in accordance with the NCCPP data submission account for approximately $90 \%$ of all tertiary costs incurred and $70 \%$ of all event-level costing data submitted. This gives a good representation from the larger tertiary facilities, but there are concerns that secondary DHBs are underrepresented in the submission.

Concerns that secondary DHBs are underrepresented in the NCCPP submission have emerged largely because six secondary DHBs do not have sophisticated costing systems, thus are not able to submit event-level cost data to the NCCPP to influence National Price. The eight secondary DHBs that do contribute cost information in accordance with the NCCPP data submission account for approximately $65 \%$ of all secondary costs incurred and $30 \%$ of all event-level costing data submitted. There are also concerns that National Price is too North Island centric. As MOH Interviewee A noted, "there is only one tertiary DHB in the South Island with a sophisticated costing system. Consequently, no event-level data is provided from secondary DHBs operating in the South Island to inform National Price”.

The major issue that arises from tertiary DHBs dominating National Price is that resources are not transferred between DHBs via IDFs as efficiently as possible. Specifically, there are concerns that National Price is too high, as tertiary costs tend to be higher than secondary costs, and there is not enough data from secondary DHBs at event-level to influence prices down. As DHB B Interviewee A stated, "National Price would be more efficient if there was a wider representation of secondary Provider Arms contributing. The small base means a volatile price and this leads to volatile prices and tertiary national adjusters”. Furthermore, secondary DHBs have expressed concerns that the true and fair cost of each IDF is not National Price (representing the full cost with fixed and variable components), but a cost somewhere between marginal and full cost.

In spite of potential inefficiencies created by the calculation of National Price, this does not inhibit service accessibility via IDFs. As DHB A Interviewee B stated, "it can hurt the bottom-line of a DHB if there is a cost implication, but patient welfare comes first and cost efficiency comes second”. To elaborate, all DHBs receive Crown funding in December and a predetermined amount is taken off for the following year's IDFs. The amount is predetermined because IDFs are agreed between the DHB of Domicile and the DHB of Service prior to the year starting. Therefore, it is factored into each DHBs budget that there will be a fixed cost (the IDF) for service provision to meet some patient's needs. "To ensure 
resources leave the district appropriately, DHBs perform a health needs assessment every 3-5 years, the purpose of which is to evaluate health needs across the community and determine what services are likely to be required to meet those needs” (DHB A Interviewee B). Each DHB will then decide whether it is more cost effective to provide particular services through their Provider Arm or to outsource to other Provider Arms (through IDFs) or other agencies, such as private hospitals, primary care, and mental health, disability and community services.

There are several tertiary services that are only provided by tertiary DHBs, and as a result secondary DHBs will always refer these services out to tertiary DHBs. In this case, secondary DHBs often feel "powerless to prevent inefficient resource flows when patients are referred out” (DHB A Interviewee B). Nevertheless, there are still opportunities for secondary DHBs to retain patients if they believe it will be more cost effective to provide care at their own Provider Arm, as opposed to referring patients out to another DHB. In actual fact a number of DHBs have tried actively to repatriate a lot of their IDFs in the last few years and that has been relatively successful. One example involves general surgery, whereby DHB A has had an increase in their general surgery output because of an increase in surgeon availability. While this has involved an increase in fixed costs for surgical and nursing labour, the DHB notes that they have actually saved money overall by performing surgical procedures inhouse. The main reason for this is that the cost of performing each surgical procedure is not the full cost represented by National Price, but the marginal cost for clinical supplies associated with each surgery.

Though the MOH and DHB's acknowledge that use of sophisticated costing systems with ABC methodologies is crucial to the calculation of National Price, there is also a realisation that not all DHBs are prepared to implement such systems. As a result, it is not plausible to expect concerns over the efficiency of National Price to be remedied through universal adoption of sophisticated costing systems. After discussions with several MOH and DHB experts, it is also unlikely that a revised methodology to calculate National Price is going to be implemented in the near future, as suggestions of a price between marginal and full cost have had little traction. As DHB A interviewee B stated, “one DHB has done quite a bit of work on an alternative transfer pricing methodology that they see as a true and fair marginal cost, rather than the full cost represented by National Price”. The DHB started performing this work because they have been hit really hard with IDFs in recent years and there is a realisation at the DHB that National Prices for IDFs are more costly than using private 
providers. "While [the DHB] would prefer to use the resources and capacity available to them in the public system, if prices continue to deteriorate their bottom-line they will be forced to use private providers, which have been proven to cost less than IDFs at National Price” (DHB A interviewee A).

Based on the discussion above, it is evident that National Price is not a perfect mechanism. While some DHBs have repatriated patients to mitigate the issues with National Price, other DHBs have expressed interest in an alternative pricing mechanism. However, the most effective approach used by DHBs to combat the inefficiencies of National Price to meet the needs of DHB populations has been a move to increase collaboration between DHBs.

\subsection{DHB Collaboration}

Several DHBs have expressed the opinion that collaboration between DHBs to forecast patient needs and discuss their treatment across districts and regions is highly important. As DHB A Interviewee B stated, “DHBs at regional level are already using various collaborative initiatives to manage available funding in different ways to maximise equity of access to health services across regions”, specifically, to plan services at regional level. DHBs have also heightened emphasis on negotiating prices away from the National Price and outside of the IDF network, the aim of which is to charge DHBs of Domicile a price that reflects the actual costs incurred by DHBs of Service to treat patients. Another major example of the types of regional collaboration occurring in the New Zealand public health sector is the 3DHB Programme. This collaborative partnership is discussed in greater detail below:

\subsubsection{The 3DHB Programme}

The 3DHB Programme is a partnership between three DHBs operating in the same region and it was formed by the Sub-Regional Clinical Leadership Group (CLG) because they realised integration of services between the DHBs was inadequate. The CLG is a group led by clinicians from the three DHBs whose purpose is to develop services across the region with a focus towards quality, efficiency and equitable access. Specifically, the CLG recognised a need to better integrate primary and secondary care across the region to improve availability of specialised services to patients and reduce duplication of service (particularly when a patient is transferred between DHBs). Accordingly, the partnership has designed the new structure to fit the constantly changing environment of health care (i.e. the patient population) and support clinical integration of services with the aim of providing quality, accessible and efficient services that will be sustainable across the region. 


\subsubsection{Structure of the 3DHB Programme}

Through the 3DHB Programme there were a number of structural changes to the health system in the region. The changes were deemed necessary to facilitate clinically led improvements, with management and organisational design in support.

As part of the 3DHB Programme, the CLG has established an initiative focussed on 'single service, several sites', whereby services such as Ear, Nose and Throat, Gastroenterology, Child health, Ophthalmology, Orthopaedics, non-melanoma skin lesions, Palliative Care, and Radiology are shared within the region. The PFUs have also combined to form a single unit called the Service Integration and Development Unit (SIDU). Previously service planning and funding was performed by each DHB for their own population and PFAs would come together to discuss the provision of health care as a region. Under SIDU there is one director and all planning and funding decisions are made with respect to the whole region and a shared financial bottom-line. "The main benefit of SIDU is that capacity can be used more effectively and efficiently to arrange the best mix of local services, equitable access to quality services and high performing centres of excellence to meet health needs of the shared population” (DHB A interviewee B).

To facilitate the aims of the 3DHB Programme, the partnership has meant an increase in mobility of human resources, meaning specialists can move between Provider Arms to treat patients as needed. Mobility of human resources between the collaborating DHBs has significant benefits to staff through shared education and new opportunities to gain experience. Furthermore, the partnership aligned the three IT teams to make both patient journeys and working between DHBs a more seamless experience. Specifically, the partnership introduced an IT system whereby all three districts operate using the same log in, email and phone network. The partnership also introduced an IT initiative called e-Tree, which houses all electronic files for the region, so clinicians can view patient's electronic medical records from any site, regardless of where they are being treated. These developments vastly improve ease of access, as DHB personnel are able to work both locally and remotely from a single portal.

One of the major changes to management structure is the two secondary DHBs amalgamated their senior management teams and share a CEO (with a view towards gradual integration across all three DHBs as opportunities arise). This initiative alone meant that more than 40 positions at the DHBs were disestablished to make way for one management team. Though 
the DHBs have been combined for administrative and management purposes, all three DHBs operating under the 3DHB programme will continue to have their own elected Boards. It is crucial to the success of the partnership that each partner DHB maintains their own Board. "This is because each DHB must be accountable to their respective DHB populations and demonstrate transparency over health targets, health initiatives and financial performance" (DHB A interviewee B). Additionally, each DHB population needs local representation so as to ensure equitable decision making, as most decisions will have an impact on all three districts and there is likely to be occasions where tension is created between the needs of a sub-regional population and the needs of the region as a whole.

\subsubsection{Centres of Excellence and the Clinical Expert Domain}

As a result of the 3DHB Programme, centres of excellence can be established, whereby the delivery of health care is arranged in such a way that "the Provider Arm which is most effective and efficient at providing a specific specialised service becomes the main provider to the entire region” (DHB A interviewee B). This not only reduces duplication, as Provider Arms do not assume the default position that they must provide all services, but it also improves the quality and efficiency of patient care. Though it is important to consider where centres of excellence are, the partnership also needs to be mindful of where patient needs are. Moreover, the partnership needs to make sure every decision is made prospectively so as to anticipate where future needs will be. "[These considerations] are crucial to the partnership if it is going to be both successful and sustainable, as they can create travel, inconvenience and social costs if ignored” (DHB A interviewee B). For that reason, a clinical expert domain has been established, whereby the delivery of health care is arranged so specialists and centres of excellence are in the district where services are most needed (assuming the Provider Arm has the requisite infrastructural capabilities to provide the service and it is cost effective to do so).

\subsubsection{Cost Savings}

Though cost savings was not the primary purpose for forming the partnership, it is noted that the overall intention of the 3DHB programme is to improve the quality, accessibility and efficiency of patient care by getting the best value for health system resources and making them sustainable into the future. To this end, it is evident that the 3DHB programme will create cost savings in a number of areas. These savings will be observed predominantly through fewer personnel costs and reduced duplication of managerial, administrative, planning and funding functions (discussed in section 8.2.2). Savings will also be experienced 
through reduced duplication of service, better co-ordination of services between the Provider Arms and improved quality and efficiency of services.

Notwithstanding the financial benefits of the 3DHB programme, there are a number of unintended non-financial costs that may eventuate as a result of the collaboration. These costs include internal conflicts and tensions between the participating DHBs during the transition phase. Specifically, there may be resistance to change if DHBs do not understand the benefits of the collaboration or they do not agree with the collective processes being implemented to purchase, fund and cost health services. This could have the effect of undermining the programme and reducing its overall effectiveness. Additionally, there are may be potential implications to the organisational legitimacy of the DHBs involved in the collaboration, particularly if members of the public do not understand the purpose of the programme or its intended benefits to them as users of the New Zealand public health sector. That is, confidence in the health sector may be reduced if the general public believes the overall impact of the collaboration is a reduction in the range and availability of services to them (i.e. DHBs are reneging on their social contract to provide sustained high quality health services).

\subsubsection{Impact on Inter-District Flows}

The two secondary DHBs operating under the 3DHB programme have a large volume of IDFs, as they cannot sustain a complete range of services to meet patient needs, and this has an equally high dollar value attached to it. Furthermore, "the share of resources committed to IDFs has been unfavourable compared to budget in the past couple of years and continues to increase, but not as a direct result of an increase in volumes” (DHB A Interviewee B). The increase is due in part to a steady rise in National Price, but more importantly, it is because tertiary DHBs are constantly improving their processes to code and count the services they provided through IDFs.

Acknowledging the inefficiencies of National Price (discussed in section 8.1.1), the 3DHB programme alleviates most of the concerns associated with IDFs. Though each district still receives their own share of population-based funding (discussed in section 5.2), all resources are used collectively to plan and provide health services to the entire region. In addition, the $\mathrm{MOH}$ has stated that the DHBs must now break-even as a region, as opposed to three separate organisations. Having one bottom-line not only reduces the negative impact National Prices may have had on the DHBs during the process of inter-district trading, but it also removes the disincentive to partake in IDFs between the DHBs in collaboration. This means 
the DHBs are united by a common objective to provide quality, accessible and efficient health services without incurring a deficit. While the collaboration mitigates most concerns associated with the inefficiency of National Price to the extent that IDFs occur within the regional (i.e. between partners of the 3DHB programme), as history indicates there may be instances where services still need to be sought away from the 3DHB Programme, particularly for unforeseen patient events. The 3DHB Programme will need to decide as a group if it is more cost effective to seek these services from other Provider Arms via IDFs, or consider other alternatives. The alternatives will include private providers or using collective resources on capital expenditure to provide such services within the region (as capital expenditure budgets are aligned through the partnership).

\subsubsection{Success of the 3DHB Programme}

The collaboration means new and in some cases radically different ways of thinking and working. "There will be a certain period of transition, which is inevitable, and there will be a number of features that will play a significant role in the success of the 3DHB programme" (DHB A Interviewee B). Two key features will be leadership and communication. Leadership is an important feature because staff needs to see what the vision is and be convinced that the partnership knows what it wants to achieve and how it is going to achieve it. As DHB A Interviewee B pointed out, these areas have been considered - "the CLG owns the project and they have a clear aim, equitable access to quality and efficient health services through greater DHB collaboration”. Communication is also important because the vision and proposed benefits thereof need to be conveyed clearly and convincingly. "This will have the dual effect of creating buy-in and it will ensure everyone works together towards one common goal with a shared vision and values” (DHB A Interviewee B). This will also have the effect of reassuring the local community that the collaboration is for the greater good and will actually yield benefits to them as users of the New Zealand public health care system. Strong communication channels will be important over the duration of the programme too, as people will be working together from several different sites. As a result there will be reliance on communication technology such as email, phone and video-conferencing (which have been aligned).

Relationships are a key feature, as people need to gain familiarity with each other and learn to work together. Forming strong relationships will create a work dynamic where trust is developed and everyone is open and honest in their discussions. Considering political 
relationships, it is important that each local community has a voice and there is accountability to these communities. Irrespective of size, each Board represents their DHB population, and it is important that they all have strong operational input and are acknowledged, respected and shown due consideration whenever a decision is made.

Another key feature is acceptance to change. Along with the reorganisation of health care in the region, there will also be constant change processes. As DHB A Interviewee B stated, "We have to build headroom in our budgets to cope with changes in demand and opportunities for innovation. This means change will become the norm as we will be constantly shifting resources to where they are most needed”. Awareness and acceptance that change processes will occur is vastly important to the success of the partnership because (1) the DHBs need to work together to make patient events less complicated; (2) the ageing population brings new levels of complexity to health care; and (3) the DHBs have limited resources to provide health services. This is not easy, but it is essential to ensure health services thrive and can adapt to the needs of the region's population as they change.

\subsection{Chapter Summary}

As Chapter 8 has discussed, the NCCPP calculates National Prices to facilities IDFs between DHBs to meet patient needs. Though National Prices are calculated with the intention of facilitating efficient and effective IDFs, there is a realisation that the calculation of these prices is dominated by tertiary DHBs with sophisticated costing systems. In spite of potential inefficiencies created by the calculation of National Prices, this does not inhibit service accessibility via IDFs. It can hurt the bottom-line of a DHB if there is a cost implication, but patient welfare comes first and cost efficiency comes second. Acknowledging the potential inefficiencies of National Prices, some DHBs have expressed interest in a revised methodology between marginal and full cost, but these suggestions have had little traction. As a result, several DHBs have tried actively to repatriate a lot of their IDFs in the last few years, which has been relatively successful. Another mechanism that has been used to mitigate the potential inefficiencies of National Prices to meet the needs of DHB populations has been a move to increase collaboration between DHBs. Specifically, DHBs have started using various collaborative initiatives to manage available funding in different ways to maximise equity of access to health services across regions, including service planning at regional level, negotiating IDF prices away from the National Price and outside of the IDF, and finally, establishing the 3DHB Programme. 


\section{Chapter 9: Discussion and Conclusion}

\subsection{Introduction}

Changes in the New Zealand public health sector in recent years, such as heightened social, political and economic pressures to manage and reduce costs while improving the quality of care in conjunction with stringent health care guidelines, have forced DHB's nationwide to reassess their approach to health care provision. This study has assessed the influence of the NHB and the twenty DHBs it monitors, using a twofold consideration. The first consideration related to adoption and use of costing systems by DHBs operating in the New Zealand public health sector. The second consideration was how service planning and provision is effectuated by inter-district co-ordination and IDFs, and the impact costing systems adoption and use have on these processes.

In recognition of the potential benefits of sophisticated costing systems, and the fact that the New Zealand public health sector is severely underrepresented in current cost accounting and transfer pricing literature, the objective of this study was to:

To examine the costing systems used by DHBs to plan and provide health services, and to evaluate how the use of such costing systems influence service planning and provision (at the district, regional and national level) in accordance with the outcomes outlined by the MOH.

To achieve this overall research objective six research questions were posed:

RQ 1: What determines and guides the costing systems used in New Zealand DHBs?

RQ 2: How are costs calculated in DHB costing systems?

RQ 3: How is cost information produced by cost systems used to plan and provide services?

RQ 4: How and for what other purposes is cost information used in the public health sector?

RQ 5: How are the transfer prices to be charged for inter-DHB trading determined?

RQ 6: How and for what purposes do DHBs collaborate with each other?

The next six sections will discuss and answer the research questions and consider the literature and theory where applicable.

\subsection{Costing Systems Adoption and Use in New Zealand DHBs}

The New Zealand public health sector has undergone significant reforms in recent years, including the NHB being established, decentralisation of decision-making to DHBs for local 
service planning and provision, and heightened emphasis on expected outcomes of the public health sector (as outlined by the $\mathrm{MOH}$ ). The outcomes include New Zealanders living longer, healthier and more independent lives; a health system that is cost-effective and supports a productive economy; health services that are delivered better, sooner and more conveniently; and finally, assurance of the future sustainability of the health system. The recent reforms to the New Zealand public health sector (which are essentially due to resourcing and sustainability concerns) and the MOH's focus on achieving the outcomes aforementioned, have led to significant regulatory, social and political pressures on DHBs. Specifically, DHBs have been pressured to evaluate current practices or institutions; revise health care systems, including locality of treatment; and assess established accounting systems and mechanisms (or lack thereof) to understand the source of costs and resource consumption.

While the overall aim of the reforms are clear, DHBs have faced a unique challenge in balancing institutional pressures imposed on them by various constituents (with varying results). Acknowledging the prospective benefits of sophisticated costing systems compared to traditional costing systems (section 2.2), it was expected that DHBs would adopt sophisticated costing systems to plan and provide health services, adhere to those institutional pressures that are most influential and strive to maintain organisational legitimacy. However, "an additional complicating factor in hospitals is that one set of institutional pressures may conflict with other sets of pressures” (Krishnan \& Yetman, 2011, p. 1006). Specifically, one set of institutional pressures can require hospitals to reduce costs by being economically and programmatically efficient (Dranove, 1998; Covaleski et al., 2003; Eldenburg \& Krishnan, 2003). Conversely, an alternative set of institutional pressures can constrain managers from pursuing opportunities to reduce costs and increase economic value, particularly if such opportunities diminish the range and/or quality of health services to sections of society (Krishnan \& Yetman, 2011). Consistent with theory, results of the current study indicate that DHBs adopt and use costing systems on different levels and with differing views about which institutional pressures are the most influential (which are discussed next).

DHBs are exposed to significant regulatory pressures to adopt and use sophisticated costing system that adhere to the CCS and enable them to contribute event-level cost information to the NCCPP for the various work programmes they run (i.e. benchmarking, productivity evaluations, national pricing, regional and national service planning). While DHBs face these pressures, the CCG also advises that the costs of providing such information should not 
outweigh the benefits of generating it (Cooper, 1988). As a result, smaller secondary DHBs have a tendency to refrain from adopting and using sophisticated costing systems, as the significant cost of establishing and operating such systems cannot be justified.

DHBs are also exposed to significant cultural-cognitive/political pressures to adopt and use sophisticated costing systems, which are placed on them by other DHBs and the MOH. These pressures are placed on DHBs because the $\mathrm{MOH}$ expects DHBs to plan and provide services to meet their directives and outcomes. If a DHB does not make use of a sophisticated costing system, their ability to provide information to the National Event-level Cost Data Cube is nonexistent. Consequently, those DHBs without sophisticated costing systems are not be able to (1) compare their cost structures and cost information with other DHB's; (2) determine if there are opportunities to create process improvements or reduce waste based on that information; and (3) efficiently and effectively plan services with other DHBs in the region to maximise use of their limited capacity.

DHBs are also exposed to significant social/normative pressures, which are placed on them by the general public. However, the impact of these pressures on adoption and use of sophisticated costing systems is changeable based on (1) the public's expectations about how the organisation should conduct its operations (Ruef \& Scott, 1998); and (2) the DHB's perceptions about which institutional pressures are the most influential and how they should respond to them to ensure organisational survival (Scott, 2001; Kostova et al. 2008). Some DHBs have institutionalised sophisticated costing systems that enable them to better understand their cost structures, provide cost and volume information to the NCCPP (to inform National Price for IDFs) and plan and provide health services to achieve the MOH's directives and desired outcomes. These DHBs tend to believe that adopting and using sophisticated costing systems for the purposes aforementioned will provide the best opportunity for the DHB to meet the health needs of the general public and thus, enable them to maintain organisational legitimacy. Conversely, other DHBs have reverted to unsophisticated costing systems, as they do not believe the information benefits of more sophisticated costing systems outweigh the costs of operating them. These DHBs tend to believe that reducing spending in administrative areas, instead opting to use their limited capacity in other areas such as service provision, will provide the best opportunity for the DHB to meet the health needs of the general public and thus, enable them to maintain organisational legitimacy. The differences in adoption and use of costing systems highlights 
how different DHBs view institutional pressures and that these views will change based on their own internal organisational environment (i.e. a small secondary DHB is less likely to use a sophisticated costing system compared a large tertiary DHB).

\subsection{Costing Systems and Costing Information}

Concordant with Cooper (1988), the CCG stresses that the benefits derived from information should meet or exceed the costs of providing the information. Therefore, DHBs operate costing systems on three levels based on the perceived costs and benefits of generating cost information (with consideration for their individual organisational structure). The three levels that DHBs operate costing systems on include (1) unsophisticated costing systems that are not formally recognised; (2) moderately sophisticated costing systems (such as CostPro) that are formally recognised; and (3) sophisticated costing systems (such as PPM) that are formally recognised. Using their respective costing systems in conjunction with the CCS and the CCGL, DHBs calculate costing information to be used for various purposes.

Those DHBs with unsophisticated costing systems cost at the MSG level (i.e. at Cost Pool level). To allocate direct patient care and clinical support costs to cost pools is relatively straightforward, as these costs are directly associated with the delivery of a specific service. However, to allocate overhead is more difficult, as these costs generally cannot be directly associated with the provision of a specific service. To allocate overhead, service-level DHBs tend to use a single arbitrary DHB-wide overhead allocation rate based on FTEs or total cost, which is consistent with Al-Omiri \& Drury’s (2007) sophistication continuum for simplistic traditional systems. Using FTE or Total Cost to allocate overhead makes it virtually impossible to cost down to a patient level, as there is not the depth of knowledge to accurately trace causal relationships between indirect costs and individual patient events (which utilise activities from multiple services both directly and indirectly).

Though allocating indirect costs using FTEs or total cost is the most suitable approach for DHBs that have unsophisticated costing systems (because there is an inability to ascertain what drives the incurrence of these costs and where/how they should be allocated), this can impact on the quality of cost information for decision-making (Bromwich \& Bhimani, 1994; Geri \& Ronen, 2005). Specifically, service planning can be less effective, as DHBs with an unsophisticated costing system do not have an accurate understanding of the costs associated with service provision or how to control them (Cooper \& Kaplan, 1992; Hussain \& Gunasekaran, 2001). Cost comparisons between DHBs with unsophisticated and 
sophisticated costing systems is severely limited too, as service costs for DHBs with unsophisticated costing systems can often be inconsistent, incomparable or incomplete (OAG, 2013).

Those DHBs with more sophisticated costing systems cost at the patient event-level. Unlike service-level DHBs, in which many of the CCS are offered as a guide to costing, event-level DHBs are expected to follow the Standards and ABC methodologies specified therein rigorously. To use the CCS congruously with their respective costing systems, event-level DHBs should apply the principle of full absorption to determine the cost of a patient event. This means that any cost that is caused by the delivery of health care, whether it is direct or indirect in nature, should be allocated to activities associated with a patient event in order to have a complete cost for the event (Brown et al., 2003; Al-Omiri \& Drury, 2007). To allocate overheads to patient events, event-level DHBs with moderately sophisticated costing systems will tend to use a combination of duration cost drivers and transaction cost drivers (for first stage and second stage allocation), which is consistent with Al-Omiri \& Drury's (2007) sophistication continuum for sophisticated ABC systems. To allocate overheads to patient events, event-level DHBs with sophisticated costing systems will tend to use duration cost drivers rather than transaction drivers (for first stage and second stage allocation), which is consistent with Al-Omiri \& Drury’s (2007) sophistication continuum for highly sophisticated ABC systems. This allocation process requires event-level DHBs to develop thorough understandings of how overhead costs are incurred, which can often lead to in-depth analysis to successfully identify activities or processes and the first stage and second stage cost drivers associated with each activity or process (Baker, 1994; Al-Omiri \& Drury, 2007).

While the CCS are not mandated, and as such, event-level DHBs are not obliged to follow them precisely as they are set out, this does not raise concerns over inconsistent applications. This is because all DHBs are actively involved in the CCG and as a member of the Group they all strive to reduce discrepancy. That is, there is sufficient cultural-cognitive/political pressure on DHBs to apply the CCS appropriately. If there are inconsistencies between DHBs that have a similar demographic or hospital structure, the Group will consult the CCS to ascertain how they were applied and why there are such inconsistencies. Often the Standards are applied dissimilarly because they were not described well enough to accommodate some scenarios or the description may not be clear enough, which creates opportunities for misinterpretation. To mitigate misinterpretation of CCS, the CCG and NCCPP constantly 
offer training sessions and forums to provide better visibility for how to cost, how costs are derived and how costing information impacts on National Pricing work. This can be viewed as a direct response to normative/social pressures, as the $\mathrm{MOH}$ seeks to align perceptions of DHB practices and characteristics with social and cultural values (in order to gain or retain organisational legitimacy) (Deegan, 2006). In addition, significant regulatory pressures are placed on DHBs, as the $\mathrm{MOH}$ has the authority to withhold funding, to impose a management regime, and in extreme cases, replace a Board if it finds a DHB under-performing. In practice, these powers are rarely used, as they are seen as drastic measures and are likely to produce unwanted effects, such as running a DHB into deficit and reduced public confidence in the New Zealand public health sector (which can have the effect of reduced organisational legitimacy).

\subsection{Service Planning and Provision}

The PFU of each DHB will choose to provide health services or purchase health services from multiple other providers based on local need and availability of resources. The main health service provider for each district is the DHB hospital, which is owned and funded by the DHB. Each DHB hospital is called the Provider Arm and mainly provides hospital-related services. For selected health care activities, DHB's will contract directly with other providers besides the main Provider Arms, such as private hospitals, primary care, and mental health, disability and community services. The Provider Arms themselves can also subcontract to these other agencies where necessary. In addition, DHBs purchase services from other DHB's Provider Arms through IDFs. As all appropriations include funding for IDFs, DHBs are required to reimburse each other for IDFs from this funding.

As noted in the previous section, DHBs with unsophisticated costing systems do not have an accurate understanding of the costs associated with service provision. In many instances these DHBs can identify where their direct costs originate, but they are severely disadvantaged when it comes to understanding, monitoring and controlling their indirect costs. Though DHBs in this situation can make use of other DHBs cost data through the National Eventlevel Cost Data Cube, there is an inability to determine the accuracy of their own costs for service provision and how these costs compare to other DHBs with a more in-depth understandings of their cost structures. This is largely because an unsophisticated costing system, which makes use of a single arbitrary DHB-wide overhead allocation rate based on FTEs or total cost, is likely to report distorted product and service costs (Cooper \& Kaplan, 
1992). As a result, DHBs that operate unsophisticated costing systems cannot accurately calculate the costs required to treat individual patient events, which can severely impact the process of service planning and provision.

For DHBs with more sophisticated costing systems, there is greater opportunity to understand, monitor and control costs associated with the provision of health services. In addition, these DHBs have greater means to make decisions associated with service planning and provision. This is consistent with literature, which states that the information costing systems generate plays a major role in the decision-making process and has a crucial influence on organisational performance. Specifically, the information sophisticated costing systems generate can be used more effectively to determine product and/or service mix (Brown et al., 2003; Geri \& Ronen, 2005). The ability to make effective product and/or service mix decisions is attributed to the fact that they are familiar with their cost structures and have access to data stored in the National Event-level Cost Data Cube. These two events have given such DHBs greater opportunities to compare and analyse cost information to make decisions associated with planning and provision of health services (including whether or not to provide services internally or outsource to other providers).

Beyond service planning at the district level, the costing information provided by these DHBs with more sophisticated costing systems can be used at the regional and national level. As the results of the current study demonstrate, one DHB uses the costing information generated by their sophisticated costing system to consider various strategic emphases associated with planning and funding the provision of health services, both to their own DHB population and across regional boundaries. Specifically, the DHB has started exploring their costs and volumes to make decisions associated with product and service mix - the goal of which is to maximise utilisation of their constrained capacity to achieve the directives and outcomes outlined by the MOH. The DHB's costing system, with its emphasis on ABC, is able to break down the patient event into specific detailed activities and show the disaggregated cost of the DRG event (including the marginal costs of taking on each additional volume), which is consistent with Canby’s (1995) findings. This level of detail is vital for the types of decisions described above, as it highlights (1) whether or not the DHB can take on additional volumes given its spare capacity; and (2) whether or not it is cost-effective to actually take on the volumes. 


\subsection{Costing Information: Other Uses}

Aside from service planning and provision, the cost information generated by DHBs costing systems is used for a variety of other purposes. From an internal organisational perspective, DHBs will use their own and other DHBs cost information to evaluate performance year-onyear and determine if there are opportunities to gain operational control and eliminate waste (Chan, 1993; Ramsey, 1994; Canby, 1995; Ross, 2004; Lawson, 2005; Yereli, 2009; Shander et al., 2010). Consistent with the literature (which states that ABC systems can be used to control costs and make strategic decisions), DHBs will use such systems to (1) identify key activities involved in health services; (2) where process improvements can be made; and (3) where non-value added activities can be eliminated, while ensuring proper functionality of each service. DHBs tend to use cost information for these purposes because they face significant institutional pressures from the $\mathrm{MOH}$ to ensure they provide low cost high quality health services that are sustainable into the future. Moreover, because DHBs have limited capacity it is crucial to their organisational legitimacy that they consider opportunities to gain operational control and eliminate waste. This is largely due to the fact that they face significant social/normative pressures to provide a range of high quality health services to meet the needs of the general public. If a DHB is unable to provide a full range of services to meet the demands placed on them by users of the New Zealand public health sector their existence and organisational legitimacy will be brought into question. This is because an inability to provide sustained high quality health services to the general public will lead to reduced public confidence and a belief that DHBs are reneging on the obligations (expressed or implied) of their social contract (Shocker \& Sethi, 1974; Suchman, 1995; Ruef \& Scott, 1998; Deegan, 2006).

From an organisational-field perspective, the cost information generated by DHBs' costing systems is used for a variety of other purposes. Firstly, the cost information is used by the CCG to maintain the CCS and the CCGL. Specifically, the CCG assembles quarterly to discuss the application of the CCS and interpretation of the CCGL. The main motivation for these quarterly meetings is to determine whether or not the Standards and the Guidelines are fulfilling their main purposes, and to ensure they are appropriate for the wider business group (the DHBs collectively). Thus, significant regulatory and political pressures are placed on DHBs to adopt and use sophisticated costing systems, as the information they provide to the $\mathrm{MOH}$ is essential to the work they perform to maintain the Standards and the Guidelines. 
Also, from an organisational-field perspective, the cost information generated by DHBs' costing systems is used by the NCCPP for a variety of other purposes. These purposes include updating the price book for IDF prices; setting the tertiary adjuster pool; developing casemix caseweights; populating the National Event-level Cost Data Cube; reviewing priority areas in non-casemix pricing; supporting work on pricing mental health and elective services; producing key pricing information for DHB comparisons by the NCCPP; contributing to the strategic review of pricing in the $\mathrm{MOH}$; re-producing data to allow DHBs and other key groups to undertake further analysis. To run these work programmes, the NCCPP requests that DHBs provide information from their Provider Arms annually. Thus, significant regulatory and political pressures are placed on DHBs to adopt and use sophisticated costing systems, as the information they provide to the NCCPP is essential to their work and the functionality of the health sector as a means to deliver sustained high quality health services.

\subsection{Approaches to Transfer Pricing for Inter-DHB Trading}

There are two main approaches used to calculate transfer prices for inter-DHB trading. The first approach (i.e. the main approach) is National Price, which is a form of cost-based transfer pricing that is calculated by the NCCPP. The main motivation for developing National Prices is to facilitate efficient and effective inter-DHB trading within the sector. To assist the NCCPP in setting National Prices for IDFs, the MOH has developed a set of CCS (based on ABC principles) that serve as common but not mandatory standards for costing health services. To calculate National Prices, the NCCPP has requested that all DHBs provide cost, revenue and volume information from their Provider Arms every November using these standards. As per the OPF, all DHBs are required to provide information in line with the NCCPP data request at either service-level or event-level. The 7 DHBs with unsophisticated costing systems provide data at the service-level, while the 13 DHBs that have adopted and currently maintain sophisticated costing systems provide data at the event-level. This process of standardised costing and rigorous cost collection to set transfer prices is consistent with the literature. To elaborate, Colbert \& Spicer (1998); Desheh et al. (1997) and Stevenson \& Cabell (2002) recognise the importance that high-quality information has on transfer pricing. Moreover, they all state that ABC can be used to provide such information.

The literature states that a full cost-based transfer price is based on the total cost of the provider's product, and is equivalent to the variable costs plus fixed costs per transfer unit (Colbert \& Spicer, 1998). National Price is effectively a full-cost based transfer price, in that 
it is based on the full cost of a patient event. Though cost-based transfer pricing is a credible substitute to market-based pricing, there is an inherent expectation that organisations applying this approach can calculate accurate product and/or service costs (Atkinson et al., 2007). This is equally important in the calculation of National Prices. Thus, the MOH and NCCPP place regulatory pressures on all DHBs to institutionalise sophisticated costing systems so they can submit cost and volume information to inform National Price (and contribute to a more efficient price representative of all DHBs costs to serve). Though the $\mathrm{MOH}$ and DHB's acknowledge that use of sophisticated costing systems with ABC methodologies is crucial to the calculation of National Price, there is also a realisation that not all DHBs are prepared to implement such systems.

An additional concern created by setting National Prices at full cost is the fact that it demotivates the buying DHB from purchasing services in the inter-organisational environment. Kaplan (1982, p. 483) views this as "the essence of the transfer pricing conundrum”. The findings of the current study reaffirm the presence of the transfer pricing conundrum. Specifically, findings reveal that one DHB, which has been hit really hard with IDFs in recent years, has been forced to consider alternative approaches to service provision beyond IDFs. This consideration stems from the realisation that National Prices for IDFs are more costly than using private providers in the external market or providing the same services through their own Provider Arm at marginal cost (if there is spare capacity to do so). While the DHB has stated that they would prefer to use the resources and capacity available to them in the public system, if prices continue to deteriorate their bottom-line they will be compelled to use such alternatives as those aforementioned.

The second approach to transfer pricing applied in the New Zealand public health sector is negotiated transfer pricing. While DHBs are permitted to negotiate their own prices, typically they will trust the efficiency of National Prices and save resources, which can otherwise be expended on lengthy price and volume negotiations. This is consistent with the transfer pricing literature, which states that the main weaknesses of the negotiated transfer pricing approach are that it can be a very time-consuming process, lead to inter-divisional conflict, and lead to sub-optimal output levels if the negotiated price is too high (Kaplan \& Atkinson, 1989). Notwithstanding the weaknesses of negotiated transfer pricing, some DHBs have performed work on an alternative transfer pricing methodology that they see as a "true and fair” marginal cost, rather than the full cost represented by National Price, the aim of which is 
to charge DHBs of Domicile a price that reflects the actual costs incurred by DHBs of Service to treat patients. Though results of the current study do not confirm whether or not negotiated transfer pricing is being applied, it is likely that in instances where DHBs are using this approach they will agree on a price somewhere between marginal and full cost.

\subsection{DHB Collaboration}

Acknowledging concerns with the current approach to calculating National Prices for IDFs, DHBs have increased collaboration to meet the needs of their DHB populations. In addition to negotiating transfer prices away from National Price and outside the IDF network, which has been discussed in the previous section, DHBs have started collaborating for the purposes of service planning at regional level. Some DHBs have also moved to more drastic means of collaboration to meet the needs of their DHB populations. One example explored as part of the current study is the 3DHB Programme. The increased collaboration between DHBs through the 3DHB Programme has largely been in response to concerns that planning at district level was insufficiently aligned with national objectives, and inter-district coordination too weak, leading to inefficiencies, duplication of services and concerns about future sustainability (Ettelt et al., 2012).

The CLG designed the 3DHB Programme to fit the constantly changing environment of health care (i.e. the patient population) and support clinical integration of services with the aim of providing quality, accessible and efficient services that will be sustainable across the region. The collaboration means new and in some cases radically different ways of thinking and working. The collaboration also drives a process of organisational change, in which current institutions at the participating DHBs are revised or replaced to ensure organisational survival (Scott, 2001; Kostova et al. 2008). As a primary example, the PFUs have combined to form a single unit called SIDU. Under SIDU there is one director and all planning and funding decisions are made with respect to the whole region and a shared financial bottomline. The main benefit of SIDU is that capacity can be used more effectively and efficiently to arrange the best mix of local services, equitable access to quality services and high performing centres of excellence to meet health needs of the shared population.

Though the 3DHB Programme has been developed with a clear vision in mind, it has created a significant change to the organisational environment in which the participating DHBs operate. As a result, the collaboration may create internal conflicts and tensions between the participating DHBs, particularly during the transition phase. Specifically, there may be 
resistance to change if DHB staff does not understand the benefits of the collaboration or they do not agree with the collective processes being implemented to purchase, fund and cost health services. This could have the effect of undermining the programme and reducing its overall effectiveness. As Scott (2001, p. 189) states, institutions can often be in conflict during the process of institutionalisation and will compete with each other by prescribing "varying forms and activities for participants, with the winners and losers to be sorted out over time”. This process can potentially be problematic as it may undermine the legitimacy of the organisations operating under the 3DHB Programme. As the participating DHBs are to be united by a common objective to provide quality, accessible and efficient health services without incurring a deficit, there is regulatory pressure and cultural-cognitive/political pressure on them to work in harmony. To alleviate concerns created by internal tensions and conflicts, the CLG needs to ensure it (1) takes leadership of the Programme; (2) clearly conveys the vision to participating DHBs; and (3) convinces the DHBs that the partnership knows what it wants to achieve and how it is going to achieve it. This will hopefully have the dual effect of creating buy-in and ensuring everyone works together towards one common goal with a shared vision and values.

Additionally, there are may be potential implications to the organisational legitimacy of the DHBs involved in the collaboration, particularly if members of the public do not understand the purpose of the programme or its intended benefits to them as users of the New Zealand public health sector. That is, confidence in the health sector may be reduced if the general public believes the overall impact of the collaboration is a reduction in the range and availability of services to them (i.e. DHBs are reneging on their social contract to provide sustained high quality health services). This potential negative outcome is reaffirmed by Ruef \& Scott (1998), who state that society (which comprises patients, donors and other community members) will tend to hold a set of expectations about how a health care organisation should conduct its operations. The best way to alleviate the potential for reduced organisational legitimacy is to ensure continued public confidence. To achieve this, clear communication channels between the 3DHB Programme and the general public need to be established, so the vision and proposed benefits thereof can be conveyed clearly and convincingly to the general public. 


\subsection{Contributions}

This study's results contribute to the academic literature and have implications for practice, which are discussed next. Firstly, the results of the current study contribute to cost accounting literature. Specifically, the results of the current study reveal that DHBs adopt and use costing systems with varying levels of sophistication, including unsophisticated costing systems that are not formally recognised, moderately sophisticated costing systems based on ABC principles (such as CostPro) that are formally recognised and sophisticated costing systems based on ABC principles (such as PPM) that are formally recognised. Additionally, the results demonstrate that DHBs tend to adopt and use sophisticated costing systems to plan and provide health services. However, the factors outlined by Cooper (1988) do not always lead to adoption and use of more sophisticated costing systems, despite DHBs identifying that such factors are present in their organisation (i.e. provision of numerous products and services; and organisational operations are multi-faceted and complex). Rather, the results indicate that DHBs will consider a range of political, economic and social factors when evaluating the usefulness of more sophisticated costing systems to assist in the planning and provision of health services.

The results also contribute to cost accounting literature in that they suggest adoption and use of sophisticated costing systems provides higher quality cost information, and that this leads to more informed and effective decision-making. To elaborate, DHBs with sophisticated costing systems understand their costs and cost structures for effective service planning and provision. To provide an example, DHBs with sophisticated costing systems will evaluate their cost information to determine whether or not it is cost effective to retain patients and provide care at their own Provider Arm, as opposed to referring patients out to another DHB. DHBs will also evaluate their cost and volume information to make decisions associated with product and service mix - the goal of which is to maximise utilisation of their constrained capacity (including taking on volumes for other DHBs).

The results also contribute to transfer pricing literature. Specifically, the results reveal that the main transfer pricing approach applied by DHBs for the purpose of IDFs is National Price (which is a variation of full cost-based transfer pricing that is specific to the New Zealand public health sector). The results also contribute to transfer pricing literature by (1) reaffirming the presence of the transfer pricing conundrum through the full cost-based transfer pricing approach; and (2) that DHBs will tend to negotiate prices away from National 
Price if they do not believe it is efficient. These results support suggestions made by Ashton et al. (2008) that the mechanisms used to inform prices unfairly affect smaller secondary DHBs due to the excessive influence tertiary DHB's supposedly have over the National Price setting process. Finally, the results contribute to literature on the nexus between costing systems and transfer pricing (IDFs). Specifically, the results of the current study indicate that adoption and use of sophisticated costing systems (based on ABC), contributes markedly to IDFs. In particular, the event-level cost information provided by DHB's with sophisticated costing systems is used directly to calculate National Prices for inter-DHB trading.

\subsection{Limitations and Future Research}

Despite this study's contributions to academic literature and practice, it has a number of limitations (notwithstanding the limitations of MCS research outlined at Chapter 4) that correspond to opportunities for future research. Firstly, this study focused on the views and opinions of CFOs, PFAs and $\mathrm{MOH}$ representatives. Though the choice of interview participants was deliberate (by selecting participants that had a detailed knowledge of their organisational environment, the costing systems used by DHBs and IDF processes), so to guarantee the validity of findings and ensure appropriate conclusions were made, this study's findings were limited by a lack of consideration of the views and opinions of other personnel, such as medical personnel. As Ross (2004) notes, there is a clear division between medical and accounting personnel, which negatively affects each, as well as patients, the health delivery system, and society. Specifically, medical personnel often have a negative illinformed view of costing systems (and the perceived benefits thereof). This can create a culture of resistance to change, which may severely impede the successfulness of strategy and constrain opportunities to improve efficiency within an organisation (Drury \& Tayles, 1995). While this is stated in the cost accounting literature, the current study is unable to contribute to this literature because it does not explore the views and opinions of medical personnel. As a result, future research could be conducted, by interviewing medical personnel, to gain insights into their views and opinions on the functionality of costing systems and IDF processes in a New Zealand public health sector context.

Secondly, the current study highlights an opportunity to conduct future research into the calculation of transfer prices for IDFs in the New Zealand public health sector. As the findings indicate, one DHB has done work on an alternative transfer pricing methodology that they see as a "true and fair" marginal cost, rather than the full cost represented by 
National Price. To better understanding the intricacies of this work, and assess its applicability to IDFs, an in-depth case study could be conducted at the DHB site. Furthermore, the current study focused on transfer pricing at an inter-organisational level (i.e. between DHBs). Thus, there is a further opportunity to contribute to the literature by considering the process of transfer pricing from an intra-organisational level (i.e. between divisions of a single DHB). As a majority of the literature cited and reviewed considers transfer pricing at an intra-organisational level, conducting an in-depth case study at a DHB or a MCS at several DHBs, would be a valuable contribution to the literature.

\subsection{Chapter Summary}

This study has examined the costing systems used by DHBs to plan and provide health services and it has evaluated how the use of such costing systems influences service planning and provision in accordance with the directives and outcomes outlined by the MOH. In particular, this study has revealed that costing systems are being used on three levels, including unsophisticated costing systems that are not formally recognised; moderately sophisticated costing systems (such as CostPro) that are formally recognised; and sophisticated costing systems (such as PPM) that are formally recognised. This study has also explored how more sophisticated costing techniques, such as ABC, are used by DHBs to (1) enhance the utilisation of limited resources; and (2) adhere to social expectations to provide sustained high quality health services. This study has also contributed to transfer pricing literature from a New Zealand public health sector context by exploring the processes that underpin IDFs, including (1) how National Prices for IDFs are calculated; and (2) to what extent the cost information produced by DHB's costing systems influences this calculation.

With consideration to the research framework that was developed for the purposes of this study, it is evident (based on the findings of the study) that DHBs have multiple institutions and will adopt and adapt these institutions at varying levels based on their differing views about which institutional pressures are the most influential. Specifically, DHBs will institutionalise costing practices, costing systems, costing rules and procedures, processes for the provision of cost and volume information, pricing mechanisms, and product/service mix based on their own underlying perceptions of regulatory, social and political pressures. While DHBs have tended to adopt and adapt institutions at different levels, they have all done so with one overarching goal in mind, to maintain organisational legitimacy and ensure organisational survival in the New Zealand public health sector. 


\section{References}

Abdallah, A. A. and Li, W. (2008). "Why did ABC fail at the Bank of China?”. Management Accounting Quarterly, October, pp. 7-14.

Ahrens, T. and Dent, J. (1998). "Accounting and organizations: Realising the richness of field research”. Journal of Management Accounting Research, Vol. 10, pp. 1-40.

Ahrens, T. and Chapman, C. S. (2006). "Doing qualitative field research in management accounting: Positioning data to contribute to theory". Accounting, Organizations and Society, Vol. 31, No. 8, pp. 819-841.

Aird, B. (1996). "Activity-based cost management in health care - Another fad". International Journal of Health Care Quality Assurance, Vol. 9, pp. 16-19.

Al-Omiri, M. and Drury, C. (2007). "A survey of factors influencing the choice of product costing systems in UK organizations”. Management Accounting Research, Vol. 18, pp. 399-424.

Arksey, H. and Knight, P. (2002). Interviewing for social scientists: An introductory resource with examples. Thousand Oaks, CA: Sage Publications Inc.

Arnaboldi, M. and Lapsley, I. (2005). “Activity Based Costing in Healthcare: A UK Case Study”. Research in Healthcare Financial Management, Vol. 10, No. 1, pp. 61-75.

Ashton, T., Tenbensel, T., Cumming J. and Barnett, P. (2008). "Decentralizing resource allocation: early experiences with District Health Boards in New Zealand”. Journal of Health Service Research Policy, Vol. 13, No. 2, pp. 109-115.

Atkinson, A. A., Banker, R. D., Kaplan, R. S. and Young, S. M. (2001). Management Accounting. Upper Saddle River, NJ: Prentice-Hall.

Atkinson, A. A., Kaplan, R. S., Matsumura, E. M. and Young, S. M. (2007). Management Accounting. Fifth edition, Upper Saddle River, NJ: Pearson-Prentice-Hall.

Baker, W. M. (1994). “Understanding Activity-Based Costing”. Industrial Management, Vol. 36, pp. 28-30.

Baker, J. J. (1998). “Activity-Based Costing and Activity-Based Management for Health care”, Maryland, USA: Aspen Publishers.

Baldenius, T., Reichelstein, S. and Sahay, S. (1999). "Negotiate versus cost-based transfer pricing”. Review of Accounting Studies, Vol. 4, pp. 67-91.

Baldenius, T. and Reichelstein, S. (2006). "External and internal pricing in multi-divisional firms”. Journal of Accounting Research, Vol. 44, pp. 1-28.

Bansal, P. and Clelland, I. (2004). "Talking Trash, Legitimacy, Impression Management, and Unsystematic Risk in the Context of the Natural Environment". Academy of Management Journal, Vol. 47, pp. 93-105.

Bishop, P. (2010). Multi-Site Case Research. In A. Mills, G. Eurepos and E. Wiebe (Eds.), Encyclopedia of Case Study Research, pp. 587-590. California: Sage Publications Inc.

Bjørnenak, T. (1997). “Diffusion and accounting: the case of ABC in Norway”. Management Accounting Research, Vol. 8, No. 1, pp. 3-17.

Brickley, R., Smith, C. and Zimmerman, J. (1995). "Transfer Pricing and the Control of Internal Corporate Transactions”. Journal of Applied Corporate Finance, pp. 473480 . 
Bromwich, M. and Bhimani, A. (1994). "Management Accounting: Pathways to Progress”. Chartered Institute of Management Accountants, London.

Brown, R. E., Myring, M. J. and Gard, C. G. (2003). "Activity-Based Costing in Government: Possibilities and Pitfalls”. Public Budgeting and Finance, Vol. 19, No. 2, pp. 3-21.

Cagwin, D. and Bouwman, M. J. (2002). “The association between activity-based costing and improvement in financial performance”. Journal of Management Accounting Research, Vol. 13, pp. 1-39.

Canby, J. B. (1995). “Applying Activity-Based Costing to Health care Settings”. Health care Financial Management, Vol. 49, No. 2, pp. 50-56.

Carpenter, V. L. and Feroz, E. H. (2001). "Institutional theory and accounting rule choice: an analysis of four US state governments' decisions to adopt generally accepted accounting principles”. Accounting, Organizations and Society, Vol. 26, No. 7-8, pp. 565-596.

Carruthers, B. G. (1995). “Accounting, ambiguity, and the new institutionalism”. Accounting, Organizations and Society, Vol. 20, pp. 313-328.

Carter, W. K., Maloney, D. M and Van Vranken, M. H. (1998). "The Problems of Transfer Pricing”. Journal of Accountancy, Vol. 186, No. 1, pp. 37-40.

Chalos, P. and Haka, S. (1990). "Transfer pricing under bilateral bargaining”. Accounting Review, Vol. 65, pp. 624-641.

Chan, Y-C. L. (1993). “Improving hospital cost accounting with activity-based costing”. Health Care Management Review, Vol. 18, No. 1, pp. 71-77.

Clarke, P.J., Hill, N.T. and Stevens, K. (1999). “Activity based costing in Ireland: barriers to, and opportunities, for change”. Critical Perspectives on Accounting, Vol. 10, pp. 443-468.

Cobb, I., Innes, J. and Mitchell, F. (1993). “Activity-Based Costing Problems: The British experience”. Advances in Management Accounting, Vol. 2, pp. 63-83.

Colbert, G. and Spicer, B. (1998). "Linking activity-based costing and transfer pricing for improved decisions and behavior”. Journal of Cost Management, May/June, pp. 2026.

Common Costing Group. (2012). DHB Costing Standards Version 13. Retrieved from www.nsfl.health.govt.nz

Cook, P. (1955). "Decentralization and the Transfer Pricing Problem”. Journal of Business, Vol. 28, pp. 87-94.

Cooper, R. (1988). "The Rise of Activity-Based Costing - Part Two: When do I need an Activity-based costing system?”. Journal of Cost Management (Fall), pp. 41-48.

Cooper, R. and Kaplan, R. S. (1990). “Measure Costs Right: Make the Right Decision”. CPA Journal, Vol. 60, pp. 38-45.

Cooper, R. and Kaplan, R. S. (1992). “Activity-Based Systems: Measuring the Costs of Resource Usage”. Accounting Horizons, Vol. 6, No. 3, pp. 1-13.

Covaleski, M. A. and Dirsmith, M. W. (1988). "An Institutional Perspective of the Rise, Social Transformation and Fall of a University Budget Category”. Administration Science Quarterly, Vol. 33, No. 4, pp. 562-587. 
Dacin, M. T., Goodstein, J. and Scott, W. R. (2002). "Institutional Theory and Institutional Change: Introduction to the Special Research Forum”, The Academy of Management Journal, Vol. 45, No. 1, pp. 43-56.

D’Andrade, R. G. (1984). Cultural Meaning Systems. In R. A. Shweder and R. A. LeVine (Eds.), Cultural Theory: Essays on Mind, Self, and Emotion, pp. 88-119. Cambridge, UK: Cambridge University Press.

Dean, M., Feucht, F. J. and Smith, L. M. (2008). “International transfer pricing issues and strategies for the global firm”. Internal Auditing, Jan/Feb, pp. 12-19.

Deegan, C. (2006). Legitimacy Theory. In Z. Hoque (Ed.), Methodological Issues in Accounting Research: Theories and Methods, pp. 161-181. London: Spiramus Press.

Delmas, M. and Toffel, M. W. (2004). "Stakeholders and environmental management practices: an institutional framework", Journal of Business Strategy and the Environment, Vol. 13, No. 4, pp. 209-222.

Desheh, E., Kaplan, R. S. and Weiss, D. (1997). “Transfer pricing with ABC”. Management Accounting, Vol. 78, No. 11, pp. 20-28.

Dillard, J. F., Rigsby, J. T. and Goodman, C. (2004). "The making and remaking of organization context: Duality and the institutional process”. Accounting, Auditing \& Accountability, Vol. 17, No. 4, pp. 506-542.

DiMaggio, P. J. and Powell, W. W. (1983). "The Iron Cage Revisited: Institutional Isomorphism and Collective Rationality in Organizational Fields”. American Sociological Review, pp. 147-160.

Drury, C. and Tayles, M. (1995). "Issues arising from surveys of management accounting practice”. Management Accounting Research, Vol. 6, pp. 267-280.

Drury, C. and Tayles, M. (2005). "Explicating the design of overhead procedures in UK organizations”. British Accounting Review, Vol. 37, pp. 47-84.

Eccles, R. (1983). “Control with fairness in transfer pricing”. Harvard Business Review, Vol. 61, pp. 149-161.

Eccles, R. (1985). The Transfer Pricing Problem: A Theory for Practice. Lexington Press.

Eccles, R. and White, H. (1988). “Price and Authority in Inter-Profit Center Transactions”. American Journal of Sociology, Vol. 94, pp. 17-51.

Eisenhardt, K. M. (1989). "Building theories from case study research". Academy of Management Review, Vol. 14, No. 4, pp. 532-551.

Ellwood, S. (2009). “Accounting For (A) Public Good: Public Healthcare in England”. Journal of Financial Accountability \& Management, Vol. 25, No. 4, pp. 411-433.

Emmanuel, C. and Messaoud, M. (1994). Transfer Pricing. New York: Academic Press.

Ettelt, S., Fazekas, M., Mays, N. and Nolte, E. (2012). “Assessing health care planning - A framework-led comparison of Germany and New Zealand”. Health Policy, Vol. 106, pp.50-59.

Flick, U. (1992). “Triangulation revisited: Strategy of validation or alternative?”. Journal for the Theory of Social Behaviour, Vol. 22, No. 2, pp. 175-197.

Flick, U., Kardorff, E. V. and Steinke, I. (2004). A companion to qualitative research. London, Sage Publications Inc. 
Garrison, R., Noreen, E. and Brewer, P. (2012). Managerial Accounting. Fourteenth Edition, New York: McGraw-Hill/Irwin.

Geri, N. and Ronen, B. (2005). "Relevance lost: the rise and fall of activity-based costing”. Journal of Human Systems Management, Vol. 25, pp.133-144.

Ghosh, D. (1994). "Intra-firm pricing: experimental evaluation of alternative mechanisms". Journal of Management Accounting Research, Vol. 6, pp. 78-92.

Ghosh, D. (2000). "Complementary arrangements of organizational factors and outcomes of negotiated transfer price”. Accounting, Organizations and Society, Vol. 25, pp. 661682.

Gosselin, M. (1997). "The effect of strategy and organizational structure on the adoption and implementation of activity based costing”. Accounting, Organizations and Society, Vol. 22, No. 2, pp. 105-122.

Gosselin, M. (2006). “A Review of Activity-Based Costing: Technique, Implementation, and Consequences”. Handbook of Management Accounting Research, Vol. 2, pp. 641671.

Göx, R. F. and Schiller, U. (2006). “An Economic Perspective on Transfer Pricing”. Handbook of Management Accounting Research, Vol. 2, pp. 673-695.

Graham, J. (1985). “The effect of culture on business negotiations”. Journal of International Business Studies, pp. 81-96.

Gray, R., Owen, D. and Adams, C. (1996). Accounting and Accountability: Changes and Challenges in Corporate Social and Environmental Reporting. London: PrenticeHall.

Greenwood, R., Suddaby, R., and Hinings, C. R. (2002). "Theorizing Change: The Role of Professional Associations in the Transformation of Institutionalized fields”, Academy of Management Journal, Vol. 45, No. 1, pp. 58-80.

Guthrie, J. and Parker, L.D. (1996). "Recent public sector financial management change in Australia", paper presented at the Second Workshop on International Trends in Public Sector Financial Management Reforms, Gothenburg.

Hirshleifer, J. (1956). “On the Economics of Transfer Pricing”. Journal of Business, Vol. 29, pp. 172-189.

Hoffman, A. W. (1997). From Heresy to Dogma: An Institutional History of Corporate Environmentalism. San Francisco: New Lexington Press.

Holmström, B. and Tirole, J. (1991). “Transfer pricing and organizational form”. Journal of Law Economics and Organization, Vol. 7, pp. 201-228.

Hopper, T. and Hoque, Z. (2006). Triangulation approaches to accounting research. In Hoque, Z. (Ed.), Methodological Issues in Accounting Research: Theories and Methods, pp. 477-486. London: Spiramus Press.

Hoque, Z. (2000). "Just-in-time production, automation, cost allocation practices and importance of cost information: an empirical investigation in New Zealand-based manufacturing organizations”. British Accounting Review, Vol. 32, pp. 33-159.

Hoque, Z. (2003). Strategic Management Accounting: Concepts, Processes and Issues. Second edition, French Forest, NSW: Pearson-Prentice-Hall. 
Hunt, C. and Fowler, C. (2009). Management Accounting: Strategic decision making, performance and risk. Pearson Education, New Zealand.

Hussain, M. and Gunasekaran, A. (2001). "Activity-based cost management in financial services industry”. Managing Service Quality, Vol. 11, No. 3, pp. 213-223.

Joskow, P. (2004). “Vertical Integration”. In Menard, C. and Shirley, M. (Eds.), Handbook of New Institutional Economics. Dordrecht: Kluwer Academic Publishers.

Kaplan, R. S. (1982). Advanced Management Accounting. Englewood Cliffs, NJ: Prentice Hall.

Kaplan, R. S. and Anderson, S. R. (2004). “Time-driven activity-based costing”. Harvard Business Review, Vol. 82, pp. 131-138.

Kaplan, R. S. and Atkinson, A. A. (1989). Advanced Management Accounting. Second edition, Englewood Cliffs, NJ: Prentice-Hall.

Kaplan, R. S. and Atkinson, A. A. (1998). Advanced Management Accounting. Third edition, Englewood Cliffs, NJ: Prentice-Hall.

King, M., Lapsley, I., Mitchell, F. and Moyes, J. (1994). "Costing needs and practices in a changing environment: the potential for ABC in the NHS”. Journal of Financial Accountability and Management, Vol. 10, No. 2, pp. 143-160.

Kochan, T. A. and Verma, A. (1983). "Negotiation in organizations: blending industrial relations and organizational behavior approaches. Negotiating in organizations. Beverly Hills, CA: Sage Publications.

Kostova, T., Roth, K. and Dacin, M. T. (2008). "Institutional Theory in the Study of Multinational Corporations: A Critique and New Directions". Academy of Management Research, Vol. 33, No. 4, pp. 994-1006.

Krumwiede, K. R. (1998). "The implementation stages of activity-based costing and the impact of contextual and organizational factors". Journal of Management Accounting Research, Vol. 10, pp. 239-278.

Kuntz, L. and Vera, A. (2005). "Transfer Pricing in Hospitals and Efficiency of Physicians: The Case of Anesthesia Services”. Health Care Management Review, Vol. 30, No. 3, pp. 262-269.

Lawson, R. A. (1994). “Activity-based costing systems for hospital management”. CMA Magazine, Vol. 68, pp. 31-35.

Lawson, R. A. (2005). "The use of Activity Based Costing in the Healthcare Industry: 1994 vs. 2004”. Research in Healthcare Financial Management, Vol. 10, No. 1, pp. 77-94.

Lax, D. A. and Sebenius, J. K. (1986). The manager as negotiator. New York: Free Press.

Lee, J. Y. (2002). “An Examination of International Differences in Adoption and Theory Development of Activity-Based Costing”. Advances in International Accounting, Vol. 15, pp. 65-77.

Lillis, A. and Mundy, J. (2005). “Cross-sectional field studies in management accounting research-closing the gaps between surveys and case studies”. Journal of Management Accounting Research, Vol. 17, No. 1, pp. 119-141.

Lillis, A. (2006). "Reliability and validity in field study research, In Z. Hoque (Ed.), Methodological Issues in Accounting Research: Theories and Methods, pp. 461-468. Spiramus, London. 
Lindblom, C. K. (1994). "The implications of organisational legitimacy for corporate social performance and disclosure”. Critical Perspectives on Accounting Conference, New York.

Lounsbury, M. (2008). "Institutional rationality and practice variation: New directions in the institutional analysis of practice”. Accounting, Organizations and Society, Vol. 33, pp. 349-361.

Malina, M. A. and Selto, F. H. (2001). "Communicating and controlling strategy: An empirical study of the effectiveness of the balanced scorecard". Journal of Management Accounting Research, Vol. 13, No. 1, pp. 47-91.

Malmi, T. (1999). "Activity based costing diffusion across organizations: an exploratory empirical analysis of Finnish firms". Accounting, Organizations and Society, Vol. 24, No. 8, pp. 649-672.

Meyer, J. W. and Rowan, B. (1977). "Institutionalized organizations: Form structure as myth and ceremony”. American Journal of Sociology, Vol. 83, No. 2, pp. 340-363.

Milgrom, P. and Roberts, J. (1992). Economics, Organization and Management. Upper Saddle River, NJ: Prentice-Hall.

Miller, P. (1998). “The margins of accounting”. European Accounting Review, Vol. 7, No. 4, pp. 605-621.

Morreim, E. H. (1995). Balancing act: The new medical ethics of medicine's new economics. Washington DC: Georgetown University Press.

Morse, J., Barrett, M., Mayan, M., Olson, K. and Spiers, J. (2002). "Verification strategies for establishing reliability and validity in qualitative research". International Journal of Qualitative Methods, Vol. 1, No. 2, pp. 1-19.

Ministry of Health. (2014). District health boards. Retrieved from www.health.govt.nz

National Cost Collection and Pricing Programme. (2012). National Costing Collection and Pricing Programme 2013 DHB Provider Arm Data Request. Retrieved from www.nsfl.health.govt.nz

North, D. C. (1990). Institutions, Institutional Change, and Economic Performance. Cambridge, UK: Cambridge University Press.

Office of the Auditor-General. (2013). Regional services planning in the health sector. Retrieved from www.oag.govt.nz

Oliver, C. (1992). “The antecedents of deinstitutionalization”. Organization Studies, Vol. 13, pp. 563-588.

Penno, E., Audas, R. and Gauld, R. (2012). The Start of the Art? An analysis of New Zealand's Population-Based Funding Formula for Health Services. Dunedin: Centre for Health Systems University of Otago.

Pettigrew, A. (1988). Longitudinal field research on change: Theory and Practice. Paper presented at the National Science Foundation Conference on Longitudinal Research Methods in Organizations, Austin.

Pfeiffer, T., Schiller, U. and Wagner, J. (2011). “Cost-based transfer pricing”. Review of Accounting Studies, Vol. 16, No. 2, pp. 219-246.

Ramsey, R. H. (1994). “Activity-based costing for hospitals”. Hospital \& Health Services Administration, Vol. 39, No. 3, pp. 385-396. 
Rodwin, M. (1993). Medicine, money, and morals. Oxford, England: Oxford University Press.

Ross, T. K. (2004). “Analyzing Health Care Operations Using ABC”. Journal of Health Care Finance, Vol. 30, No. 3, pp. 1-20.

Sahay, S. A. (2003). "Transfer pricing based on actual costs". Journal of Management Accounting Research, Vol. 15, pp. 177-192.

Schneider, A. J. (1992). “TQM and the Financial Function”. Journal of Business Strategy, Vol. 13, No. 5, pp. 21-25.

Schram, D. H. and Steen, G. (2001). The psychology and sociology of literature. Amsterdam, The Netherlands: Johns Benjamin Publishing.

Scott, W. R., Ruef, M., Mendel, P. J., and Caronna, C. A. (2000). Institutional change and health care organizations: From professional dominance to managed care. Chicago: University of Chicago Press.

Scott, W. R. (2001). Institutions and Organizations. Second Edition, Thousand Oaks, California: Sage Publications Inc.

Shander, A., Hofmann, A., Ozawa, S., Theusinger, O. M., Gombotz, H. and Spahn, D. R. (2010). “Activity-based costs of blood transfusions in surgical patients at four hospitals”. Transfusion Practice, Vol. 50, pp. 753-765.

Shocker, A. D. and Sethi, S. P. (1974). An approach to incorporating social preferences in developing corporate action strategies. In S. P. Sethi (Ed.), The Unstable Ground: Corporate Social Policy in a Dynamic Society, pp. 67-80. Melville, California.

Silverman, D. (2006). Interpreting qualitative data: Methods for analysing talk, text, and interaction. Third Edition, London: Sage Publications Inc.

Spencer, E. M., Mills, A. E., Rorty, M. and Werhane, P. H. (2000). Organization ethics in health care. Oxford, England: Oxford University Press.

Spicer, B. (1988). "Towards an organizational theory of transfer pricing process". Accounting, Organizations and Society, Vol. 13, pp. 303-322.

Stevenson, T. H. and Cabell, D. W. (2002). "Integrating Transfer Pricing Policy and ActivityBased Costing”. Journal of International Marketing, Vol. 10, No. 4, pp. 77-88.

Suchman, M. C. (1995). “Managing Legitimacy: Strategic and Institutional Approaches”. Academy of Management Review, Vol. 20, pp. 571-610.

Tebogo, B. (2011). “The Transfer Pricing Problem: When Multinational Corporations Shift Profits Across International Borders”. Institute of Development Management Working Paper, pp. 1-11.

Tenbensel, T., Mays, N. and Cumming, J. (2011). “A successful mix of hierarchy and Collaboration? Interpreting the 2001 reform of the governance of the New Zealand public health sector”. Policy \& Politics, Vol. 39, No. 2, pp. 239-255.

Toulmin, S. (1990). Medical institutions and their moral constraints. In R. E. Bulger and S. J. Reiser (Eds.), Integrity in health care institutions: Humane environments for teaching, inquiry, and healing, pp. 21-32. Iowa City: University of Iowa Press.

Upda, S. (1996). “Activity-Based Costing for Hospitals”. Health Care Management Review, Vol. 21, No. 3, pp. 83-96. 
Vaysman, I. (1998). “A model of negotiated transfer pricing”. Journal of Accounting and Economics, Vol. 25, No. 3, pp. 349-384

Wagenhofer, A. (1994). "Transfer pricing under asymmetric information-an evaluation of alternative methods”. European Accounting Review, Vol. 1, pp. 71-104.

Warren, C. A. B. (2002). "Qualitative interviewing”. In Gubrium, J. and Holstein, J. (Eds.), Handbook of interview research: Context and meaning, pp. 83-101. Thousand Oaks, CA: Sage Publications Inc.

Yereli, A. N. (2009). “Activity-Based Costing and Its Application in a Turkish University Hospital”. AORN Journal, Vol. 89, No. 3, pp. 573-591.

Yin, R. K. (1984). Case study research. Beverly Hills, CA: Sage Publications Inc.

Yin, R. K. (2003). Case study research: Design and methods.Thousand Oaks, CA: Sage Publications Inc.

Young, D. W. (1998). “Two-Part Transfer Pricing Improves IDS Financial Control”. Health care Financial Management, Vol. 52, No. 8, pp. 56-65.

Zimmerman, J. (2001). “Conjectures regarding empirical managerial accounting research”. Journal of Accounting and Economics, Vol. 32, No. 1-3, pp. 411-427. 


\section{Appendices}

\section{Appendix I Interview Questions for MOH Research Exploration}

Interviewee Name:

Common Costing Group:

1) What is the Common Costing Group?

2) For what purpose was the Common Costing Group formed?

3) How does the Common Costing Group interact with DHBs (describe relationship)?

4) Who is involved with the Common Costing Group?

- Membership

- Relationships

- Other influences

5) What does the Common Costing Group provide standards for?

- Choices

- Restrictions

- Flexibility

- $\quad$ DHB feedback

6) How does the Common Costing Group influence overhead allocation?

- Choices

- Restrictions

- Flexibility

- $\quad$ DHB feedback

7) What are the advantages and disadvantages of offering these standards as guidelines?

8) Could mandating these standards be a potential method to alleviate any disadvantages - why?

National Cost Collection and Pricing Programme (NCCPP) and National Price:

9) What is the NCCPP?

10) How many DHBs nationwide provide costing information to this submission?

11) How does this submission influence national price?

12) What processes are involved in the calculation of national price?

13) Are there any difficulties associated with the determination of national price?

14) Are national prices dominated by costing information from tertiary DHBs?

15) If possible, how do you think IDF efficiency could be improved?

16) Should a minimum costing system requirement be imposed on national DHBs to ensure a more complete submission to the NCCPP?

Operational Policy Framework:

17) What is the OPF?

18) How is the OPF utilised in the public health sector?

19) How does the OPF support IDFs between DHBs? 


\section{Appendix II Interview Questions for DHB Research Exploration}

Interviewee Name:

Job Title:

Department:

Interview Time:

Interview Day:

1) What drives use of the current costing system at the DHB?

2) Overhead allocation:

How does the DHB allocate overheads?

- $\quad$ How does the Common Costing Group influence overhead allocation?

- Choices

- Restrictions

- Flexibility

- $\quad$ DHB feedback

3) Can you explain how the current costing system at the DHB utilises ABC?

4) Overall, is the current costing system successful?

5) Could you explain any limitations/weaknesses of the current costing system?

6) How do front line/operational staff view the costing system?

- $\quad$ Ease of use

- Applicability to organisational structure and goals

- Relevance of costing information

- Resistance/reservations

- What costs does this costing system create and are they justified (overall cost versus benefit)

7) Which transfer pricing approach does the DHB use?

- $\quad$ Market-based transfer prices

- $\quad$ Cost-based transfer prices

- Variable-cost transfer prices

- Full-cost transfer prices

- $\quad$ Negotiated transfer prices

- $\quad$ Other (please explain)

8) How does the DHB decide which transfer pricing method to use?

9) Could you describe how the DHB uses transfer pricing information for decision-making?

- $\quad$ On an internal basis

- $\quad$ On an external basis

10) How does the current costing system support transfer pricing decisions?

- $\quad$ Internally at the DHB

- $\quad$ Externally to the NCCPP

Acknowledging recent concerns regarding Inter District Flows:

11) Could you explain what these concerns are?

12) How have these concerns been mitigated?

13) Have recent attempts to improve IDF between DHBs your region been successful?

14) Could you explain any additional limitations/weaknesses of the current transfer pricing approach? 


\section{Appendix III}

31 August 2012

Dear [Insert Name],

I am Master of Commerce student at Victoria University of Wellington undertaking a study to explore activity-based costing (ABC) and inter-district flows (IDF) in the New Zealand public health sector. The key objectives of the research are to provide information on the use of $\mathrm{ABC}$ in DHBs and to comprehend the efficiency of IDFs between New Zealand public health sector organisations.

You have been selected as one of the potential participants of my research project because of your knowledge and expertise regarding costing systems use and the movement of IDFs (in your DHB/at DHBs in the New Zealand public health sector).

To enable me to complete the study, I would appreciate your co-operation in participating in an interview, which will take approximately 45 minutes of your time to complete. If you are interested in participating in this research please give me notification via email or telephone. Equally, if you are not familiar with the costing system used (in your DHB/at DHBs) or the movement of IDFs to and from (your DHB/DHBs in the New Zealand public health sector), please give me notification via email or telephone by 30 September 2012.

The Victoria University of Wellington Human Ethics Committee has granted ethics approval for this study. The responses provided will be used as support to the main findings of my research project and for academic publication. The responses of the survey will be used by me and shared with my supervisor. The results of the survey will be reported in a summary format, so your identity will be anonymous. All data will be stored securely at Victoria University of Wellington and will be destroyed 3 years after the completion of this study.

If you would like to receive a summary of the transcribed results, please provide your email address to either myself or my supervisor, Dr Carolyn Fowler, via email or phone.

If you have any questions or would like to receive further information about the research project, please contact me at Victoria University of Wellington via:

Email: matt.vankesteren@vuw.ac.nz_～Phone: (027) 6307750

Alternatively, you may contact my academic supervisor, Dr Carolyn Fowler, via:

Email: carolyn.fowler@vuw.ac.nz

Phone: (04) 4636506

Thank you for your cooperation and assistance in our research efforts.

Yours sincerely

Matt van Kesteren

Master of Commerce Student

Victoria Business School

Victoria University of Wellington
Dr Carolyn Fowler

Senior Lecturer

Victoria Business School

Victoria University of Wellington 